\title{
Electrochemical Materials Science: Calculation vs. Experiment as Predictive Tools in Tailoring Intrinsically Conducting Polythiophenes
}

\author{
von der Fakultät für Naturwissenschaften der Technischen Universität Chemnitz \\ genehmigte Dissertation zur Erlangung des akademischen Grades
}

doctor rerum naturalium

(Dr. rer. nat)

\author{
vorgelegt von \\ M.Sc. Wasim Alhalasah \\ geboren am 31.07.1975 in Alkarak, Jordan
}

eingereicht am 18 August 2006

Gutachter: Prof. Dr. Rudlof Holze

Prof. Dr. Klaus Banert

Prof. Dr. Lothar Dunsch

Tag der Verteidigung: 01 March 2007 


\title{
Bioliographische Beschreibung und Referat
}

\author{
Alhalasah, Wasim \\ Electrochemical Materials Science: Calculation vs. Experiment as Predictive Tools in Tailoring \\ Intrinsically Conducting Polythiophenes
}

Eine Reihe 3-(p-X-phenyl)-Thiophenmonomeren ( $\left.\mathrm{X}=-\mathrm{H},-\mathrm{CH}_{3},-\mathrm{OCH}_{3},-\mathrm{COCH}_{3},-\mathrm{COOC}_{2} \mathrm{H}_{5},-\mathrm{NO}_{2}\right)$ wurde elektrochemisch polymerisiert, um Filme zu erhalten, die umkehrbar reduziert und oxidiert werden konnten $(n$ und $p$-dotiert wurden). Die Oxidationspotentiale der Monomere und die formalen Potentiale der $n$ und $p$ Dotierprozesse der Polymere wurden mit Resonanz- und induktiven Effekten der Substituenten (Hammett konstanten) am Phenylring sowie semiempirisch errechneten Bildungswärmen der Monomereradikalkationen korreliert. Außerdem wurden die Oxidationspotentiale mit den Ionisierungspotentialen der Monomere verglichen, die über die Dichtefunktionialtheorie (DFT) errechnet wurden, die der Energie für das Erzeugen der Radikalkationen entsprechen.

Um theoretische Grundlagen für die Einstufen-Bildung regioregulär $\alpha$-konjungierter Oligo- und Polythiophene zu erhalten, wurden die elektronischen Zustände von 3-Phenylthiophen-Derivaten anhand von Molekülorbitalberechnungen auf Grundlage der Dichtefunktionaltheorie mit Becke's Drei-Parameter-Funktion (B3LYP), sowie mit den Basissätzen 6-31G(d) und 3-21G(d) erklärt. Die Reaktivität der Verknüpfung von monound oligo-3-Phenylthiophenen wurde von den berechneten ungepaarten Elektronenspindichten der entsprechenden Radikal-Anionen abgeleitet. Die Ionisierungspotentiale, die den Energien zur Erzeugung der Radikal-Anionen während der Oxidation entsprechen, wurden abgeschätzt. Die aus den 3-Phenylthiophenen entstandenen regioselektiven Hauptprodukte können gut durch die Größe der Spindichten erklärt werden. Da die Verknüpfungsreaktion an der zwei-Position des Thiophnrings (C-2) sterisch durch die Phenylgruppe und den Thiophenring gehindert ist, startet die Initiierung der 3-Phenylthiophene über die Bildung eines Kopf-SchwanzDimers. Folglich spielt das Kopf-Schwanz-Dimer eine wichtige Rolle bei den Wachstumsreaktionen der 3Phenylthiophene. Die Ursache dafür liegt darin, dass das Kopf-Schwanz-Dimer in 5'-Position die höchste SpinDichte besitzt und die Wahrscheinlichkeit einer Kopf-Kopf-Verknüpfung aufgrund der sterischen Hinderung zwischen dem Thiophenring und der Phenylgruppe gering ist.

Polymerfilme von 3-Phenylthiophenderivaten, die durch elektrochemische Polymerisation synthetisiert wurden, sind in situ und ex situ durch Resonanz-Raman-Spektroskopie bei verschiedenen Anregungswellenlängen, sowie durch in situ und ex situ UV-Vis Spektroskopie analysiert wurden.

Die Entwicklung der in situ UV-Vis-Spektren der Polymer von 3-Phenylthiophene nach der Dotierung wird durch ähnliche Eigenschaften gekennzeichnet, wie für viele Polythiophene mit einem hohen Grad der Konjugation beobachtet. Während der schrittweisen Oxidation der Poly-3-phenylthiophen Filme verringert sich die Intensität der Absorption wegen des Überganges $\pi \rightarrow \pi *$ bei 450-566 nm und ein neues ausgedehntes Absorptionsband, das auf (bi)polaron Zustände bezogen wird erscheint bei ungefähr 730-890 nm. Andererseits wird während der Oxidation ( $p$-Dotierung) des Poly3-phenylthiophen Filmes eine blau/hypsochrome Verschiebung für beide Absorptionsbänder beobachtet . Es wird durch die Tatsache erklärt, dass ein Polymer eine Verteilung der Kettenlängen enthält und die längste Polymer kette (dessen Absorption bei niedriger Energie auftritt), bei niedrigeren Potentialen zu oxidieren beginnt.

Die elektrochemischen Bandlücken der Derivate von 3-Phenylthiophen sind durch zyklische Voltametrie gemessen worden. Der Effekt der Substituenten auf den Oxidations-/Reduktions- potentiale wird besprochen. Bei Bandlücken, die durch zyklische Voltammetrie erhalten wurden, hat sich herausgestellt, dass sie im Allgemeinen höher liegen als optische Bandlücken.

Erste Resultate der in situ Resonanz-Raman-Spektroskopie, von dem elektrochemisch erzeugten Polymerderivate von 3-Phenylthiophen Filmen auf einer Platinelektrode, in einer organischen Elektrolytlösung, werden berichtet. Beobachtete Raman Banden werden zugewiesen; gegründet auf diesen Resultaten werden die zuvor angenommenen molekularen Strukturen diskutiert.

Stichworte: Polythiophen, Elektropolymerisation, Zyklische Voltammetrie, Bandlücken, DFT, $p$-dotiert, $n$ dotiert, in situ Raman, in situ UV-Visible, Hammett - Konstante 


\section{Abstract \\ Alhalasah, Wasim \\ Electrochemical Materials Science: Calculation vs. Experiment as Predictive Tools inTailoring Intrinsically Conducting Polythiophenes}

A series of 3- $\left(p\right.$-X-phenyl) thiophene monomers $\left(\mathrm{X}=-\mathrm{H},-\mathrm{CH}_{3},-\mathrm{OCH}_{3},-\mathrm{COCH}_{3}\right.$, $\mathrm{COOC}_{2} \mathrm{H}_{5},-\mathrm{NO}_{2}$ ) was electrochemically polymerized to furnish polymer films that could be reversibly reduced and oxidized ( $n$ - and $p$-doped). The oxidation potentials of the monomers and formal potentials of the $n$ - and $p$-doping processes of polymers were correlated with resonance and inductive effects (Hammett constants) of the substituents on the phenyl ring as well as the semiempirically calculated heats of formation of the monomer radical cations. Moreover, the oxidation potentials of the monomers were correlated with the ionization potentials of the monomers calculated via density functional theory (DFT), which correspond to the energies for generating radical cations during oxidative processes.

For obtaining a theoretical basis for the one-step formation of regioregular $\alpha$-conjugated oligo-and polythiophenes, the electronic states of 3-phenylthiophene derivatives were elucidated by molecular orbital calculations using density functional theory with the Becketype three parameters functional (B3LYP), the 6-31G(d), and 3-21G(d) basis sets. The reactivity for coupling reaction of mono- and oligo-3-phenylthiophenes are inferred from the calculated unpaired electron spin densities of the respective radical cations, and the ionization potentials which correspond to the energies for generating radical cations during oxidative processes were estimated. The major regioselective products of the oligomerization of 3phenylthiophene can be well understood in terms of the magnitude of spin densities. Since the steric hindrance between the phenyl group and thiophene ring interferes with the coupling reaction occurring between 2-postions $(\mathrm{C}-2)$ of thiophene rings, the initiating reaction of 3phenylthiophene is generaton of a head-to-tail (HT) dimer. Thus, the head-to-tail (HT) dimer plays an important role in the propagation reactions of 3-phenylthiophene. This originates from the highest spin density at the $5^{\prime}$ - position of the HT dimer and low probability of the $\mathrm{HH}$ coupling due to the steric hindrance between thiophene ring and phenyl group. 
Polymer films of the 3-phenylthiophene derivatives prepared by electrochemical polymerization were analyzed, in situ and ex situ, with resonance Raman spectroscopy using several excitation wavelengths as well as in situ and ex situ UV-Vis-spectroscopy.

The evolution of the in situ UV-Vis-spectra of poly 3-phenylthiophene derivatives upon doping is characterized by similar features as observed for many polythiophenes with high degree of conjugation. During stepwise oxidation of the poly-3-phenylthiophene films the intensity of the absorption due to the transition $\pi \rightarrow \pi *$ around 450-566 nm decreases and a new broad absorption band related to (bi)polaron states appears around 730-890 $\mathrm{nm}$. On the other hand, during the oxidation (p-doping) of the poly-3-phenylthiophene films a blue/hypsochromic shift is observed for both absorption bands. It is explained by the fact that a polymer contains a distribution of chain lengths, and the longest polymer chains (the absorption of which occurs at lower energies) start to oxidize at lower potentials.

The electrochemical bandgaps of 3-phenylthiophene derivatives have been measured by cyclic voltammetry. The effect of substituents on the oxidation / reduction potentials is discussed. Bandgaps obtained by cyclic voltammetry have been found to be in general higher than optical bandgaps.

Preliminary results of in situ resonance Raman spectroscopy of electrochemically generated poly-3-phenylthiophene derivatives films on a platinum electrode exposed to an organic electrolyte solution are reported. Observed Raman bands are assigned; based on these results previously suggested molecular structures are discussed.

Keywords: Polythiophene, electropolymerization, cyclic voltammetry, bandgap, DFT, $p$ doping, $n$-doping, in situ Raman sectroscopy, in situ UV-Vis spectroscopy, Hammett constant 
Die vorliegende Arbeit wurde in der Zeit von November 2003 bis April 2006 unter Leitung von Prof. Dr. Rudolf Holze am Lehrstuhl für Physikalische Chemie/Elektrochemie der Technischen Universität Chemnitz durchgeführt. 
To My Lovely Family......

My Father and Mother

My Brother and Sisters

Zaid, Hunaida and Suhad 


\begin{tabular}{lc}
\hline Content & Pag \\
\hline I Acknowledgement
\end{tabular}

I Acknowledgement

$\begin{array}{ll}\text { II List of Symbols and Abbreviations } & 10\end{array}$

$1 \quad$ Introductions and Aim of Study 13

$\begin{array}{lll}1.1 & \text { Conducting Polymers } & 13\end{array}$

1.2 Polyheterocycles as Conducting Polymers 13

1.3 Mechanism of Electrical Conduction 15

$\begin{array}{lll}1.4 & \text { Synthesis of Conducting Polymers } & 17\end{array}$

1.4.1 Chemical Synthesis 17

$\begin{array}{lll}\text { 1.4.2 Electrochemical Synthesis } & 17\end{array}$

1.5 Derivatized Conducting Polymers 20

1.5.1 Substituted Heterocycles 20

1.5.2 Soluble Conducting Polymers 22

1.6 Theoretical Studies of Conducting Polymers 22

$1.7 \quad$ Applications of poly 3-phenylthiophene derivatives 23

1.7.1 Doped Polymers in Electrochemical Capacitors 23

1.7.2 3-phenylthiophene derivatives as conducting polymers 26

$\begin{array}{lll}1.8 & \text { Aim of the Study } & 27\end{array}$

2 Experimental Section 28

$\begin{array}{lll}2.1 & \text { Synthesis of Monomers } & \mathbf{2 8}\end{array}$

2.2 Chemicals 30

2.3 Electrochemical Measurements $\quad 30$

$2.4 \quad$ Resonance Raman Spectroscopy Measurements 31

2.5 UV-Visible Spectroscopy Measurements 31

2.6 Theoretical Calculation Methods 32

3 Results and Discussion $\quad 33$

3.1 Electrochemical Polymerization and Cyclic Voltammetry. 33

3.2 Resonance Raman Spectroscopy of Poly $p$-(3-thienyl) benzene Derivatives. 47

3.2.1 Resonance Raman Spectroscopy of Poly $p$-(3-thienyl) benzene Derivatives. 48

3.2.2 Resonance Raman Spectroscopy of Poly $p$-(3-thienyl) acetophenone. 55

3.2.3 Resonance Raman Spectroscopy of Poly $p$-(3-thienyl) nitrobenzene. 58 
3.2.4 Raman Spectroscopic Studies of regioregularity of poly-3-phenylthiophene

61 derivatives

3.3 UV-Visible and Electrochemical Bandgaps of 3-Phenylthiophene Derivatives

3.4 Theoretical Treatment of 3-Phenylsubstituted Thiophenes and Their Intrinsically conducting polymers.

4 Summary

85

5 References 


\section{Acknowledgment}

First of all, I would like sincerely to thank my supervisor Professor Dr. Rudolf Holze for his guidance, kindness and encouragement throughout this project. It has been a great experience to learn from him through the many discussions on chemistry, research and life and I am so grateful for his patience and trust.

I also wish to thank the members and former members of our research group for their encouragement and for valuable discussions and support during this project. My sincere thanks to all of my friends who shared my misery and were great support to me especially Dr. Baker Al-Hourani, Dr. Gopakumar Thiruvancheril and Dr. Abey Issac. My special thanks to Frau Elke Rahm and Frau Nora Younadam for their personal help and for their efforts to make everybody in the group as comfortable as possible.

I express my appreciation gratefully to Prof. Dr. K. Banert for helpful discussions and for the support in synthesis of the monomers, and to Dr. A.A. Auer for helpful discussions in density functional theory calculations.

I deeply appreciate the Chemnitz University of Technology that embraced me as one of its students.

Finally I feel indebted to every member of my great family especially (my father, my mother, my brother Zaid, my sisters Hunaida and Suhad, Nayl, Odate, Celina, Fajir, Shahm, Danial, Lelean and Neta) without whom I would never be able to finish this degree. Above all and before everything I am grateful to God for everything he gave me. 


\section{List of Symbols and Abbreviations}

\begin{tabular}{|c|c|}
\hline $\mathrm{A}^{\mathrm{o}}$ & Angstrom \\
\hline AM1 & Austin Model 1 \\
\hline Asym. & Asymmetric \\
\hline B3LYP & Three parameter compound functional of Becke \\
\hline${ }^{\circ} \mathrm{C}$ & Degree Celsius \\
\hline${ }^{13} \mathrm{C} \mathrm{NMR}$ & Carbon-13 nuclear magnetic resonance \\
\hline CVs & Cyclic voltammograms \\
\hline DFT & Density functional theory \\
\hline$E_{\text {ea }}$ & Electron affinity \\
\hline ECCs & Electrochemical capacitors \\
\hline $\mathrm{E}(\mathrm{EC})_{\mathrm{n}}$ & Electrochemical mechanism \\
\hline$E_{\mathrm{i}}$ & Ionization potential \\
\hline$E_{\mathrm{pa}}$ & Anodic peak potential \\
\hline$E_{\mathrm{pc}}$ & Cathodic peak potential \\
\hline Et & Ethyl \\
\hline $\mathrm{eV}$ & Electron Volt \\
\hline$\Delta G$ & Gibbs free energy change \\
\hline GC-MS & Gas chromatography-mass spectrometry \\
\hline $\mathrm{h}$ & Hour(s) \\
\hline$\Delta H$ & Heat of formation change \\
\hline $\mathrm{HH}$ & Head to Head \\
\hline HOMO & Highest occupied molecular orbital \\
\hline HT & Head to Tail \\
\hline ICPs & Intrinsically conducting polymers \\
\hline ITO & Indium doped tin oxide \\
\hline IUPAC & International Union of Pure and Applied Chemistry \\
\hline $\mathrm{K}$ & Kelvin \\
\hline kcal & Kilocalorie \\
\hline LUMO & Lowest unoccupied molecular orbital \\
\hline
\end{tabular}




\begin{tabular}{|c|c|}
\hline $\min$ & Minute(s) \\
\hline $\mathrm{ml}$ & Milliliter \\
\hline $\mathrm{mm}$ & Millimeter \\
\hline$\mu \mathrm{m}$ & Micrometer \\
\hline mmole & Millimole \\
\hline MO & Molecular orbital \\
\hline $\mathrm{mV}$ & Millivolt \\
\hline $\mathrm{mW}$ & Milliwatt \\
\hline $\mathrm{nm}$ & Nanometer \\
\hline NMR & Nuclear magnetic resonance \\
\hline $\mathrm{Ox}$ & Oxidation \\
\hline $\mathrm{P}$ & Para position of the phenyl ring \\
\hline PETB & Poly-ethyl $p$-(3-thienyl) benzoate \\
\hline ppm & Parts per million \\
\hline PPT & Poly-p-(3-thienyl) toluene \\
\hline PTAN & Poly- $p$-(3-thienyl) anisol \\
\hline PTAP & Poly- $p$-(3-thienyl) acetophenone \\
\hline PTB & Poly-3-thienyl benzene \\
\hline PTNB & Poly- $p$-(3-thienyl) nitrobenzene \\
\hline$r_{25}$ & Ratio of spin density at $(\mathrm{C}-2)$ to $(\mathrm{C}-5)$ of the heterocycle ring \\
\hline Red & Reduction \\
\hline Roman numbers & $\begin{array}{l}\text { Table of contents, synthesis procedure numbers and types of } \\
\text { electrochemical capacitors }\end{array}$ \\
\hline RT & Room temperature \\
\hline s & Second(s) \\
\hline$\Delta S$ & Entropy change \\
\hline SCE & Saturated calomel electrode \\
\hline SHE & Standard hydrogen electrode \\
\hline Sym. & Symmetric \\
\hline TBATFB & Tetrabutylammoniumtetrafluoroborate \\
\hline TEATFB & Tetraethylammoniumtetrafluoroborate \\
\hline THF & Tetrahydrofuran \\
\hline
\end{tabular}




\begin{tabular}{ll} 
TLC & Thin layer chromatography \\
TT & Tail to Tail \\
UB3LYP & Open shell (Unrestricted) Three parameter compound functional of Becke \\
UV-Vis & Ultra violet visible \\
V & Volt \\
$Z$ & Carrier type (active dopant species) \\
$\sigma$ & Hammett constant \\
$\sigma_{\mathrm{i}}$ & Hammett constant of inductive effect \\
$\sigma_{\mathrm{p}}$ & Hammett constant of para position \\
$\sigma_{\mathrm{r}}$ & Hammett constant of resonance effect \\
$\alpha$ & 1-position of the heterocycle \\
$\beta$ & 2-position of the heterocycle \\
$\pi$ & Pi-bonding orbital \\
$\pi^{*}$ & Pi-antibonding orbital \\
$\rho$ & Electron density \\
$\lambda$ & Wavelength \\
$\delta$ & Resistance unit (ohm) \\
$\nu$ & On plane deformation \\
\hline & Out of plane deformation \\
\hline &
\end{tabular}




\section{Introductions and Aim of Study}

\subsection{Conducting Polymers}

Intrinsically conducting polymers (ICPs) are an exiting new class of electronic materials, which have attracted rapidly increasing interest since their discovery in 1979 [1]. ICPs have the potential of combining the high conductivities of pure metals with the processibility, corrosion resistance, and low density of polymers [2]. Additionally, they have many applications in the fields of batteries [3,4], electrochromic display devices [5,6], electromagnetic shielding [7], sensor technology [8], non-linear optics [9], and molecular electronics $[10,11]$.

\subsection{Polyheterocycles as Conducting Polymers}

Large-scale interest in conducting polymers is a relatively recent occurrence, although materials that might be considered electrically conductive polymers, such as filled polymers and aniline blacks, were known at the beginning of this century. The current interest in conductive polymers began in the 1970's, when it was found that the electrical conductivity of polyacetylene, a semi-conductor when pristine, could be increased by over fifteen orders of magnitude by treatment with oxidizing agents such as iodine.

The synthesis of polyacetylene in the highly conducting doped form was a starting point for a considerable number of studies. Electrodeposition of freestanding films of polypyrrole from organic media [12] opened the way to intensive research into polyheterocyclic and polyaromatic conducting polymers [13].

The electrochemical oxidation of these resonance-stabilized aromatic molecules has become one of the principal methods for preparing the conjugated, electronically conducting polymers. Since the first reports of the oxidation of pyrrole, many other aromatic systems have been found to undergo electropolymerization to produce conducting polymers, like thiophene [14-17], furan [14], selenophene [18], aniline [19-22], azulene [23,24], indole [14], Paraphenylene [25,26], as well as many substituted, multi-ring and polynuclear aromatic hydrocarbon systems (Table 1). It was found that all of the resulting polymers have a conjugated backbone, which is required for conductivity. 
Furthermore, these polymers are electrochemically oxidized to their doped states as they are formed. This oxidation necessitates the incorporation of charge compensating anions, also known as dopants, into the oxidized film to maintain electroneutrality.

Table 1. Names and idealized structures of the most widely studied conducting polymers.

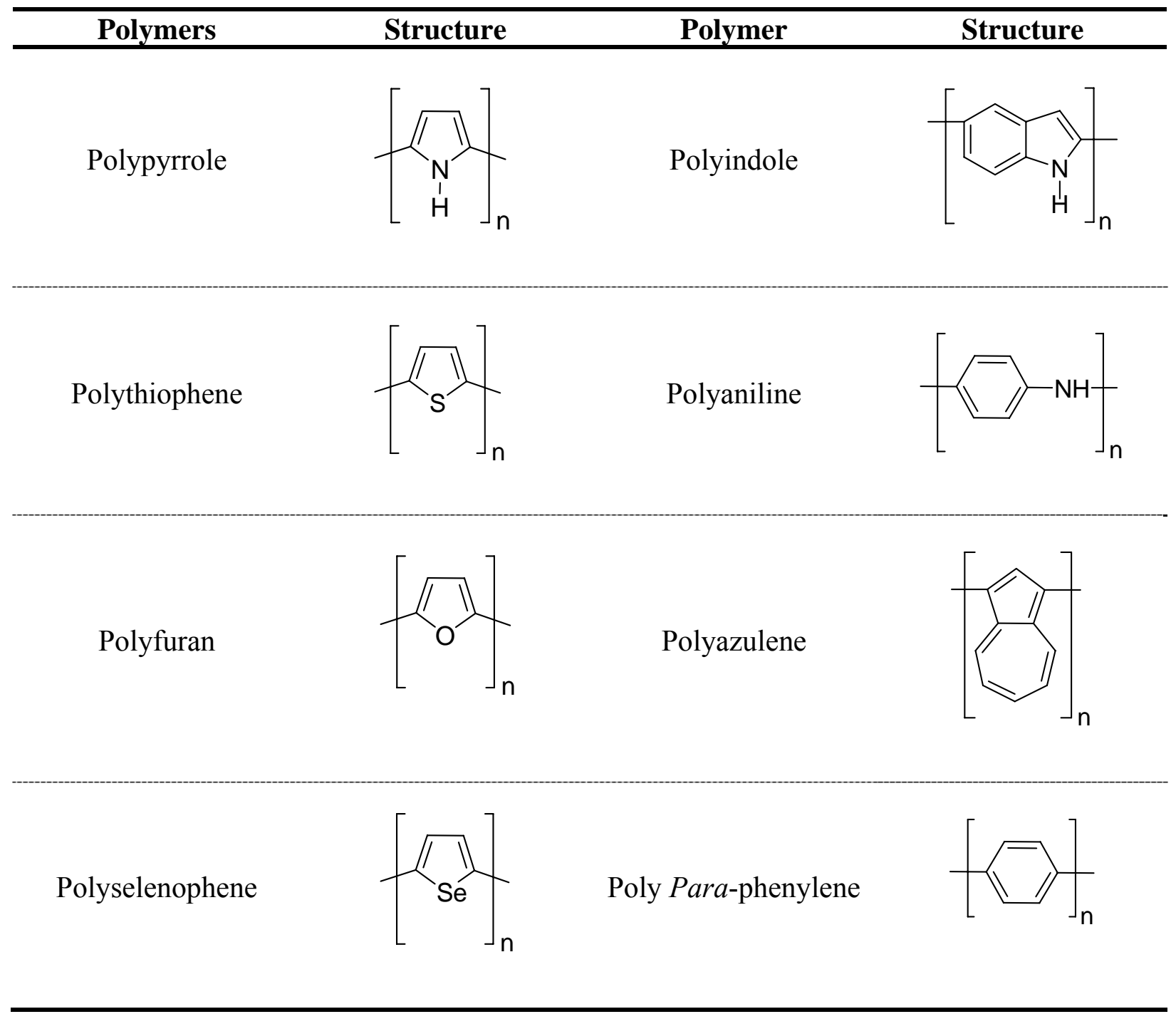

Before the synthesis and properties of polyheterocyclic conducting polymers are discussed, the mechanisms for the electronic conductivity and the nature of the charge carriers in conjugated polymers are first considered. 


\subsection{Mechanism of Electrical Conduction}

Mechanisms for the electronic conductivity and the nature of charge carriers in conjugated polymers are still a subject of debate. A brief summary of the theoretical models of the electronic conductivity of conjugated polymers, using polythiophene as example, is given in Figure 1.

In heterocyclic polymers, where two non-degenerate regions are separated by a topological defect, the formation of single solitons like polyacetylene is energetically unfavorable [27], and paired sites are formed [28]. This is the case for polythiophene, which can be drawn with either aromatic (Fig. 1a) or quinoid (Fig. 1b) structures, of which the latter possesses a higher energy configuration. Two neutral radicals on a single chain will recombine to eliminate the structural defect [27], although, if one is charged, a polaron is formed, which is delocalized over about four rings (Fig. 1c). However, when both defects are charged, they are predicted to pair up to form a 'bipolaron' [27], consisting of a doubly charged defect with no spin (Fig. 1d) and extending over a number of rings to a similar polaron. At higher doping levels, bipolarons may also combine to form 'bipolaron bands' within the gap [29]. Polymer doping is considered further in section 1.4.2.

Although these charge carriers are responsible for electrical conductivity in conjugated polymers, many structural imperfections are present in all polymers and thus when discussing mechanisms of bulk conductivity, these defects need to be considered.

Conductivity is not only a result of charge transfer along the chain, but is also due to electron hopping between chains and between different conjugated segments of the same chain. In addition to these effects, which act at molecular level, bulk conductivity values are also dominated by electron transfer between grain boundaries and variations in morphology [30,31]. Thus, the bulk conductivity of a conjugated polymer may be described by Eq. 1 [2].

$$
\sigma=\sum \frac{\mathrm{n}_{\mathrm{i}} \mathrm{Z}_{\mathrm{i}} \mathrm{ev}_{\mathrm{i}}}{\mathrm{E}}
$$

Eq. 1

where,

$$
\begin{aligned}
& \sigma=\text { Conductivity }\left(\mathrm{S} \mathrm{cm}^{-1}\right), \\
& n_{i}=\text { number of charges carried by each type } e_{i} \text {, }
\end{aligned}
$$




$$
\begin{aligned}
& \mathrm{Z}_{\mathrm{i}}=\text { carrier type (active dopant species), } \\
& \mathrm{e}=\text { electronic charge }\left(1.60 \times 10^{-19} \mathrm{C}\right), \\
& \mathrm{V}_{\mathrm{i}}=\text { drift velocity of electron }\left(\mathrm{cm} \mathrm{s}^{-1}\right), \text { and, } \\
& \mathrm{E}=\text { electric field }\left(\mathrm{V} \mathrm{cm}^{-1}\right)
\end{aligned}
$$

Eq. 1 takes into account different types of charge carriers, which contribute to the overall observed electrical conductivity in the bulk polymer.<smiles>Cc1ccc(-c2ccc(-c3ccc(-c4ccc(-c5ccc(-c6ccc(C)s6)s5)s4)s3)s2)s1</smiles>

(a)<smiles>C=c1ccc(=c2ccc(=c3ccc(=c4ccc(=c5ccc(=c6ccc(=C)s6)s5)s4)s3)s2)s1</smiles>

(b)<smiles></smiles>

(c)<smiles>Cc1ccc([C@H]2C=C/C(=c3\cc/c(=c4/cc/c(=C5/C=C[C@H](c6ccc(C)s6)S5)s4)s3)S2)s1</smiles>

(d)

Figure 1. Possible structures of polythiophene showing the non-degenerate (a) and quinoid (b) configurations; a polaron defect, and (d) a bipolaron defect. 


\subsection{Synthesis of Conducting Polymers}

Conducting polymers can be synthesized via chemical or electrochemical routes, although the former has now been largely superseded by electrochemical methods. However, many polymers, most notably polyacetylene, are still only accessible via chemical synthesis. The following sections describe these two different synthetic routes.

\subsubsection{Chemical Synthesis}

A large number of conducting polymers can be synthesized via catalytic oxidation [32,33]. However, control over polymer morphology is extremely limited, purification can be problematic and processing is virtually impossible.

\subsubsection{Electrochemical Synthesis}

Electrochemical synthesis of conducting polymers offers many advantages over chemical synthesis, including the in situ deposition of the polymer at the electrode surface, and, hence, eliminating processibility problems and the control of the thickness, morphology and degree of polymer doping by quantity of passed charge. In addition, the polymers are simultaneously oxidized to their doped conducting forms during polymer growth.

Electropolymerization is achieved by the electrooxidation of the heterocycle in an inert organic solvent containing supporting electrolyte [34]. A schematic of the generally accepted mechanism for electropolymerization of five membered heterocycles [35] is shown in Fig. 2. The initial electrochemical step (E) is a one-electron oxidation of the monomer to form its radical cation. A high concentration of these species is maintained at the anode surface because the rate of electron transfer greatly exceeds the monomer diffusion rate to the electrode surface. The second step, a chemical reaction (C), involves the spin pairing of two radical cations to form a dihydro dimer dication, which subsequently undergoes the loss of two protons and rearomatization to form the dimer. Aromatization is the driving force of the chemical step (C). Coupling occurs primarily through the $\alpha$-carbon atoms of the heterocyclic ring since these positions have the highest unpaired electron $\pi$-spin density and hence reactivity. At the applied potential, the dimer, which is more easily oxidized than the 
monomer, exists in a radical cation form and undergoes further coupling reactions with other radical cations. This electropolymerization mechanism, according to the general scheme $\mathrm{E}(\mathrm{CE})_{\mathrm{n}}$, continues until the oligomer becomes insoluble in the electrolytic medium and precipitates onto the anode surface [36]. However, this mechanism of electropolymerization is greatly simplified with regard to the nature of the rate limiting step and the exact role of oligomers in the initial deposition step, which are remaining unresolved [37].

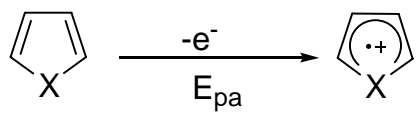
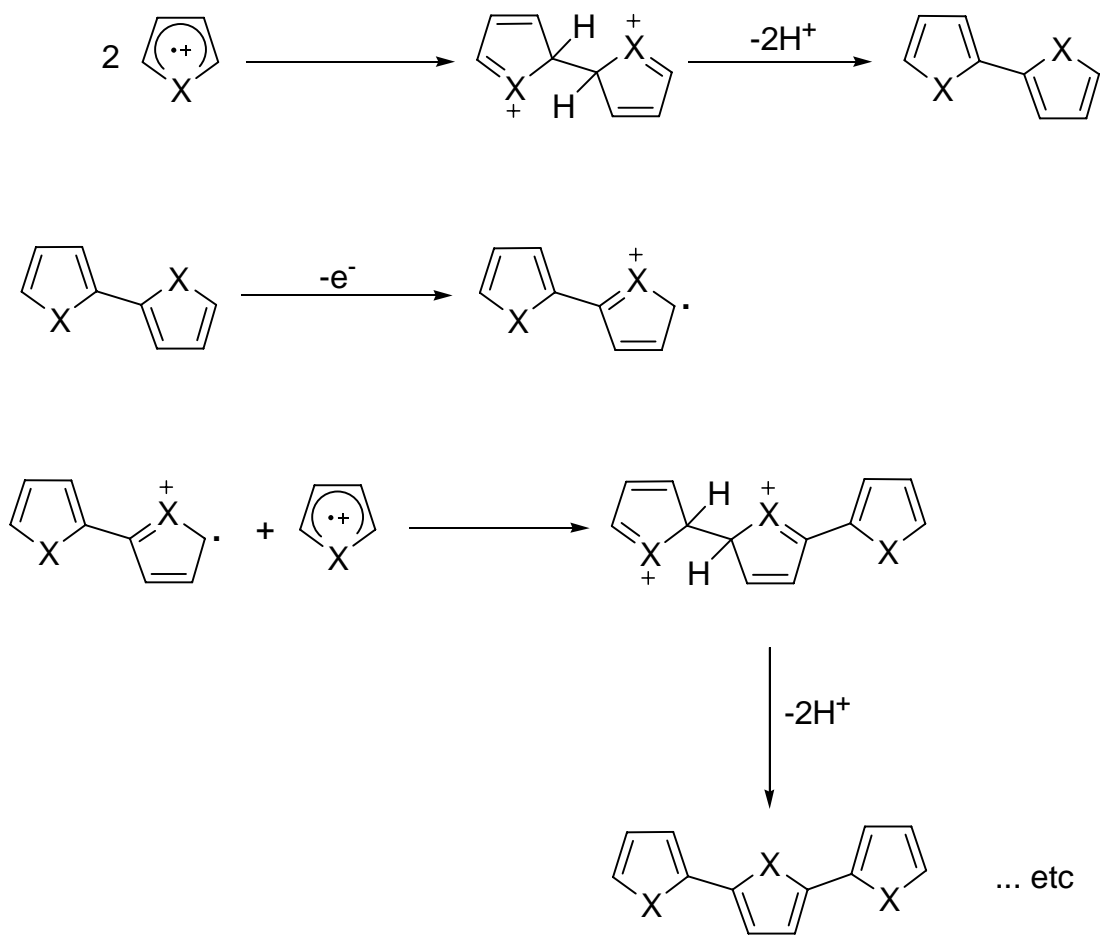

Figure 2. Proposed mechanism of the electrochemical polymerization of five membered aromatic heterocycles; where $\mathrm{X}=\mathrm{NH}, \mathrm{S}$ or $\mathrm{O}$. 
Non- $\alpha, \alpha^{\prime}$-linkages (e.g. $\alpha, \beta^{\prime}$ and $\beta, \beta^{\prime}$ couplings) can occur to variable extents, causing breaks in the conjugation and hence, reduction in film conductivity. Such linkages are more profound in the later stages of electropolymerization where the unpaired electron $\pi-\operatorname{spin}$ density of the $\beta$-carbon atom of the oligomer approaches that of the $\alpha$-carbon atom [38].

Since conjugated oligomers are oxidized at less positive potentials than their corresponding monomer, polymer oxidization occurs concurrently with electrodeposition. Typically, removal of one electron from the polymeric backbone for every three-four monomer units to form polar structures is responsible for inherent conductivity (see section 1.3). Anions, termed 'dopants', are thus incorporated into the film to maintain electroneutrality. The doping terminology of conductive polymers should be distinguished from its conventional use in semi conductor physics, since considerably higher concentrations of dopant are employed in the former, typically up to $33 \%$ [39]. Conductive polymers can be cycled between the oxidized or reduced ( $n$-doped) conducting state and the neutral insulating state [15], this process being controlled by the diffusion of counter ions into and out of the film [35].

The type of counter ion can greatly affect the conductivity of the film [40]. For example, on the one hand, polypyrrole with equal degrees of tetrafluoroborate doping, typically has conductivities in the range of $30-100 \mathrm{~S} \mathrm{~cm}^{-1}$, on the other hand, using perchlorate as counter anions increase the conductivity range of the polypyrrole to be $60-200 \mathrm{~S} \mathrm{~cm}^{-1}$ [41].

It is generally assumed that polymer growth occurs via a nucleation process similar to that of metal deposition. However, ellipsometric measurements of polypyrrole formation [42] suggest that polymerization does not occur via localized nucleation but by homogeneous growth of the product on the surface. Potential step experiments have shown instantaneous nucleation on the bare metal surface followed by rapid formation of a polymer monolayer [43]. Spectroscopic measurements [43] have shown that initially short oligomers are produced with longer chains appearing subsequently and that the electrical properties of the bulk material only become evident when the growth centers have overlapped to form a continuous film. 


\subsection{Derivatized Conducting Polymers}

Derivatization provides one of the best methods of achieving molecular level control of the structural, electronic, and electrochemical properties of conductive polymers [15,44-47]. This was originally achieved through the use of dimers $[31,48]$, trimers $[31,49]$, and tetramers [50] of thiophene and pyrrole, which were found to undergo electropolymerization to produce electroactive films with properties modified as compared to those of the parent monomer. For example, poly(bithiophene) and poly(terthiophene) are usually obtained as powdery deposits rather than homogeneous films, showing lower conductivities [approx. $3-0.02 \mathrm{~S} \mathrm{~cm}^{-1}$, in the case of poly(bithiophene)] than the typically observed value of polythiophene [31,36]. This is reflected in the electronic absorption spectra, which show a hypsochromic shift in the maximum absorption, suggesting a decrease in the mean free conjugation length of the polymer. Thus, electropolymerization of monomers and oligomers does not produce the same polymer as might be expected.

\subsubsection{Substituted Heterocycles}

Pyrroles and thiophenes substituted at the 3-( $\beta-)$ position (and also the $N$-position for pyrrole) can often undergo electropolymerization to produce conducting polymers, since the 2and 5-( $\alpha-)$ positions remain available for monomer coupling [51]. The electrochemical behavior of a wide range of $\beta$-substituted pyrroles and thiophenes has been investigated, although $\beta$-substituted thiophenes are generally more suitable than their pyrrole analogues due to their high stability and ease of preparation [41]. Properties of the products formed by electrooxidation depend highly on the substituent, with some reactions producing conducting polymers and others, insulating layers or soluble species. This has been attributed to electronic and steric considerations [41].

The linear correlation, which has been found between monomer oxidation potential and Hammett constant for a series of $\beta$-substituted thiophenes (Fig. 3), explain, dramatically, the electronic effects (electronic density and, hence reactivity) of the thiophene ring [15]. Highly electron withdrawing substituents, such as nitro- and nitrile- groups, coupled directly to thiophenes at the $\beta$-position cause the monomer oxidation process to shift to much higher anodic potentials than the thiophene itself (e.g. $2000 \mathrm{mV}$ c.f. $1400 \mathrm{mV}$ ) and as a result, 
electropolymerization does not occur. Similarly, highly electron-donating species, such as amino groups increase the electron density at the thiophene ring thus allowing monomer oxidation to occur at less anodic potentials relative to that of thiophene itself. Such a stabilization of the radical cation results in diffusion of the species away from the electrode interface into the bulk electrolyte before eventually being attacked by the electrolyte or other nucleophilic species in solution. Between these two extreme cases, other substituents may be used too. In cases where conducting polymers are produced, electronic effects also have an effect on redox behavior, where polymer oxidation potentials are also found to vary linearly with Hammett constant [15]. Thus, in principle, a substituent may be chosen to produce the desired electrochemical properties. In addition to electronic effects, steric factors also influence the electropolymerization reaction and properties of conducting polymers when they are formed [36].

Epa monomer (mV vs. SCE)

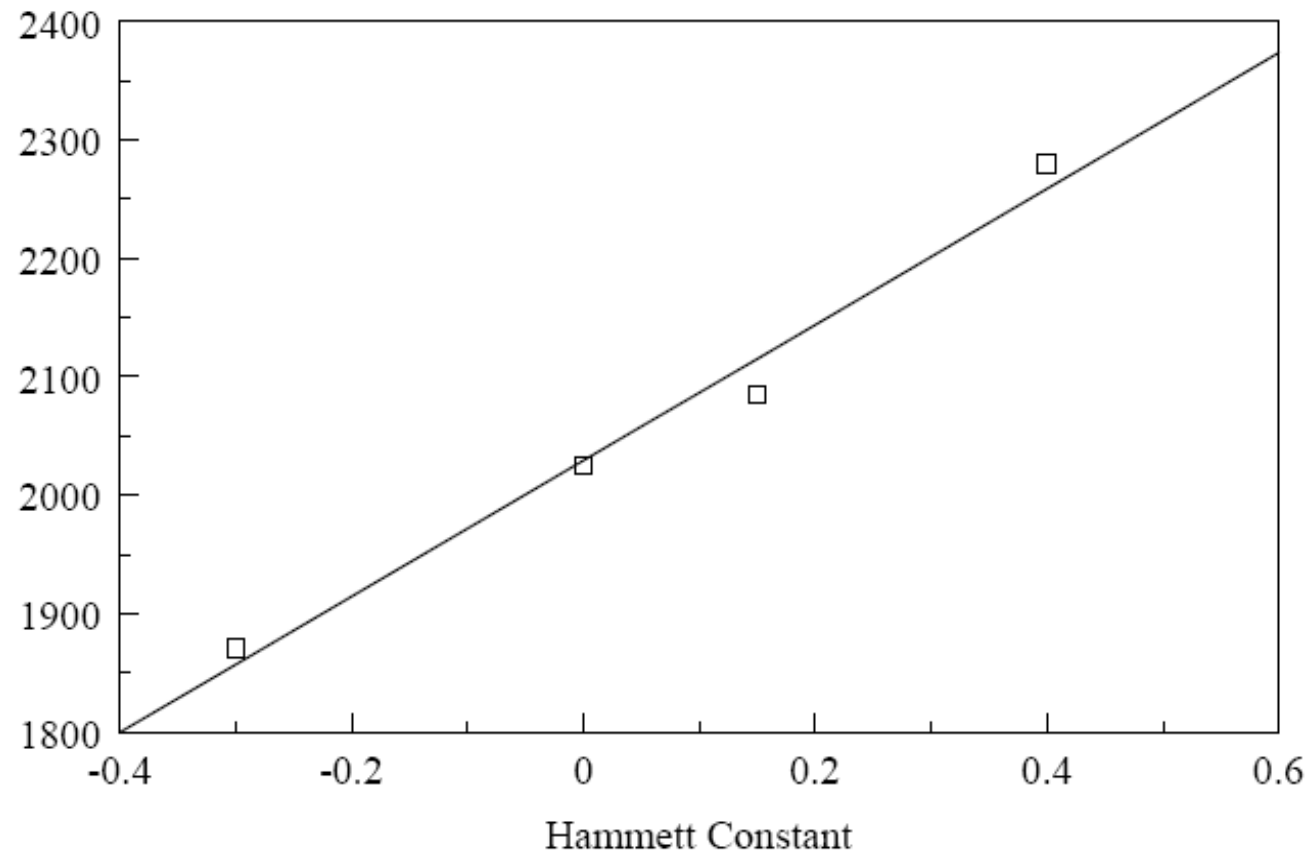

Figure 3. Variation of monomer oxidation potential with Hammett constant for $\beta$-substituted thiophene monomers; where $\beta=\mathrm{Me}, \mathrm{H}, \mathrm{Br}$ and $\mathrm{COOH}$ from left to right, respectively. The films were grown on a Pt electrode and sodium chloride saturated calomel electrode was used as a reference electrode and TEATFB as electrolyte in acetonitrile [15]. 
Steric effects do not significantly hinder the formation of the radical cation but appear to become important in the subsequent coupling reaction [36]. For example, 3-methylthiophene undergoes electropolymerization at a potential of $200 \mathrm{mV}$ less anodic than that of the thiophene, as might be expected from Hammett constant considerations. However, a polymer of higher conductivity than polythiophene $\left(\sigma: 450-510 \mathrm{~S} \mathrm{~cm}^{-1}\right.$ compared to $\left.270 \mathrm{~S} \mathrm{~cm}^{-1}\right)$ is produced [46] and this can be explained by blocking one of the $\beta$-positions of the thiophene ring by a methyl substituent, which reduces the incidence of defect $\alpha, \beta^{\prime}$ - and $\beta, \beta^{\prime}$-linkages. Therefore, it might be expected that 3,4-dimethylthiophene would produce a polymer of even higher conductivity than of the poly (3-methylthiophene). However, a polymer of significantly reduced conductivity $\left(\sigma: 0.5 \mathrm{Scm}^{-1}\right)$ was produced and this may be explained by steric interactions between methyl substituents grafted on consecutive thiophene rings, which distort the $\pi$-system and thus decrease the degree of conjugation.

\subsubsection{Soluble Conducting Polymers}

In addition to conductivity enhancement, $\beta$-substituted thiophenes have a variety of other potential applications. Polythiophenes containing alkyl [52-54] and alkoxy [54] $\beta$-substituents are soluble in common organic solvents in the conducting state, considerably aiding processibility and characterization of these electroactive materials. Poly-(3-alkythiophenes) with alkyl groups with chain lengths equal or greater than four carbons (i.e. butyl) are readily soluble in THF, dichloromethane, chloroform, benzene, toluene, xylene, benzonitrile and nitrobenzene at room temperature. Solubilized polymers can subsequently be processed into films, which show similar electrochemical properties to those produced directly. Doped solution-cast films, generally, show lower conductivities than the electropolymerized films, although, stretching the films can increase the conductivity [36].

\subsection{Theoretical Studies of Conducting Polymers}

The electric conductivity in the conjugated polymers is attributed to the overlap between $p$ atomic orbitals [55]. This extension of overlap is associated with conformation of the chain; thus knowledge of the possible conformations and the energies involved in the conformational equilibrium can be used to understand the electric properties of these compounds. With this 
aim, theoretical methods have been applied to determine structures and electronic properties related to the electric conductivity [56-61]. On the other hand, polythiophenes substituted with aryl groups are interesting from several viewpoints. The analysis of the electronic and steric effects of such substituents represents an important step in the structure properties relationships in substituted polythiophenes, and the phenyl groups constitute interesting sites for future substitutions with further functionalization.

\subsection{Applications of poly-3-phenylthiophene derivatives}

\subsubsection{Doped Polymers in Electrochemical Capacitors}

Electrochemical capacitors (ECCs) have received much attention in recent years due to their potential application in electric vehicles [62]. Devices that incorporate electroactive polymers as the active material are particularly promising in that they are low cost materials relative to noble metal oxides, have high volumetric capacities leading to high energy densities and in some configurations provide nearly all the charge at relatively high voltage.

Unlike most galvanic cells or batteries, but similar to electrostatic capacitors, electrochemical capacitors can be rapidly and repeatedly cycled through their charge/discharge process. These devices therefore fill the void between conventional capacitors and batteries in terms of their energy and power densities. Thus they are ideal for the load leveling that will be required in electric vehicles during acceleration or hill climbing [63]. Furthermore, devices of this type can potentially be utilized in any electrical system where sudden power surges are required.

Although the concept of electrochemical capacitors is well established, several challenges remain such as improvements in the electroactive materials, the development of multi-layer stacks, reduction in weight as well as cost and the ability to mass-produce with quality and ease [64].

The electrochemical capacitors have been classified into three different types depending on the electroactive polymers i.e. the charge storage material; Type I, II, and III [63,65] (Fig 4). Type I capacitor is based on a symmetric configuration, with identical $p$-dopable (only) conducting polymer active layers (eg polypyrrole) on each of the two electrodes in a cell. A Type II capacitor has an asymmetric configuration, with two different $p$-dopable active 
materials, (eg polypyrrole and polythiophene) on each of the cell electrodes. The third and the most promising one is based on a conducting polymer that can be both $n$ - and $p$-doped electrochemically. In this Type III capacitor, the charged capacitor consists of one electrode in the fully n-doped state and the other in the fully p-doped state. After discharge, both polymer films will be in the undoped state. Apart from the increase in cell voltage to about $3 \mathrm{~V}$ and the ability to release the total charge within a doping regime, there are also two further advantages of the Type III capacitor, over Type I and II. When the Type III capacitor is charged, both conducting polymer films are doped and, therefore, both have a high electronic conductivity. In contrast, in a charged capacitor of Type I or II, one of the polymer films will be in the undoped form, associated with low electronic conductivity. Hence, it is expected that this low electronic conductivity will diminish the instantaneous power density that can only be achieved on discharge of Type I or II capacitor, but not in the case of Type III. The second advantage of Type III is that, because of the separation in potential between the regions of $n$ doping and p-doping, all the charge is released at high voltage (in the case of polythiophenes, between 3 and $2 \mathrm{~V}$ ). A more detailed comparison of type I, II, and III electrochemical capacitors can be found in ref. [63].
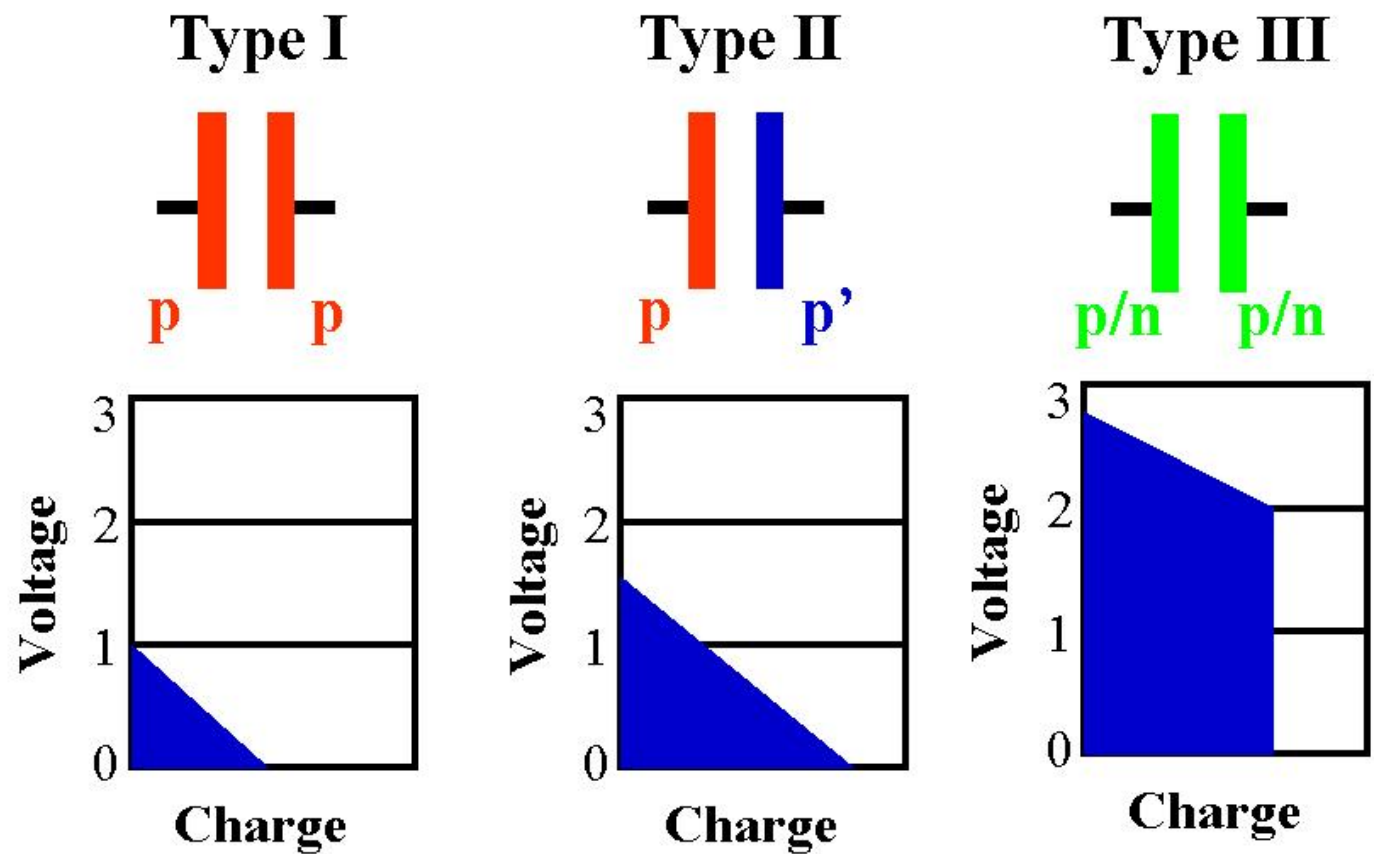

Charge

Figure 4. Electrochemical capacitors types. 
Polymers that are capable of both $p$ and $n$-doping in a reversible and consistent manner are comparatively rare $[36,66]$. The $p$-doping process involves the removal of an electron from the polymer backbone via the external circuit, while the charge neutrality is maintained via insertion of an anion from the electrolyte solution (Fig 5). The $n$-doping process proceeds with injection of electrons onto the polymer backbone, while cations are inserted into the polymer to maintain charge neutrality (Fig 5). For this it is important that the ionic conductivity of the polymers must be high. This criteria is met by producing a polymer that has a network of electrolyte filled pores. One family of polymers that have shown promise in this regard is 3substituted thiophenes especially 3-phenylthiophene derivatives [65-69].
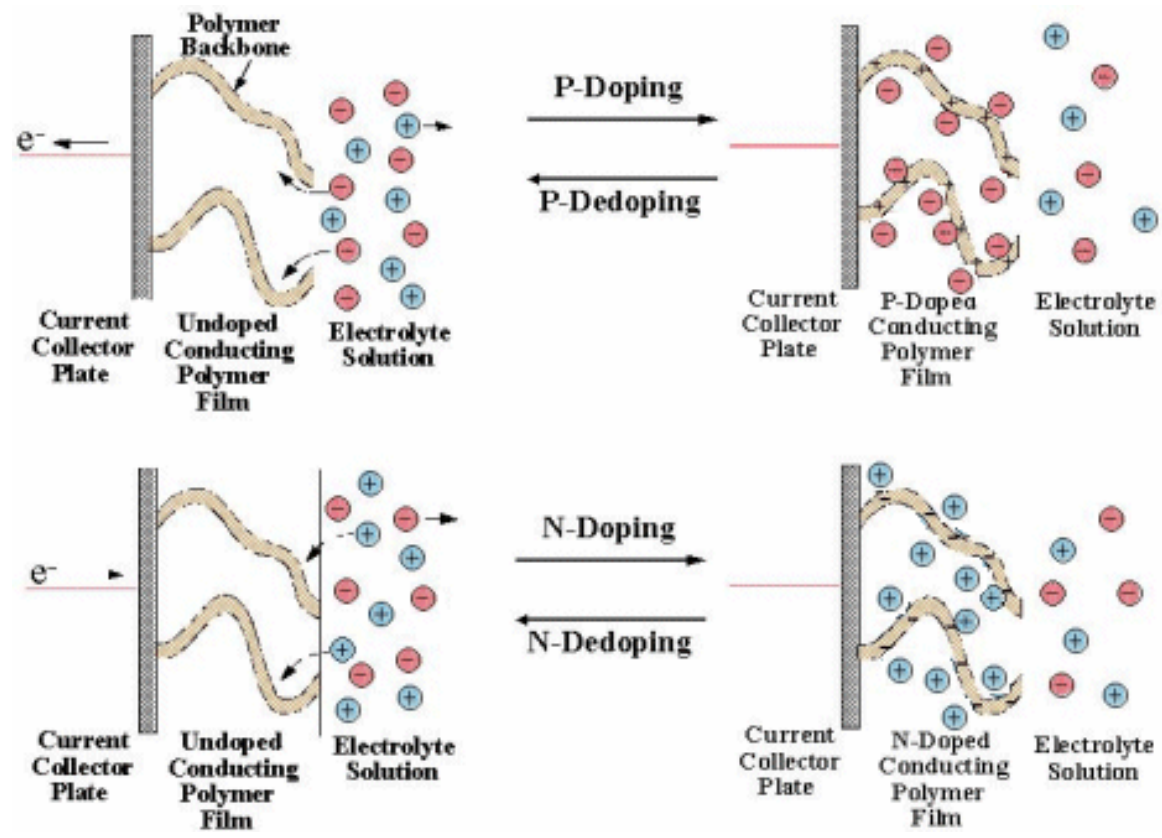

Figure 5. $n$-and $p$-doping process in polymers in electrochemical capacitors. 


\subsubsection{3-phenylthiophene derivatives as conducting polymers}

Sato et al [70] have found that poly-3-phenylthiophene is highly $p$-dopable and also suggested its application in a p-n junction diode. The high $p$-doping activity of poly-3phenylthiophene was explained in terms of a favorable conjugation effect between the phenyl rings and the polythiophene backbone [71]. On the other hand, Onoda et al. [72] studied the $n$ doping properties of poly 3-phenylthiophene films and found a high degree of electrochemical reversibility. However, this group concluded that rather than being in conjugation with the polythiophene backbone, the phenyl rings were perpendicular to it and the interchain charge transport processes limited the observed electronic properties.

Guerrero et al [73] studied the relationship between the redox properties of a series of para-substituted 3-phenylthiophene monomers and the respective polymers with Hammett parameter substituent constants and found a good correlation between the redox properties and Hammett constants.

Sato et. al. [71] and Guerrero et. al. [73] further demonstrated that the oxidation potential of poly-3-phenylthiophene increased when an electron-withdrawing substituent was placed on the phenyl ring and the electron-donating groups produced a stable anion-doped material. Thus, the oxidation potential decreased. 


\subsection{Aim of the Study}

The ability to dope conjugated polymers electrochemically is important for several reasons. Many applications of conjugated polymers, such as light emitting electrochemical cells [55,74], microactuators [75-77], energy storage [78], photovoltaic [79], electrochromic devices [80], and sensors $[60,81]$ are based on electrochemical transitions between doped and neutral states or rely on the stability of a specific doping level.

The aim of this study is to synthesize electroactive conducting materials via the electrochemical polymerization of a series of para-substituted 3-phenylthiophene derivatives ($\mathrm{H},-\mathrm{CH}_{3},-\mathrm{OCH}_{3},-\mathrm{COCH}_{3},-\mathrm{COOC}_{2} \mathrm{H}_{5},-\mathrm{NO}_{2}$ ), which exhibit $n$-type doping because only a limited number of conducting polymers can be electrochemically $n$-doped due to the poor stability of the polymers at extremely negative potentials.

The polymers formed have been characterized by cyclic voltammetry as well as spectroelectrochemical techniques, such as, in situ and ex situ resonance Raman spectroscopy, and in situ and ex situ UV-Vis spectroscopy.

Molecular modeling has been used to identify polymer structure / property relationships and to determine monomer coupling positions. These theoretical studies will be developed further to provide a useful predictive tool to screen novel monomers prior to experimental investigation and the approach may be used to form a key step in the rational design of novel conductive polymers via computational methods. 


\section{Experimental Section}

\subsection{Synthesis of Monomers}

3-thienyl benzene (1a), p-(3-thienyl)-toluene (1b) , p-(3-thienyl)-anisol (1c) (see Scheme. 1) were prepared according to the literature [82].The general description for this method is:

Reaction of phenyl Grignard reagent $(0.50$ mole $)$ with 3 -ketotetrahydrothiophene $(0.50$ mole). The reaction mixture was acidified with $2.0 \mathrm{~N} \mathrm{HCl}$ and extracted with ether. The ether layer was neutralized with $\mathrm{KHCO}_{3}$, dried over $\mathrm{MgSO}_{4}$, and concentrated to give an oily carbinol. The later was heated slowly with $\mathrm{KHSO}_{4}$ and $\mathrm{S}$ (a considerable excess of $\mathrm{KHSO}_{4}$ and $\mathrm{S}$ are necessary for good reaction) to $225^{\circ} \mathrm{C}$ until water and $\mathrm{H}_{2} \mathrm{~S}$ ceased to be evolved. The remaining materials were steam distilled to give the products $(\mathbf{1 a}, \mathbf{1 b}, \mathbf{1 c})$, then $p$-(3-thienyl)toluene and $p$-(3-thienyl)-anisole were recrystallized from $n$-hexane. The products after recrystallization were purified by column chromatography using silica gel (stationary phase) and $n$-hexane (as eluent). Chromatographic resolutions were checked periodically by using a silica gel TLC plate ( $n$-hexane as eluent), and ${ }^{1} \mathrm{H}$ NMR, ${ }^{13} \mathrm{C}$ and GC-MS, which were found to be in agreement with published data [82], with yields in the range of 44-55\% (Scheme 1).

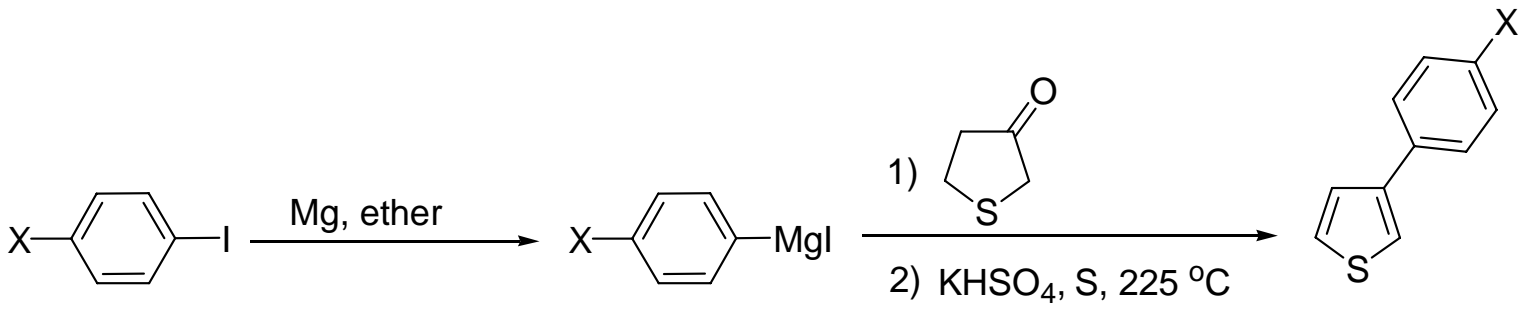
1a) $X=H, 55 \%$
1b) $\mathrm{X}=\mathrm{CH}_{3}, 50 \%$
1c) $\mathrm{X}=\mathrm{OCH}_{3}, 44 \%$

Scheme 1. Preparation of 3-phenyl derivatives (1a-c). 
Ethyl-p-(3-thienyl)-benzoate (1d), $p$-(3-thienyl)-acetophenone (1e) and $p$-(3-thienyl)nitrobenzene (1f) (see Scheme. 2) were prepared by catalyzed coupling reaction according to literature [83]. The general procedure for their preparation can be summarized in:

\section{Preparation of Highly Active Zinc (Zn $\left.{ }^{*}\right)$}

Active zinc was prepared by the reduction of anhydrous zinc chloride $\left(\mathrm{ZnCl}_{2}\right)$ with lithium using naphthalene as an electron carrier. In a representative preparation, $\mathrm{ZnCl}_{2}(10 \mathrm{mmol})$ in THF (10 ml) was transferred drop wise via cannula to lithium $(20 \mathrm{mmol})$ and naphthalene (2 mmol) in stirred THF $(5 \mathrm{ml})$. The stirring was stopped when the lithium was completely consumed, and the active zinc powder was allowed to settle for $0.5 \mathrm{~h}$. The supernatant was then removed via cannula, and freshly distilled THF $(10 \mathrm{ml})$ was added. The slurry was briefly stirred and then allowed to settle down for $0.5 \mathrm{~h}$ again, and the supernatant was subsequently removed. Freshly distilled THF (15 ml) was added to newly formed and washed $\mathrm{Zn}$ * which was ready for oxidative addition.

\section{Preparation of 3-Thienylzinc Iodide and 3-Arylthiophene:}

3-Iodothiophene $(5 \mathrm{mmol})$ was added via syringe to active zinc $(10 \mathrm{mmol})$ being stirred in THF $(15 \mathrm{ml})$ at room temperature. The slurry was stirred at room temperature for 8-10 $\mathrm{h}$. After completion of the oxidative addition, the mixture was allowed to stand so that the excess $\mathrm{Zn}$ * powder could settle out of the solution. Since the newly prepared 3-thienylzinc iodide was dissolved in THF, the supernatant was then transferred to a mixture of aryl iodide ( $4 \mathrm{mmol}$ ) and $\mathrm{Ni}(\mathrm{dppe}) \mathrm{Cl}_{2}$ or $\mathrm{Pd}\left(\mathrm{PPh}_{3}\right)_{4}(0.4 \mathrm{~mol} \%)$ with stirring in $\mathrm{THF}(5 \mathrm{ml})$ at room temperature. After evaporating THF under vacuum, ether was added to the crude product and the organic layer was washed three times with water. The drying of the organic layer over anhydrous magnesium sulfate was followed by evaporation and resulted in a brown solid. The product was recrystallized from pentane at $0{ }^{\circ} \mathrm{C}$ with charcoal followed by sublimation. ${ }^{1} \mathrm{H}$ NMR, ${ }^{13} \mathrm{C}$ and GC-MS are measured and found to be in agreement with published data [83], with yields in the range of $62-80 \%$, (Scheme 2$)$. 


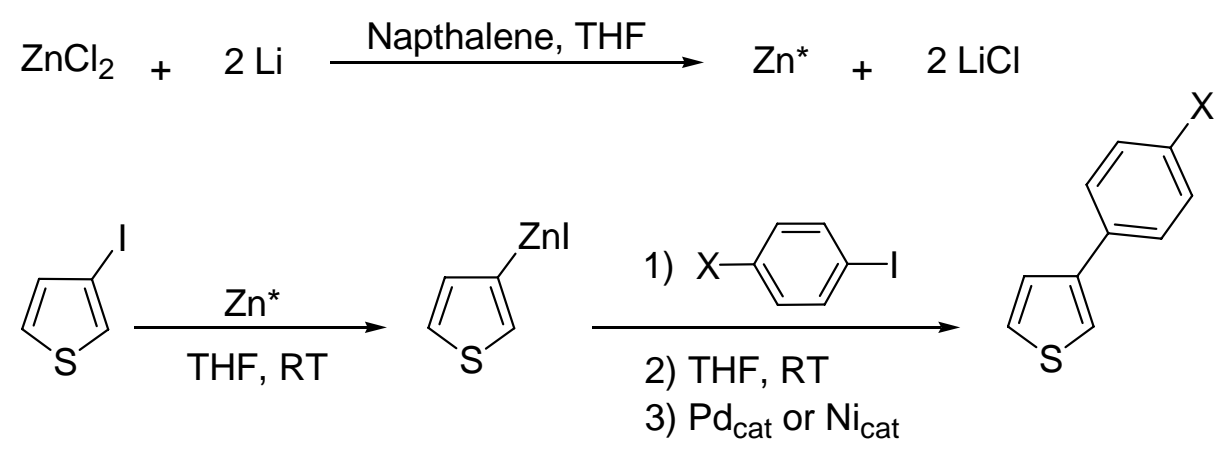

1d) $\mathrm{X}=\mathrm{CO}_{2} \mathrm{C}_{2} \mathrm{H}_{5}, 80 \%$

1e) $\mathrm{X}=\mathrm{COCH}_{3}, 68 \%$

1f) $\mathrm{X}=\mathrm{NO}_{2}, 62 \%$

Scheme 2. Preparation of 3-phenyl derivatives (1d-f).

\subsection{Chemicals}

Tetraethylammoniumtetrafluoroborate (TEATFB) (ACROS, 99\%) was recrystallized thrice from methanol and dried under vacuum at $140^{\circ} \mathrm{C}$ for $24 \mathrm{~h}$. Acetonitrile (Merck, anhydrous, $<10 \mathrm{ppm} \mathrm{H}_{2} \mathrm{O}$ ) was used without further purification.

\subsection{Electrochemical Measurements}

Anodic electropolymerization was used to prepare polymers by applying constant electrode potential (oxidation potential) for 2-4 min. After each polymerization process the film was washed with acetonitrile to remove any traces of oligomers.

All electrochemical experiments were carried out at room temperature with nitrogenpurged solutions. A three-compartment cell containing a Pt disc (diameter $=1 \mathrm{~mm}$ ) electrode (99.99\%, Schiefer, Hamburg) embedded in glass was used as working electrode. The platinum disk electrode was polished with diamond polishing paste down to $0.3 \mu \mathrm{m}$ and then to $0.05 \mu \mathrm{m}$ with aqueous alumina slurry. A platinum sheet counter electrode and a non-aqueous $\mathrm{Ag} / \mathrm{AgCl}$ reference electrode filled with the supporting electrolyte solution were used. The reference electrode potential was verified frequently with respect to an aqueous saturated calomel electrode because the employed non-aqueous reference electrode system is prone to potential 
drift [84]. A custom built potentiostat interfaced with a standard PC via an ADDA-converter card operating with custom developed software was used to record cyclic voltammograms (CVs).

\subsection{Resonance Raman Spectroscopy Measurements}

Spectroelectrochemical experiments (in situ Raman Spectroscopy) for the polymers (2a-f) (Figure. 6) were performed in a three-electrode cell with a disk platinum-working electrode. The electrolyte was a monomer free acetonitrile solution, while the same electrodes as in CV experiments had been used in Raman measurements. The normal Raman spectra for the solid monomers (1a-f) (Figure. 6) were measured by capillary sampling technique. Raman spectra were recorded on a Raman ISA T64000 (Jobin-Yvon Instruments S.A.) spectrometer connected to a spectra view 2D CCD detection system under illumination of the samples at $\lambda_{\mathrm{o}}$ $=514.5,528.7$ and $488.0 \mathrm{~nm}$ of an Innova 70A (Coherent) argon ion laser. Spectral resolution was $<2 \mathrm{~cm}^{-1}$ and the laser power was measured at the laser head with a Coherent 200-power meter and always kept at low value $(\sim 50 \mathrm{~mW})$ to avoid destruction of the sample. All potentials in this work are reported with respect to the $\mathrm{Ag} / \mathrm{AgCl}$ electrode.

\subsection{UV-Visible Spectroscopy Measurements}

In situ UV-Vis-spectra of the monomers (1a-f) and polymers (2a-f) (Figure. 6) were recorded with a Shimadzu model UV-2101PC spectrometer (resolution $0.1 \mathrm{~nm}$ ). Spectroelectrochemical experiments were done in a $1 \mathrm{~cm}$ path length quartz cuvette serving as single compartment cell with an indium-doped tin oxide (ITO)-coated glass electrode with a specific surface resistance of about 10-20 $\Omega$ /square, installed perpendicular to the light path. A platinum wire was used as a counter electrode. A non-aqueous $\mathrm{Ag} / \mathrm{AgCl}$ reference electrode filled with the supporting electrolyte solution connected via salt bridge was used. The blank cuvette contained a solution of supporting electrolyte and an uncoated ITO electrode. UV-Visspectra of monomers in acetonitrile solutions were recorded with the same spectrometer. All potentials in this work are reported with respect to the $\mathrm{Ag} / \mathrm{AgCl}$ electrode. 


\subsection{Theoretical Calculation Methods}

DFT [84-88] of the three-parameter compound functionals of Becke (B3LYP) was used to optimize the geometry as well as to calculate the ionization potentials of neutral compounds and total atomic spin densities of the radical cations. The 6-31G(d) [89-100] basis set was used to optimize the structures as well as the total spin densities, while the 3-21G(d) [101-107] basis set was used to calculate the ionization potentials for neutral and radical cations of the compounds. The geometric structures of neutral molecules were optimized under no constraints. Nearly planar structures were used as the initial states because most of the crystalline oligothiophenes show planar conformations [108-110]. Ionization potentials were computed as the energy differences between the neutral molecule and the respective radical cation, in which the radical cation has the same molecular geometry as the neutral molecule (the Frank-Condon state was assumed for the cations). On the other hand, the geometric structures of the radical cations were optimized independently from the neutral molecules prior to the calculations of spin densities. Radical cations were treated as open shell systems (UB3LYP). Semiempirical calculations (heat of formation) were carried out by using AM1 method [111]. All calculations were performed using the Gaussian-98 software [112].

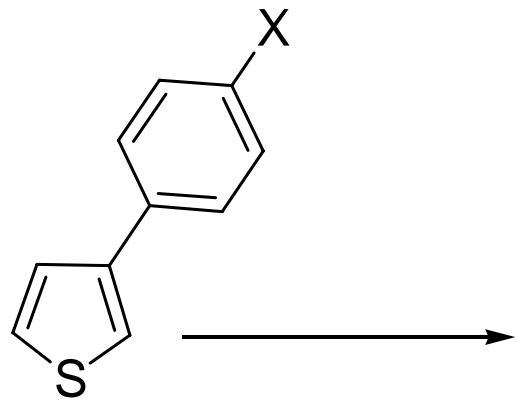

\begin{tabular}{ccc}
11 & & 2 \\
\hline 1 & $\mathbf{X}$ & 2 \\
\hline $\mathrm{a}$ & $-\mathrm{H}$ & $\mathrm{a}$ \\
\hline $\mathrm{b}$ & $-\mathrm{CH}_{3}$ & $\mathrm{~b}$ \\
\hline $\mathrm{c}$ & $-\mathrm{OCH}_{3}$ & $\mathrm{c}$ \\
\hline $\mathrm{d}$ & $-\mathrm{COOC}_{2} \mathrm{H}_{5}$ & $\mathrm{~d}$ \\
\hline $\mathrm{e}$ & $-\mathrm{COCH}_{3}$ & $\mathrm{e}$ \\
\hline $\mathrm{f}$ & $-\mathrm{NO}_{2}$ & $\mathrm{f}$
\end{tabular}

Figure 6. Polymerization of 3-phenylthiophene derivatives. 


\section{Results and Discussion}

\subsection{Electrochemical Polymerization and Cyclic Voltammetry.}

From polythiophene it is known that the properties and the quality of the deposited films depend on the solvent, electrolyte and electrochemical condition used during electrochemical polymerization [36] (Fig. 7). Platinum electrodes were used because of their inert behavior against monomers and polymers. In addition, polymers generated on platinum electrodes show in general higher conductivities than films generated on any other electrodes $[15,17,113$, 114].

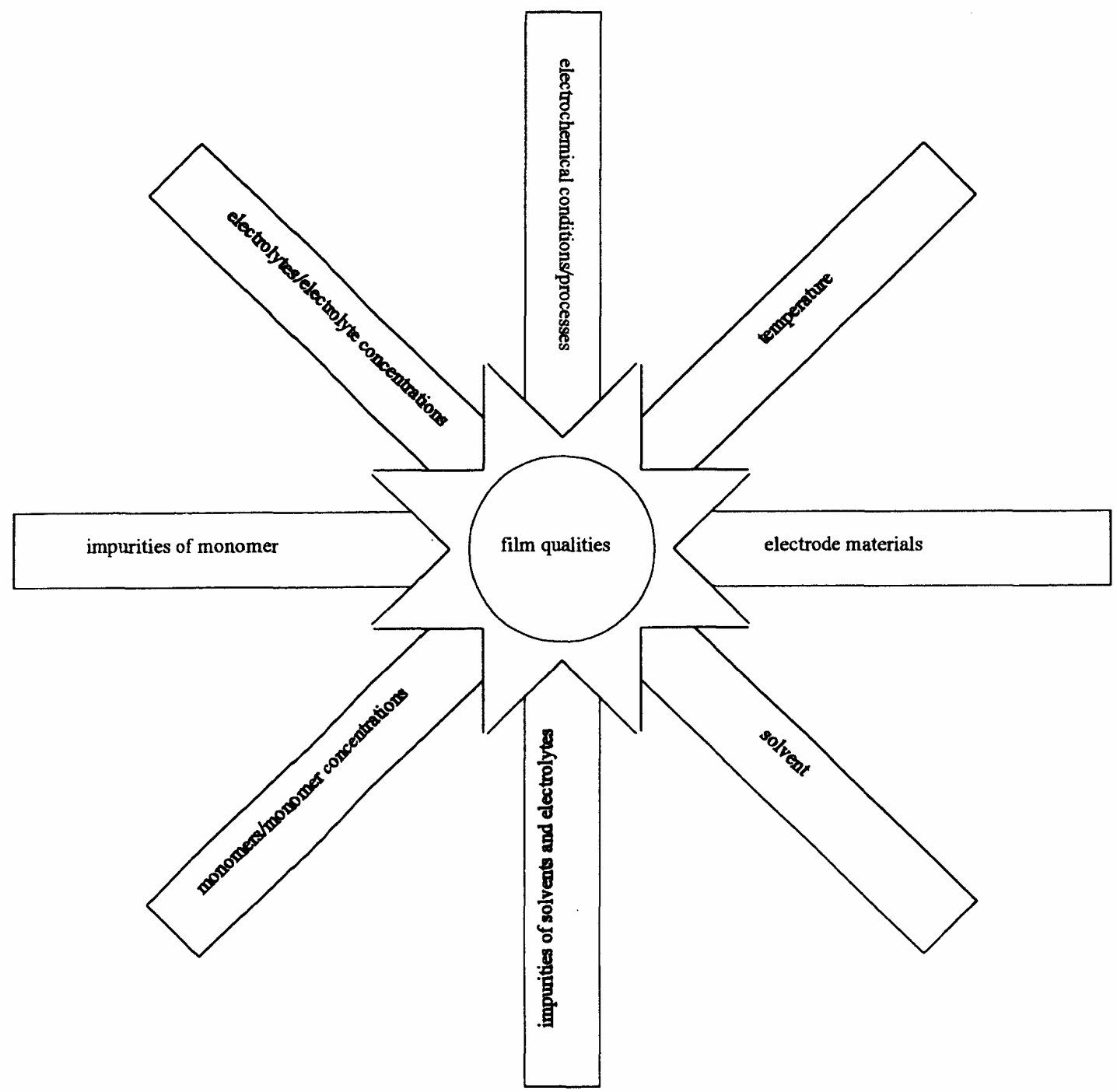

Figure 7. Parameters with influence on electrochemical film deposition and film quality. 
Film depositions of monomers 1a-f (Fig. 6) were carried out at room temperature. On the other hand, conditions between 0 and $-20^{\circ} \mathrm{C}$ lead to powdery films with poor mechanical quality while the film formation is totally retarded at $-40^{\circ} \mathrm{C}$ [115]. It is known that thiophene affords polymers with short chain lengths at $40^{\circ} \mathrm{C}[46,113]$. Thus room temperature appears to be the best condition for formation of good films of polymers on the electrode.

Acetonitrile was chosen as a solvent because of its high dielectric constant, [116] low viscosity $(0.3 \mathrm{cP}=0.3 \mathrm{mPa})$, wide potential window $(-2.8$ to $+3.3 \mathrm{~V}$ vs. $\mathrm{SCE})$, and low nucleophilicity $[67,117,118]$.

Monovalent polarizable cations such as quaternary alkyl ammonium salts are known to be effective counter ions for reversible $n$-doping processes so we used TEATFB $\mathrm{Et}_{4} \mathrm{NBF}_{4}$. This electrolyte was chosen rather than TBATFB $\mathrm{Bu}_{4} \mathrm{NBF}_{4}$ because the $\mathrm{Et}_{4} \mathrm{~N}^{+}$cation can easily penetrate into the film due to its smaller size [65]. Alkali metal salts are not suitable electrolyte materials for our purpose because $n$-doping of polythiophene appears to be inhibited by the large solvation shell which accompanies them in acetonitrile solution, [119, 120] although $n$-doping of poly-3-phenyl benzene in $\mathrm{LiClO}_{4}$ electrolyte in acetonitrile has been reported [121]. Even trace amounts of alkali metal cations present in the electrolyte have been shown to impede severely the ability to n-dope polythiophene [119]. The $n$-dopability was better at higher electrolyte concentrations.

Electropolymerization was chosen because it presents several distinct advantages such as absence of catalyst, direct grafting of the doped conducting polymer onto the electrode surface (which is of particular interest for electrochemical applications), easy control of the film thickness by the deposition charge, and possibility to perform a first in situ characterization of the growing process of the polymer by electrochemical and/or spectroscopic techniques [36].

Scheme 3 shows the proposed mechanism for the electropolymerization of 3phenylthiophene derivatives in analogy to the already known coupling reactions of aromatic compounds $[36,122,123]$. The first electrochemical step is the oxidation of the monomer (1) to its radical cation (2). Since the electron transfer reaction is much faster than the diffusion of the monomer from the bulk solution, it follows that a high concentration of radicals is continuously maintained near the electrode surface. The second step involves the formation of dimer (4) via dihydro-dimerization and deprotonation as explained in section 1.4.2. The radical of dimer (5) undergoes further coupling with a monomeric radical (6) and the Electropolymerization proceeds according to steps according to a general $\mathrm{E}(\mathrm{EC})_{\mathrm{n}}$ mechanism. 
The oxidation potentials of the monomers were measured by cyclic voltammetry at $100 \mathrm{mV} / \mathrm{s}$ in acetonitrile (first cycle) containing $0.2 \mathrm{M} \mathrm{Et} \mathrm{ENBF}_{4}$ and low monomer concentration $(0.05 \mathrm{M})$ in order to prevent polymerization. Figure 8 shows the CVs of the monomers (1a-f) during the polymerization. Soluble oligomers were observed to stray away from the electrode with subsequent coloration of the monomers solution, and the resulting polymer films were very thin especially the ones with electron donating substituents.

The possibility to undergo electropolymerization does not depend on the nature of the substituent on the phenyl ring. The monomers with electron withdrawing groups like $\mathrm{COCH}_{3}$ $\left(\sigma_{p}=0.36\right)$ or $\mathrm{NO}_{2}\left(\sigma_{p}=0.80\right)$ as well as with donor groups like $\mathrm{CH}_{3}\left(\sigma_{p}=-0.18\right)$ or $\mathrm{OCH}_{3}\left(\sigma_{p}\right.$ $=-0.15) \quad$ were electrooxidized yielding stable electroactive polymers. The electropolymerization of the monomers with electron withdrawing (1d-f) substituents proceeds with low current efficiency and requires higher anodic potentials, while those with electron donating groups $(\mathbf{1 a}-\mathbf{c})$ show lower oxidation potential. The corresponding radicals are stabilized and formation of soluble short chain oligomers is more favorable [44]. Alternatively these radicals can thus diffuse away from the electrode surface to form soluble oligomers in solution.

Cyclic voltammograms of polymers recorded at a scan rate of $100 \mathrm{mV} / \mathrm{s}$ in acetonitrile and electrolyte. Formal potentials for both $p$-and $n$-doping processes were estimated by averaging the anodic and cathodic peak potentials of each process. 

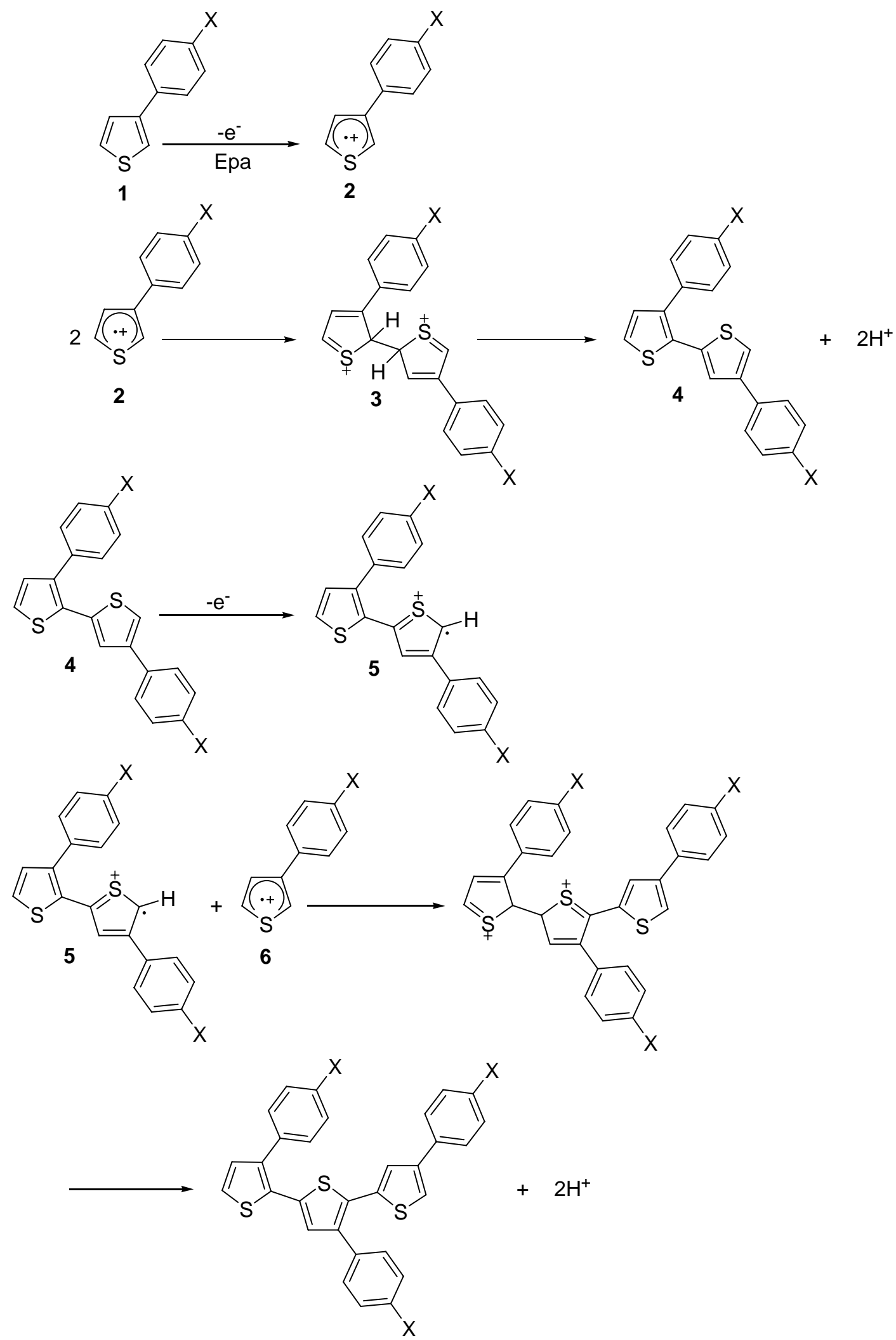

Scheme. 3. Mechanism of electropolymerization of 3-phenylthiophene derivatives. 

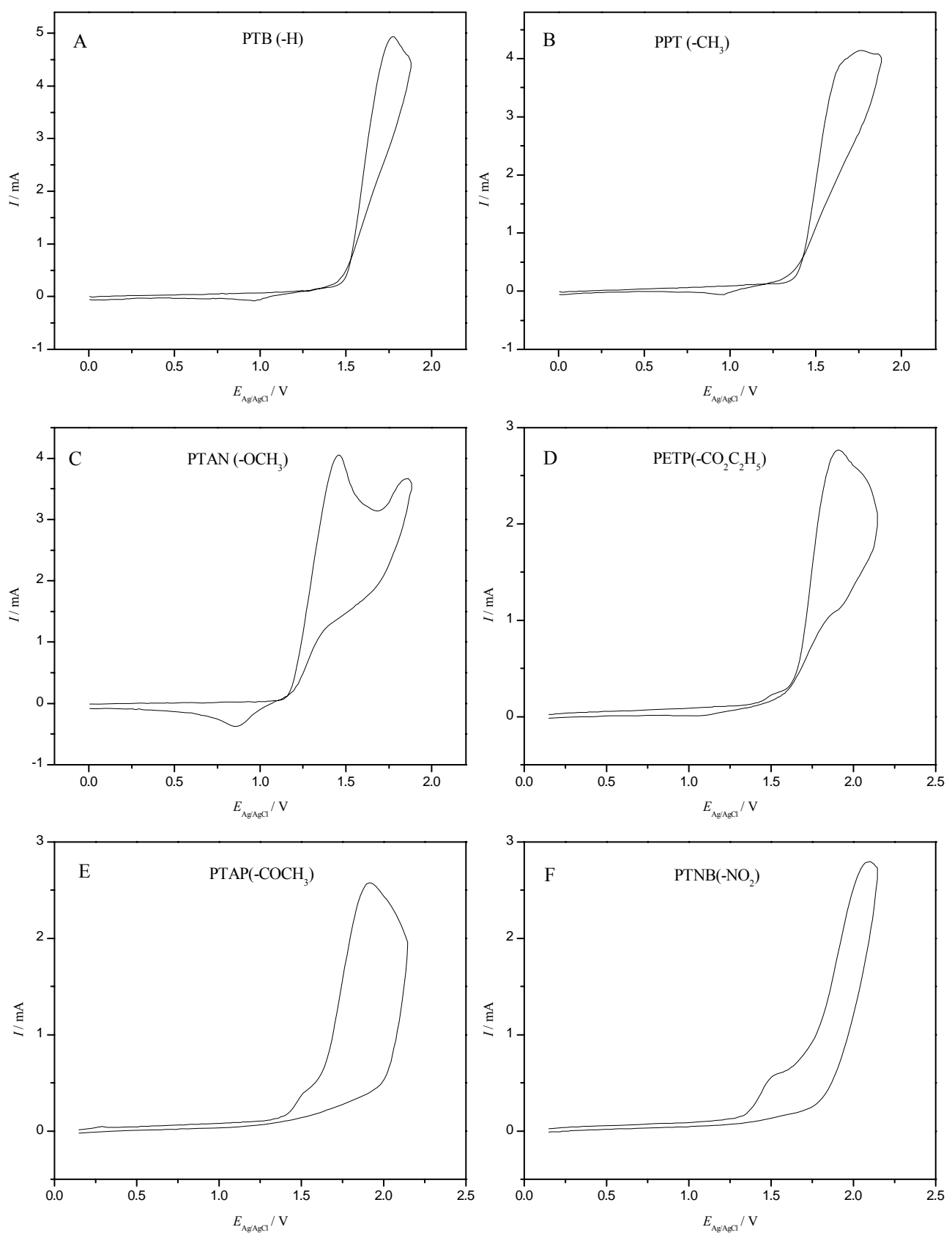

Figure 8. Cyclic voltammograms of monomers (first cycle) recorded in acetonitrile containing 0.2 $\mathrm{M} \mathrm{Et}_{4} \mathrm{NBF}_{4}$ and 0.05 M monomers: A) PTB, B) PPT, C) PTAN, D) PETB, E) PTAP and F) PTNB, at a scan rate of $100 \mathrm{mV} / \mathrm{s}$. See Table 2 (page 40) for the acronyms of polymers. 
Changes in the molecular structure of a monomer affect the voltammetric response of the monomer and the polymer film in various ways. The effect of substitution on the redox properties of the monomers and polymers stems from interplay of steric and electronic (resonance/inductive) factors. The latter can be estimated from Hammett $\sigma$ constants [124]. For the 3-arylthiophenes studied here, the substituents in the para position makes $\sigma_{\mathrm{p}}$ (which is the sum of inductive $\left(\sigma_{\mathrm{i}}\right)$ and resonance $\left(\sigma_{\mathrm{r}}\right)$ contributions) the most appropriate. It is important to note that these effects do not always work in the same direction. [65, 125-129]. Table 2 lists the $\sigma_{\mathrm{i}}, \sigma_{\mathrm{r}}$, and $\sigma_{\mathrm{p}}$ constants, the oxidation potentials of the monomers, the formal redox potentials for their respective polymers and the heat of formation for the monomers. Figures 10, 11 and 12 show the respective correlations with $\sigma_{\mathrm{p}}$ for the monomers and polymers. These trends are as expected with the potentials shifting cathodically (more negative direction) for electron donating substituents $\left(\sigma_{\mathrm{p}}<0\right)$ and anodically (more positive potentials) for electron withdrawing groups $\left(\sigma_{\mathrm{p}}>0\right)$. These new results are in agreement with published results $[65,73,125-129]$.

Increasing the upper positive and decreasing the lower negative potential is limited by destruction of the polymers film. It has been observed that the size of the substituents does not have a significant effect. Moreover, steric factors do not significantly affect the oxidation potentials of the monomers. The overall diminished substituent effect in the polymers suggests a decreased conjugation between the substituted phenyl rings and the polythiophene backbone. Figures 11 and 12 also show that the difference between the $p$ - and $n$-doping formal potentials of the polymers is essentially unchanged upon substitution. This is expected since the symmetries of the frontier orbitals of 3-arylthiophenes are such that the substituents can interact with both energy levels, shifting them downward (or upward) to comparable extents, thus the $\Delta E_{\text {gap }}$ remains essentially the same $[36,73,130]$. The very weak correlation between $\sigma_{\mathrm{p}}$ values and the $p$-doping in this series of polymers suggests that a different mechanism is responsible for the stabilization of the $\pi$-system in the case of excess positive charge. The sulfur atom in the thiophene ring is known to stabilize the structure of the $\pi$-conjugated polythiophene, but participates only to a very limited extent in the delocalization of the electrons of the $\pi$-system $[125,130,131]$. Therefore, upon the oxidation of the $\pi$-system the electron rich sulfur atom stabilizes the oxidized state by electron donation. If the acquired excess positive charge is delocalized over the sulfur atom and the coupling between phenyl derivatives and the sulfur is weak then the $p$-doping potentials are expected to be 
approximately constant and independent of the $\sigma_{\mathrm{p}}$ values. Similarly, if the sulfur orbitals are weakly coupled to the polymeric $\pi$-system, the electron withdrawing character of the phenyl substituents will dominate the main contribution to the stabilization of the excess charge in the $n$-doped state.

In Fig. 9 considerable differences in the charge transferred in the $n$-doping process are observed. This can be related to the nature of the substituent on the para position of the phenyl group: In the case of electron withdrawing substituents like $-\mathrm{CO}_{2} \mathrm{C}_{2} \mathrm{H}_{5},-\mathrm{COCH}_{3},-\mathrm{NO}_{2}$ showing an extended conjugated system the $n$-doping process is much more extended

In Figs. 13 and 14 inductive as well as resonance effects are correlated with oxidation potentials. From these figures it is obvious that the resonance effect dominates the inductive effect $[124,132]$. Thus, the resonance effect plays a more important role to obtain good correlations between oxidation potentials of the monomers and Hammett constants (c.f. Fig. 10).

Zuman [133] pioneered a classic method for determining how the oxidation (or reduction) potential of an organic substance is affected by electron-withdrawing or electron-supplying groups by studying the correlation between the reduction potentials and Hammett constants. This procedure has a number of limitations: (a) compounds containing certain substituents, such as amino or carbonyl groups, which are capable of interaction with the electroactive group via resonance, fall far from the correlation line, (b) the method is limited to substituted aromatics; it cannot be used to estimate the reduction (or oxidation) potentials of any other type of compounds such as conjugated polyenes, heterocyclic substances and polycyclic benzenoid and non-benzenoid aromatic hydrocarbons (PAH). Thus, we used a semiempirical method to calculate the heat of formation for the monomers in gas phase as well as in liquid phase (acetonitrile) (1a-f) (see Table 2). Figures 15 and 16 show the correlation between the oxidation potentials and the heat of formation of these monomers in gas and liquid phases, respectively. It has been observed that with included solvent effect the correlation shows a smaller value of $\mathrm{R}^{2}$, which means that the correlation between the oxidation potentials and heat of formation is not as good as in the gas phase. 

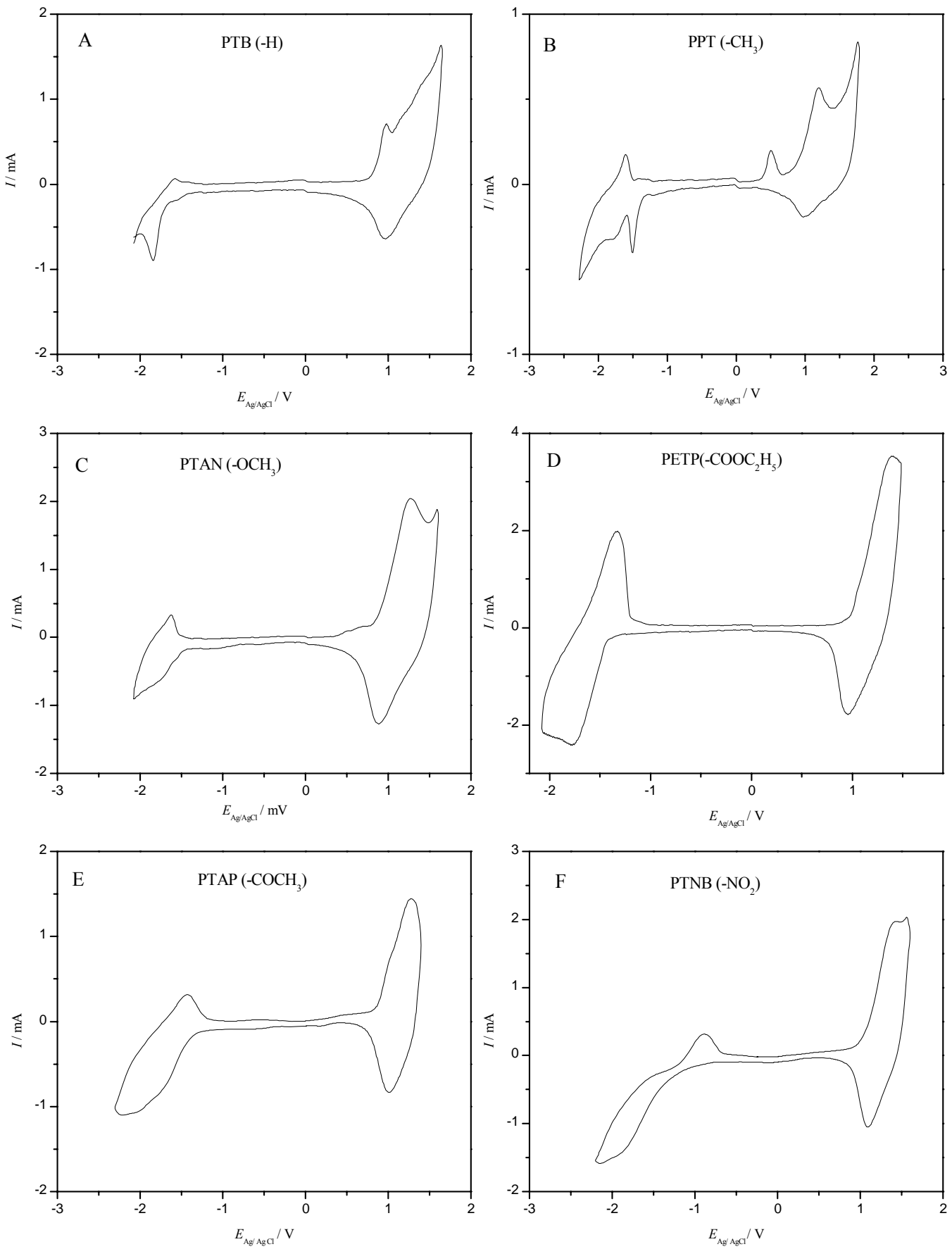

Figure 9. Cyclic voltammograms of polymer films coated on Pt electrode immersed in $0.2 \mathrm{M}$ $\mathrm{Et}_{4} \mathrm{NBF}_{4}$ acetonitrile solution: A) PTB, B) PPT, C) PTAN, D) PETB, E) PTAP, F) $\mathrm{PTNB}$, at a scan rate of $100 \mathrm{mV} / \mathrm{s}$. See Table 2 (page 40) for the acronyms of polymers 
Table 2. $\sigma_{\mathrm{i}}, \sigma_{\mathrm{r}}, \sigma_{\mathrm{p}}$, oxidation potential, ionization potential and formal potentials of $p$-and $n$-doping and heat of formation of the monomers in gas phase as well as in acetonitrile.

\begin{tabular}{|c|c|c|c|c|c|c|c|c|c|c|}
\hline \multirow[b]{2}{*}{ Monomers } & \multirow{2}{*}{$\begin{array}{l}\text { Acronym } \\
\text { for } \\
\text { Polymer }\end{array}$} & \multicolumn{3}{|c|}{ Hammett values $^{124}$} & \multirow{2}{*}{$\begin{array}{c}E_{\mathrm{ox}, \mathrm{Ag} / \mathrm{AgCl}} \\
/ \mathrm{V}\end{array}$} & \multirow{2}{*}{$\begin{array}{l}\text { Ionization } \\
\text { potentials } \\
\text { /ev }\end{array}$} & \multirow{2}{*}{$\begin{array}{c}\Delta H_{f} / \\
\mathrm{kcal} / \mathrm{mol} \\
\text { in gas phase }\end{array}$} & \multirow{2}{*}{$\begin{array}{c}\Delta H_{f} / \\
\mathrm{kcal} / \mathrm{mol} \\
\text { in } \mathrm{CH}_{3} \mathrm{CN}\end{array}$} & \multicolumn{2}{|c|}{ Polymer } \\
\hline & & $\sigma_{\mathrm{i}}$ & $\sigma_{\mathrm{r}}$ & $\sigma_{p}$ & & & & & $\begin{array}{c}E_{n \text {-doping }} \\
/ \mathrm{V}\end{array}$ & $\begin{array}{c}E_{p \text {-doping }} \\
/ \mathrm{V}\end{array}$ \\
\hline$-\mathrm{H}$ & PTB & 0 & 0 & 0 & 1.771 & 8.636 & 185.94 & 140.17 & -1.716 & 1.215 \\
\hline$-\mathrm{CH}_{3}$ & PPT & -0.05 & -0.13 & -0.18 & 1.762 & 8.394 & 182.88 & 139.09 & -1.823 & 1.150 \\
\hline$-\mathrm{OCH}_{3}$ & PTAN & 0.27 & -0.42 & -0.15 & 1.476 & 8.201 & 178.57 & 140.22 & -1.857 & 1.134 \\
\hline$-\mathrm{CO}_{2} \mathrm{C}_{2} \mathrm{H}_{5}$ & PETB & 0.20 & 0.16 & 0.36 & 1.908 & 8.930 & 184.96 & 148.70 & -1.702 & 1.156 \\
\hline$-\mathrm{COCH}_{3}$ & PTAP & 0.20 & 0.16 & 0.36 & 1.916 & 8.905 & 190.93 & 143.13 & -1.686 & 1.180 \\
\hline$-\mathrm{NO}_{2}$ & PTNB & 0.65 & 0.15 & 0.80 & 2.102 & 9.340 & 200.59 & 144.60 & -1.519 & 1.298 \\
\hline
\end{tabular}




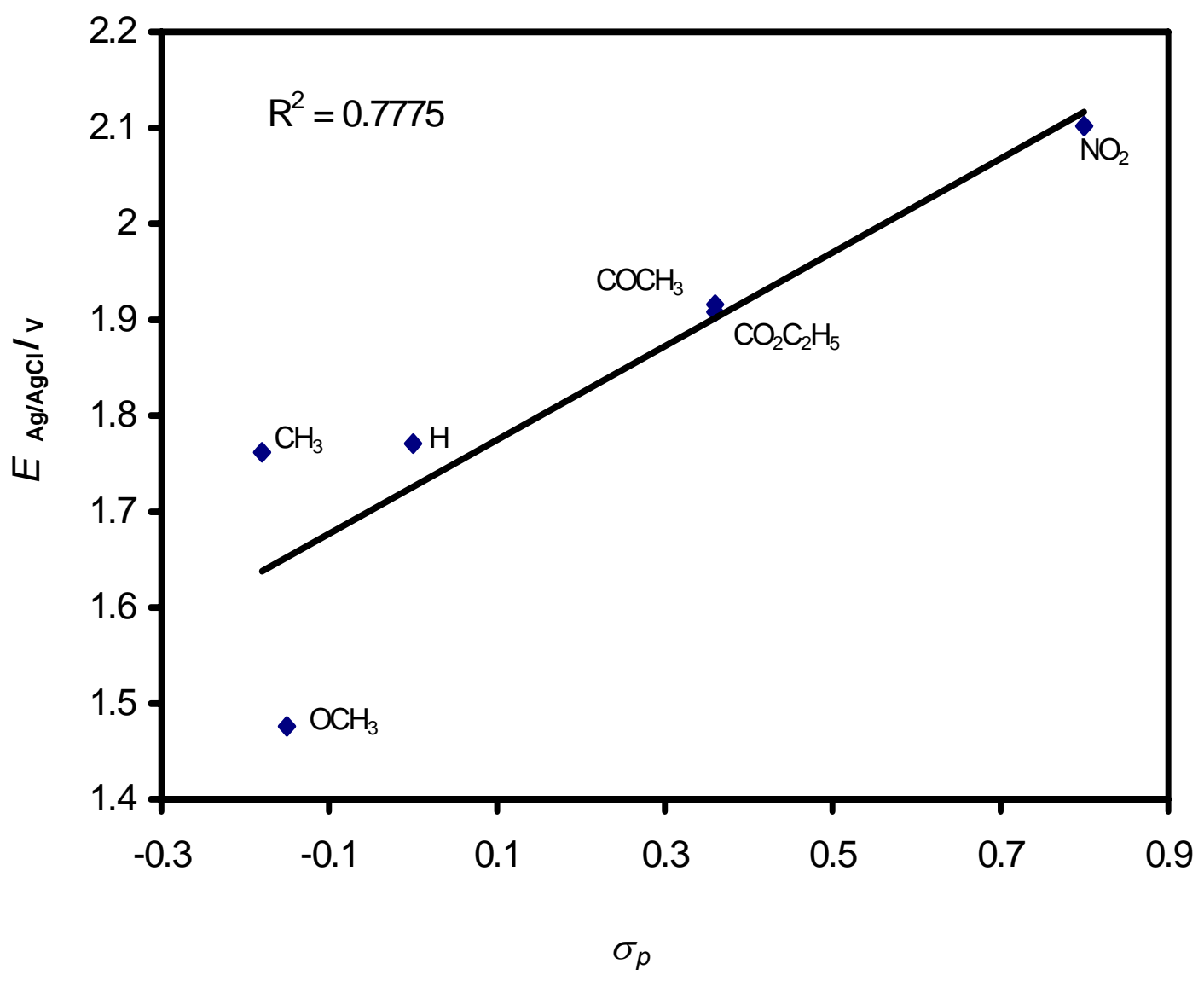

Figure 10. Plot of the oxidation potential of the monomers against $\sigma_{\mathrm{p}}$ values

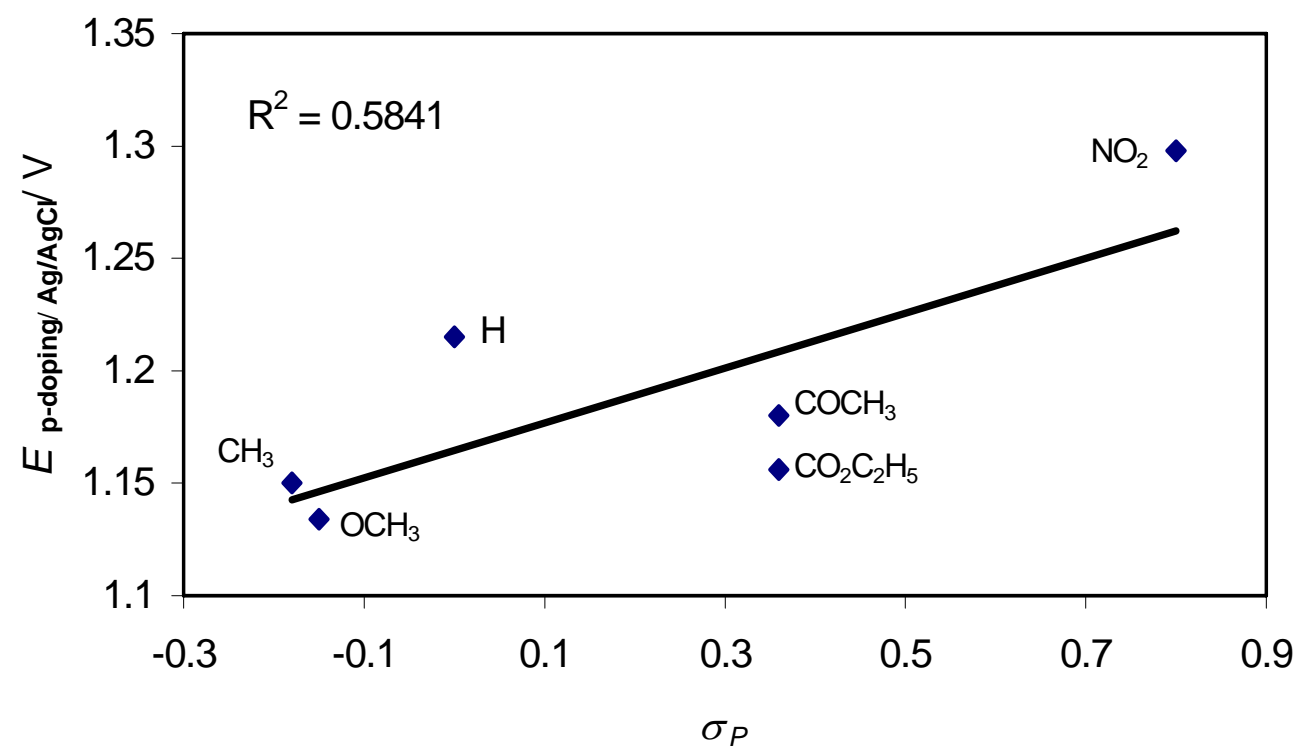

Figure 11. Plot of oxidation potential of the polymers ( $p$-doping) against $\sigma_{\mathrm{p}}$ values 


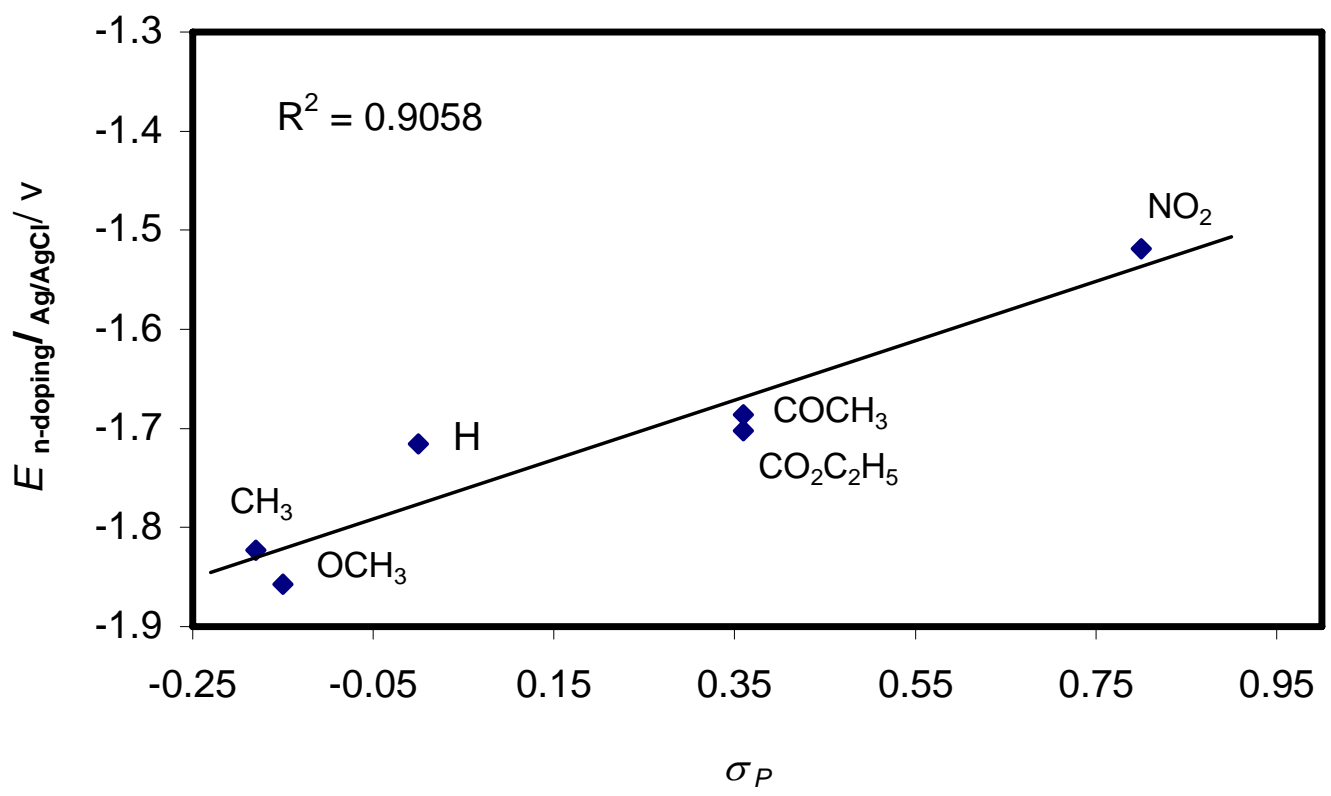

Figure 12. Plot of reduction potential of the polymers (n-doping) against $\sigma_{\mathrm{p}}$ values

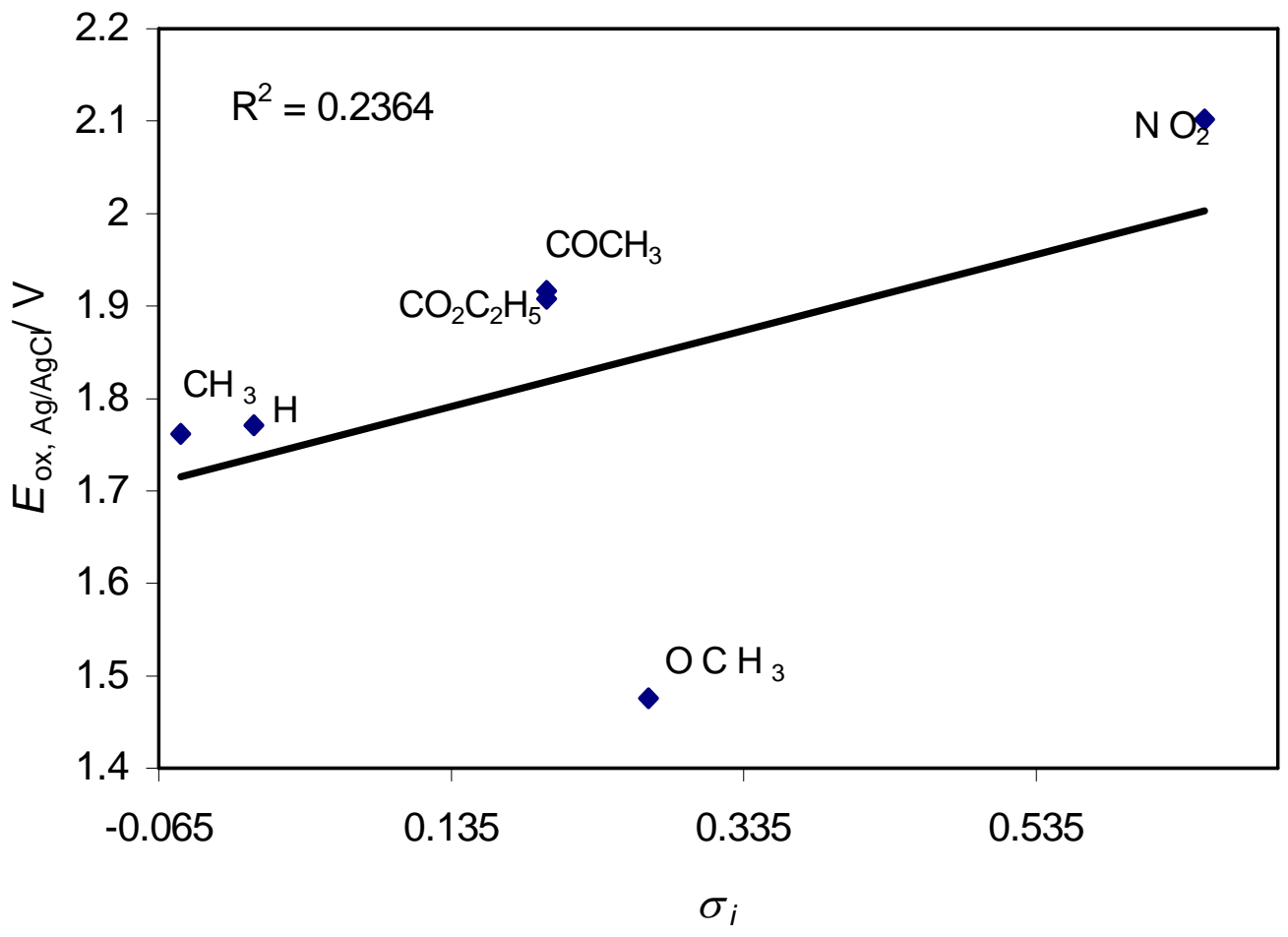

Figure 13. Plot of the oxidation potential of the monomers against $\sigma_{\mathrm{i}}$ values 


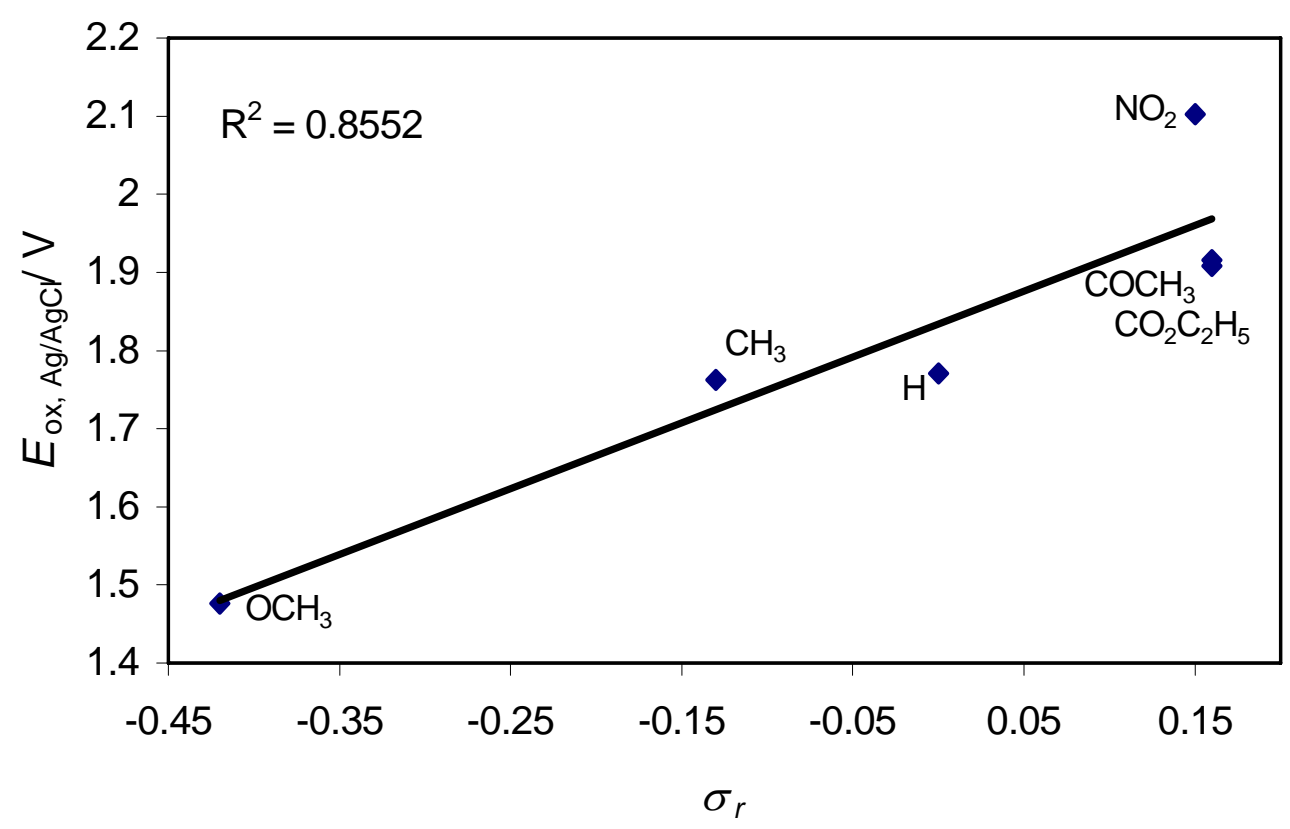

Figure 14. Plot of the oxidation potential of the monomers against $\sigma_{\mathrm{r}}$ values

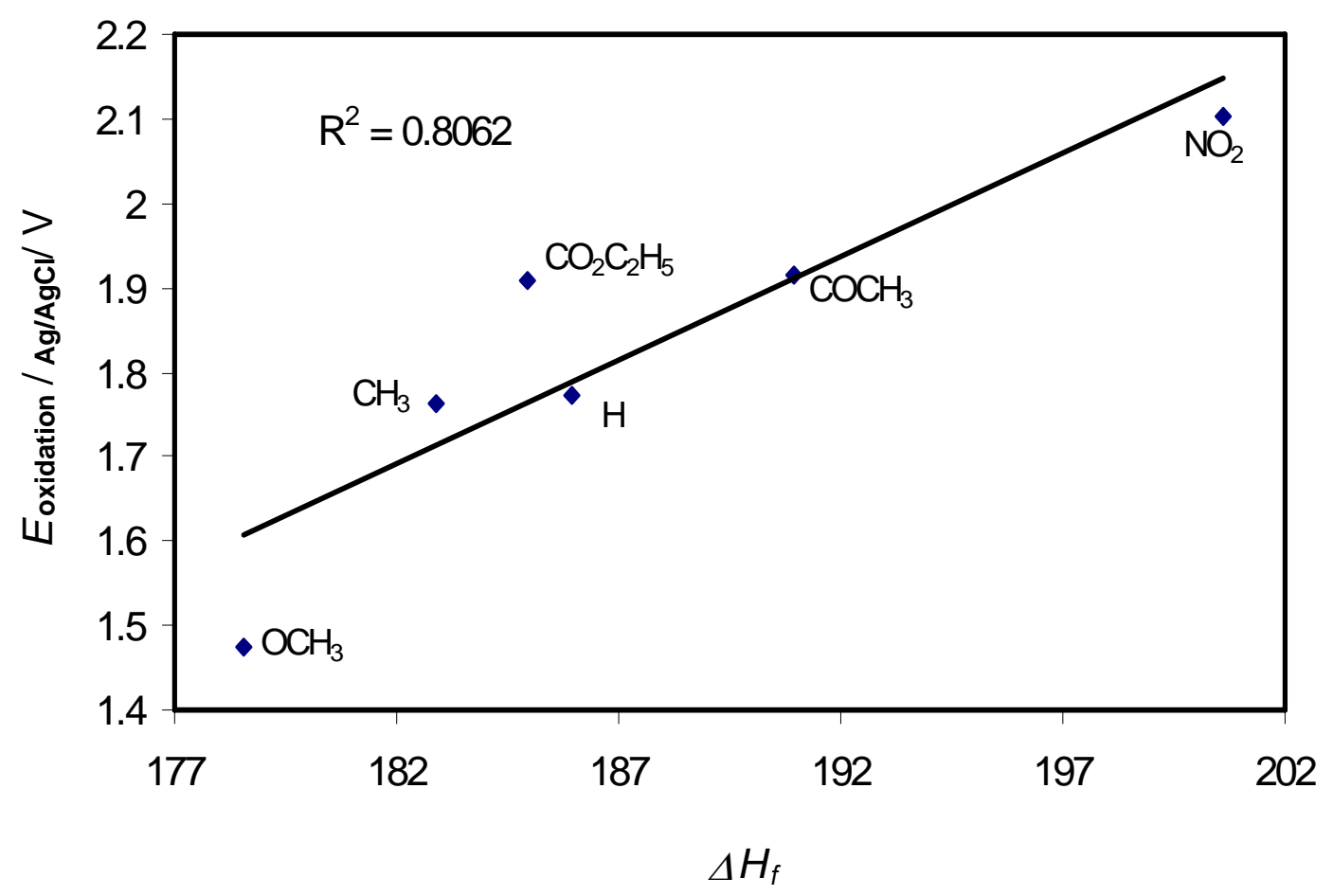

Figure 15. Plot of oxidation potentials of the monomers against heat of formation in gas Phase. 


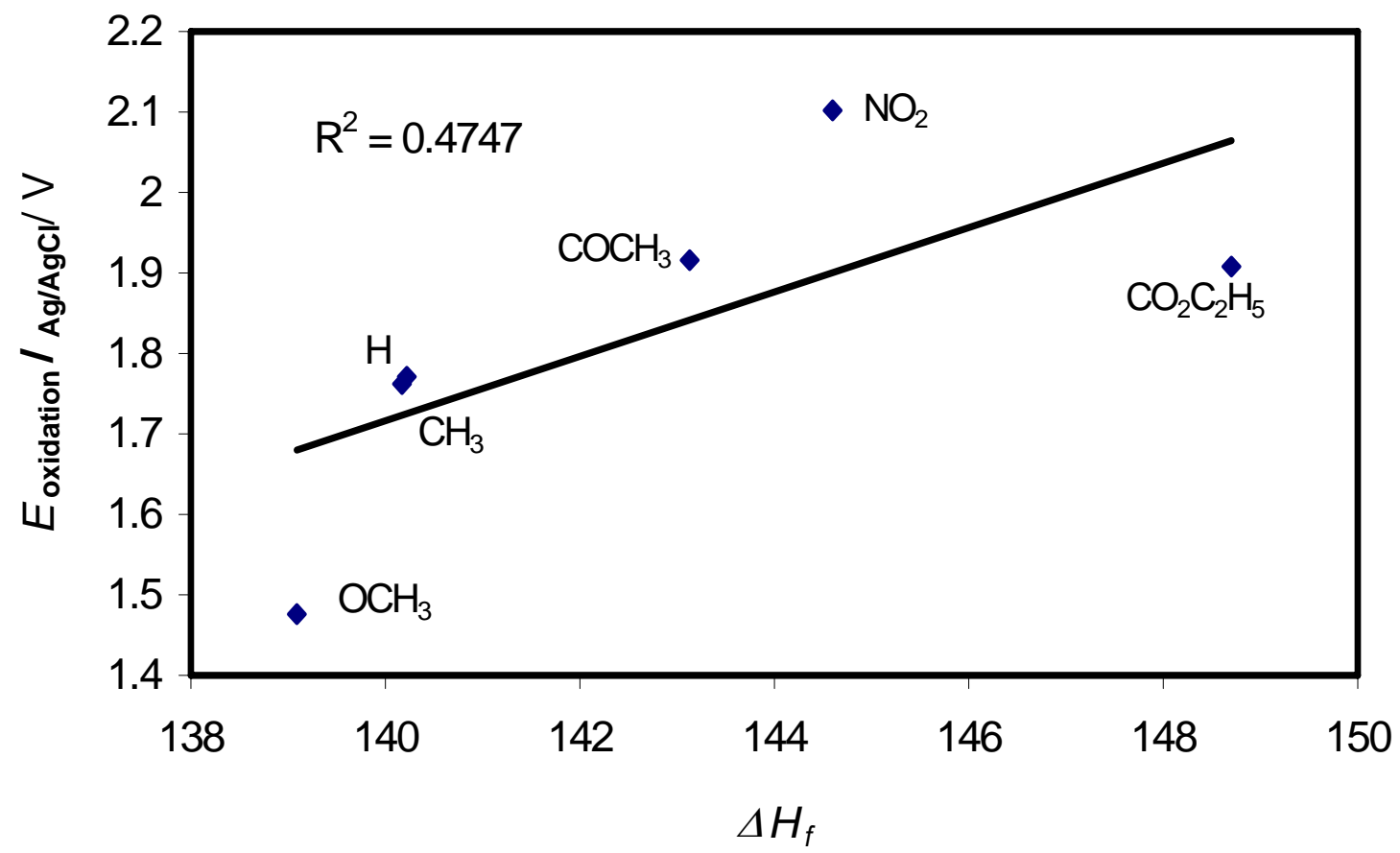

Figure 16. Plot of oxidation potentials of the monomers against heat of formation in Acetonitrile

Although $\Delta G_{f}$ is more directly related to the oxidation potential of the electrode than $\Delta H_{f}$, the correlation of the oxidation potentials of the monomers (1a-f) was based on $\Delta H_{f}$ values only. Calculation of $\Delta S_{f}$ and subsequently of $\Delta G_{f}$ is basically possible. The obtained values of both entities show considerable uncertainty. Ab initio molecular orbital (MO) methods provide total energies as the sum of electronic and nuclear-nuclear repulsion energies for molecules; isolated in vacuum, without vibration at $0 \mathrm{~K}$. From the $0 \mathrm{~K}$ potential surface and using the harmonic oscillator approximation, they can calculate the vibrational frequencies, $v_{i}$, of the normal modes of vibration. Using these, they can calculate vibrational, rotational and translational contributions to the thermodynamic quantities that arise from heating the system from 0 to $T \mathrm{~K}$. However, at $298.15 \mathrm{~K}$, due to higher number of degrees of freedom the degree of uncertainty is larger and therefore this calculated values of $\Delta G_{f}$ have too large uncertainty.

The initial step of the electropolymerization reaction is a one-electron oxidation of the monomer resulting in its radical cation. The posibility of this step should be related to the ionization potential of the molecule, which in turn corresponds to the energy of generating a radical cation during the oxidative process (Table 2). The correlation between the oxidation 
potentials and the ionization potentials of the monomers is indeed fairly high (Figure 17). It is actually much better than the correlation between the oxidation potentials and the heats of formation calculated semiempirically. Although the absolute range of values of the ionization potentials shows a variation similar to the variation of the heat of formation the predictive capability of the ionization potentials is obviously better.

It was observed that the polymers (2a-f) are not soluble in common solvents like THF, dichloromethane, chloroform, benzene, toluene, xylene, benzonitrile and nitrobenzene at room temperature.

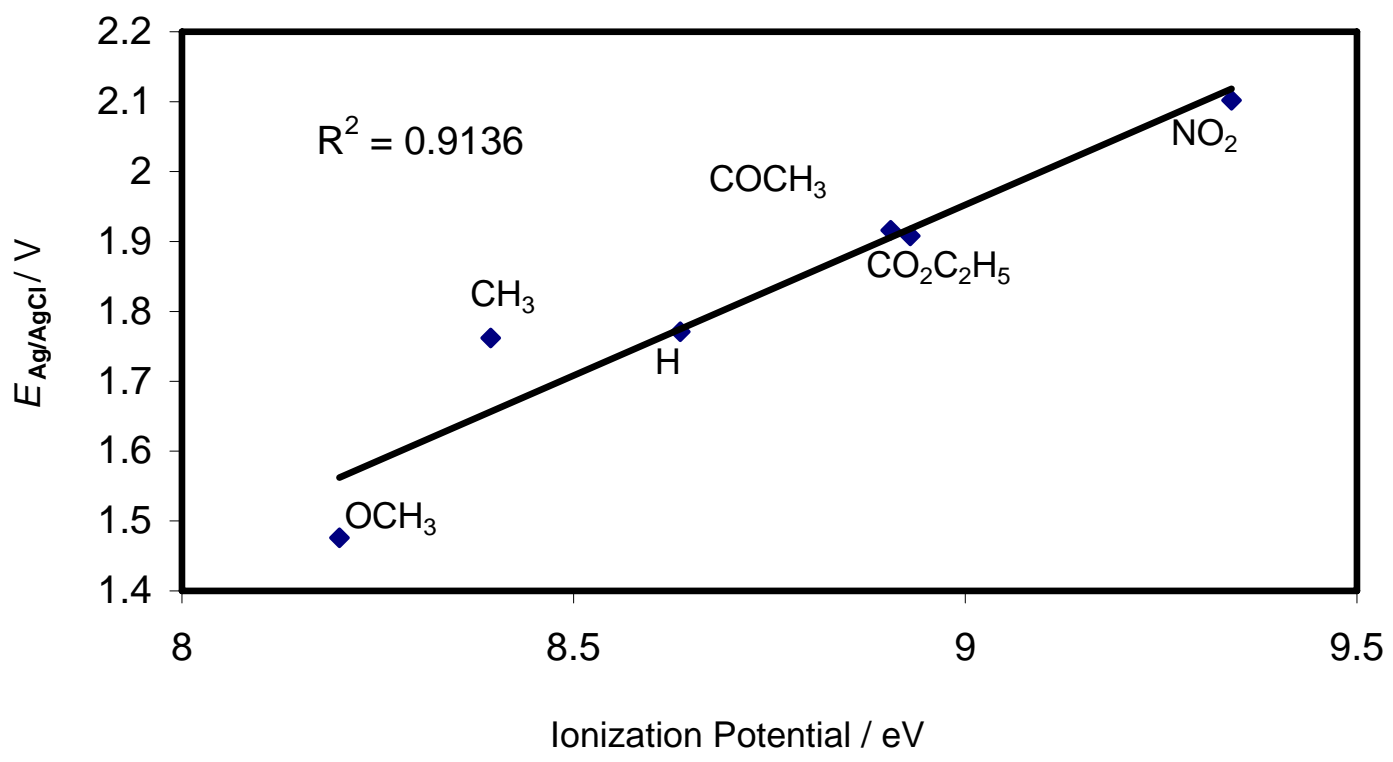

Figure 17. Plot of the oxidation potential of the monomers against the ionization potentials.

In some cases a prepeak was observed for both $n$ - and $p$-doping processes. Prepeaks for polythiophene have been previously explained suggesting a charge-trapping mechanism [73, 119] that was initially discovered by Murray et al. [44, 134] at bilayer films of redox polymers. The prepeak appears before the peak for the $n$-doping process and corresponds to the release of most of the $p$-doped charge that had been trapped in the film while in its neutral state. Similarly, the prepeak appears before the peak for $p$-doping process. It corresponds to the release of most of the $n$-doped charge that had been trapped in the film while in its neutral state. The size of the prepeaks depends on the current density for growth and the condition of the film. 


\subsection{Resonance Raman Spectroscopy of Poly p-(3-thienyl) benzene Derivatives (2a-f)}

Raman spectroscopy is a powerful technique to study the structure of the polymers. However, to the best of our knowledge there is only one paper concerned the Raman spectrum of poly-p-(3-thienyl) benzene (2a) [135]. Moreover, there is no paper published until now on the Raman spectrum of polymers (2b-f) as well as the monomers (1a-f) (Figure 6).

It should be stated that Raman spectroelectrochemical studies of polythiophenes are usually complicated due to strong resonance phenomena. Thus, Raman spectra of these polymers depend not only on the electrode potential but also on the energy of the excitation line [136-139]. The green excitation line $\left(\lambda_{\mathrm{exc}}=514.5 \mathrm{~nm}\right)$ is very close to the maximum of the $\pi \rightarrow \pi *$ transition of the polymers (2a-d). On the other hand, we carried out our in situ Raman measurements for the two polymers $2 \mathbf{e}$ and $2 \mathbf{f}$ using all available lines in our instrument $(457.9,476.5,488.0,501.7,514.5,528.7,647.1 \mathrm{~nm})$. The best wavenumbers for obtaining the correct spectra were at $\lambda_{\text {exc }}=528.7,488.0 \mathrm{~nm}$ (yellow green, blue lines) for polymer $2 \mathbf{e}$ and $2 \mathbf{f}$, because these lines are the closest to the maximum of the $\pi \rightarrow \pi *$ transition of polymers $2 \mathbf{e}$ and $\mathbf{2 f}$, respectively. The results of Raman spectroelectrochemical studies of $p$-doped and $n$-doped polymers (2a-f) are depicted in Figures 18, 21, and 23. Assignments of Raman bands were based on previous studies (Table 3, 5, 7) [135-163]. In this way, comparisons with previously assigned bands of parent polymers permitted us to unambiguously assign some of the bands observed in our case to help choosing between possible assignments for others.

In the Raman spectra of the polymers (2a-d) (Figure 18), it is observed that with increasing electrode potential, the overall intensity of the spectrum decreases, while the essential features of the spectrum remain unchanged. This means that the observed Raman bands originate from the undoped segments of the polymer, which become less and less abundant with increasing doping level [138]. The difference in the intensity may be attributed to a larger resonance effect of the reduced film, which is associated with a stronger UV-Vis absorption at the laser excitation wavelength $(514.5 \mathrm{~nm})$.

On the other hand, it is observed that the films of the polymers (2a-d) are compact and can be easily peeled off from the electrode surface especially at high potential, whereas the films of polymers 2c, $2 \mathbf{d}$ are destructed when the potential exceed 1.4, $-1.9 \mathrm{~V}$, respectively. In the contrary, the films of the polymers $2 \mathbf{e}$ and $\mathbf{2 f}$ are compact and adhere strongly to the 
electrodesurface. These aspects are important in applications like corrosion protection and microelectronics. However, the peaks in the spectra of polymers 2e and $\mathbf{2 f}$ (Figure 21 and 23) vanished when the potential increased to the negative or positive direction.

The results of Raman spectroelectrochemical study of monomers (1a-f) were obtained at $\lambda_{\text {exc }}=514.5 \mathrm{~nm}$ (Figure 20, 22, 24). The assignments of the Raman bands were based on previous studies (Table 4, 6, 8) [135-163].

\subsubsection{Resonance Raman Spectroscopy of Poly $p$-(3-thienyl) benzene Derivatives (2a-d)}

Figure 18 depicts the Raman spectra of poly $p$-(3-thienyl) benzene derivatives (2a-d), which show many characteristic bands. The bands at 1605, 1580 and $1531 \mathrm{~cm}^{-1}$ are assigned to phenyl origins as characteristic of Raman spectra of para-disubstituted benzenes. According to Scott the band at $1448 \mathrm{~cm}^{-1}$ is due to a symmetric $\mathrm{C}_{\alpha}=\mathrm{C}_{\beta}$ inter-ring stretching mode [145]. Its shoulder at higher wavenumbers (tail) $1496 \mathrm{~cm}^{-1}$ has been assigned to the corresponding asymmetric $\mathrm{C}_{\alpha}=\mathrm{C}_{\beta}$ stretching mode. The broadness of the tail has been used as an argument for the presence of shorter polymer units, since the position of this band increases in wavenumber with decreasing chain length. On the basis of the molecular structure of polythiophenes, the chain length is identical with the conjugation length. This conjugation length, which is associated with $\pi$-electron delocalization, is favored when the polymer rings are coplanar, owing to the overlapping of the $\mathrm{C}-\mathrm{C}$ inter-ring carbon $\mathrm{p}_{z}$ orbitals (Figure 19). The well-defined band at $1348 \mathrm{~cm}^{-1}$ in the spectra is associated with the $C_{\beta}-C_{\beta^{\prime}}$ ring stretching. The $1306 \mathrm{~cm}^{-1}$ band is due to para-disubstituted benzenes stretching. The two bands at 1280 and $1109 \mathrm{~cm}^{-1}$ are assigned to in plane deformation of the $\mathrm{C}-\mathrm{H}$ bands of the phenyl ring, while the $1236 \mathrm{~cm}^{-1}$ is due to in plane deformation of the $\mathrm{C}-\mathrm{H}$ bond of the thiophene ring. The 1202 and $1150 \mathrm{~cm}^{-1}$ bands are ascribed to symmetric and asymmetric stretching of $\mathrm{C}_{\alpha}-\mathrm{C}_{\alpha^{\prime}}$ bond, respectively. The $1050 \mathrm{~cm}^{-1}$ band is assigned to $\mathrm{C}_{\beta}-\mathrm{H}$ bending of the thiophene ring, while the $778 \mathrm{~cm}^{-1}$ band is due to out of plane deformation of the $\mathrm{C}-\mathrm{H}$ bond of thiophene ring. The two bands of $\mathrm{C}_{\alpha}-\mathrm{S}-\mathrm{C}_{\alpha^{\prime}}$ asymmetric and symmetric deformation appeared at 730 and $682 \mathrm{~cm}^{-1}$, respectively. The two bands at 580 and $540 \mathrm{~cm}^{-1}$ are due to thiophene ring deformation, while the $342 \mathrm{~cm}^{-1}$ band is due to skeletal deformation. 

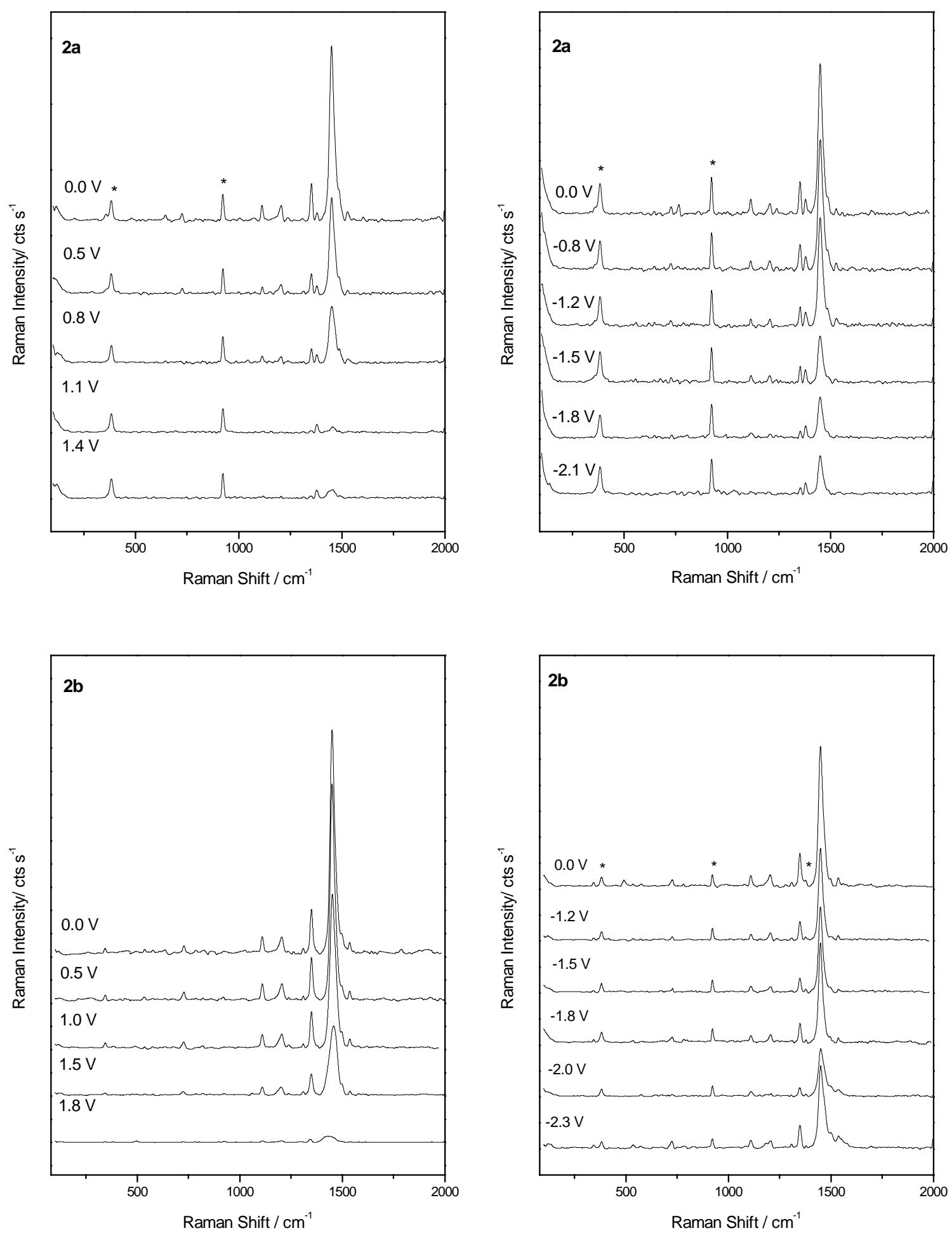

Figure 18. Raman Spectra of poly $p$-(3-thienyl) benzene derivatives (2a-d) with $\lambda_{\mathrm{o}}=514.5$ $\mathrm{nm}$ in $0.2 \mathrm{M} \mathrm{Et}_{4} \mathrm{NBF}_{4} /$ acetonitrile solution at different potentials for $p$ and $n$ doping regions (asterisks indicate solvent bands). Figure continued. 

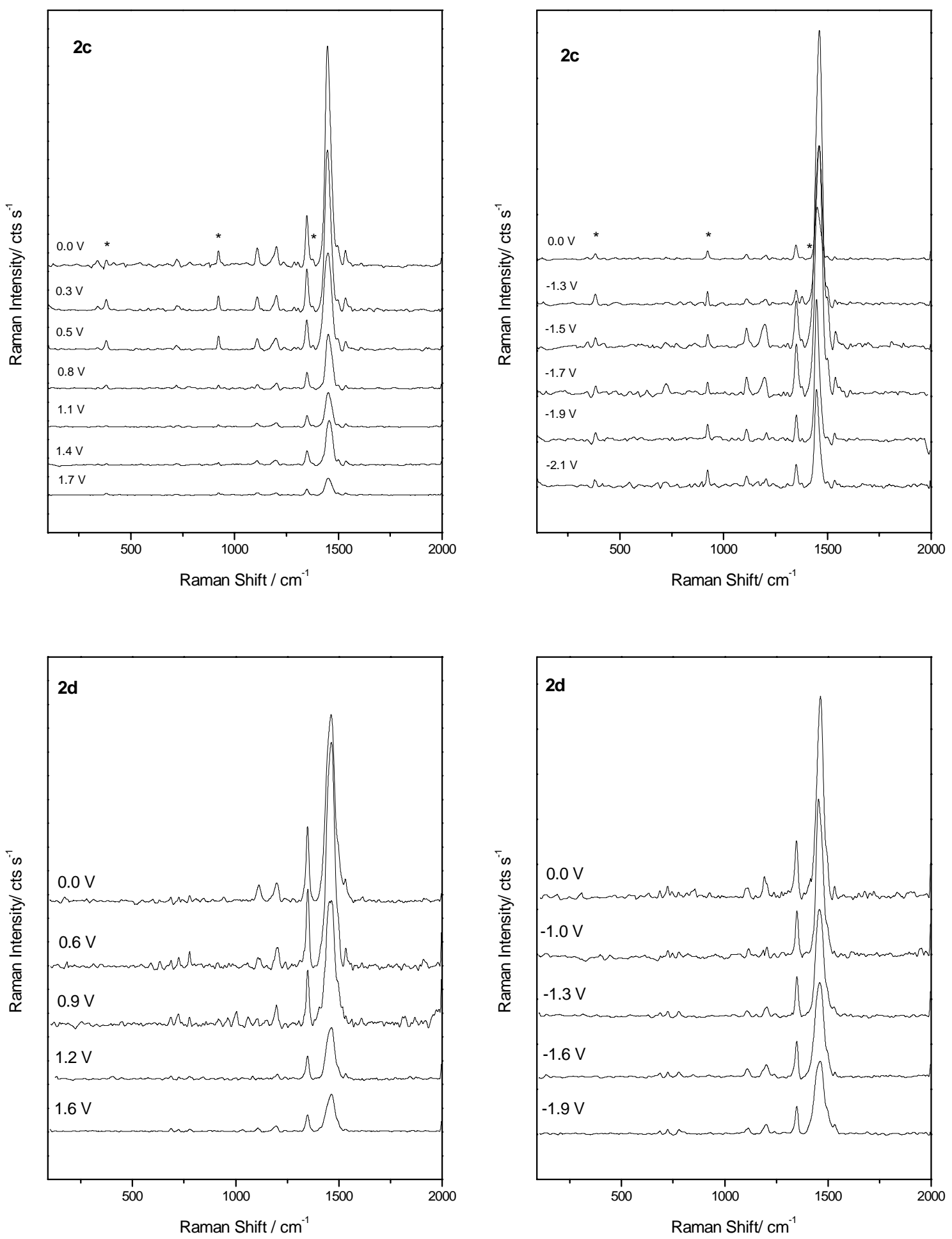

Figure 18. Continued from previous page. 
From the Raman spectra of poly $p$-(3-thienyl) benzene derivatives (1a-d) (Figure 20), the position of $\mathrm{C}_{\alpha}=\mathrm{C}_{\beta}$ asymmetric and symmetric stretching of thiophene ring at $1505,1411 \mathrm{~cm}^{-1}$ in the case of monomers (1a-d) is shifted to 1496, $1448 \mathrm{~cm}^{-1}$ for polymers (2a-d). However, a large difference in intensity of the symmetric stretching band between the monomers (1a-d) and the polymers (2a-d) was observed. This may be ascribed to the conjugation effect in the polymer backbone chain. New bands appear and the most important are the bands at 1251 and $1709 \mathrm{~cm}^{-1}$, which represent asymmetric $\mathrm{C}-\mathrm{O}-\mathrm{C}$ stretch of the methoxy functional group of the monomer (1c) and the stretching of carbonyl $(\mathrm{C}=\mathrm{O})$ functional group of the monomer (1d), respectively.

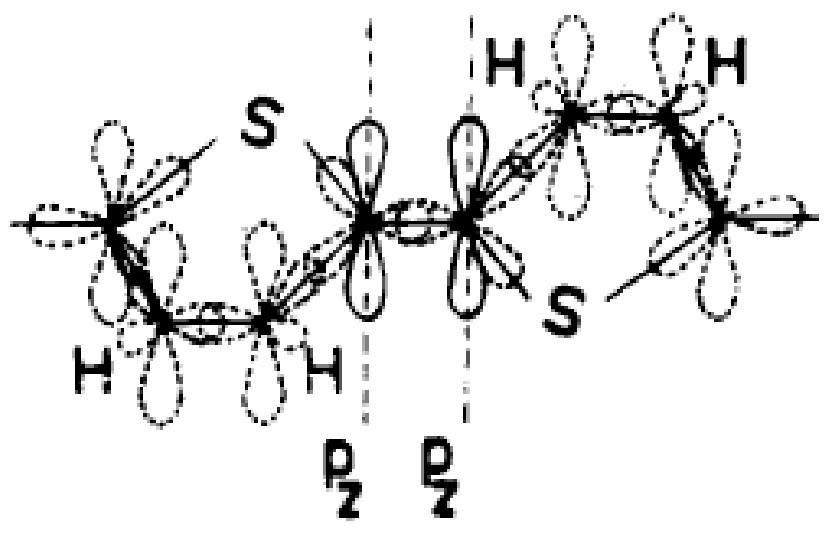

Figure 19. Schematic representation showing the maximum overlapping of the $\mathrm{C}-\mathrm{C}$ inter-ring carbon $\mathrm{P}_{\mathrm{z}}$ orbitals, taken from ref: Bazzaouai et al. [139]. 

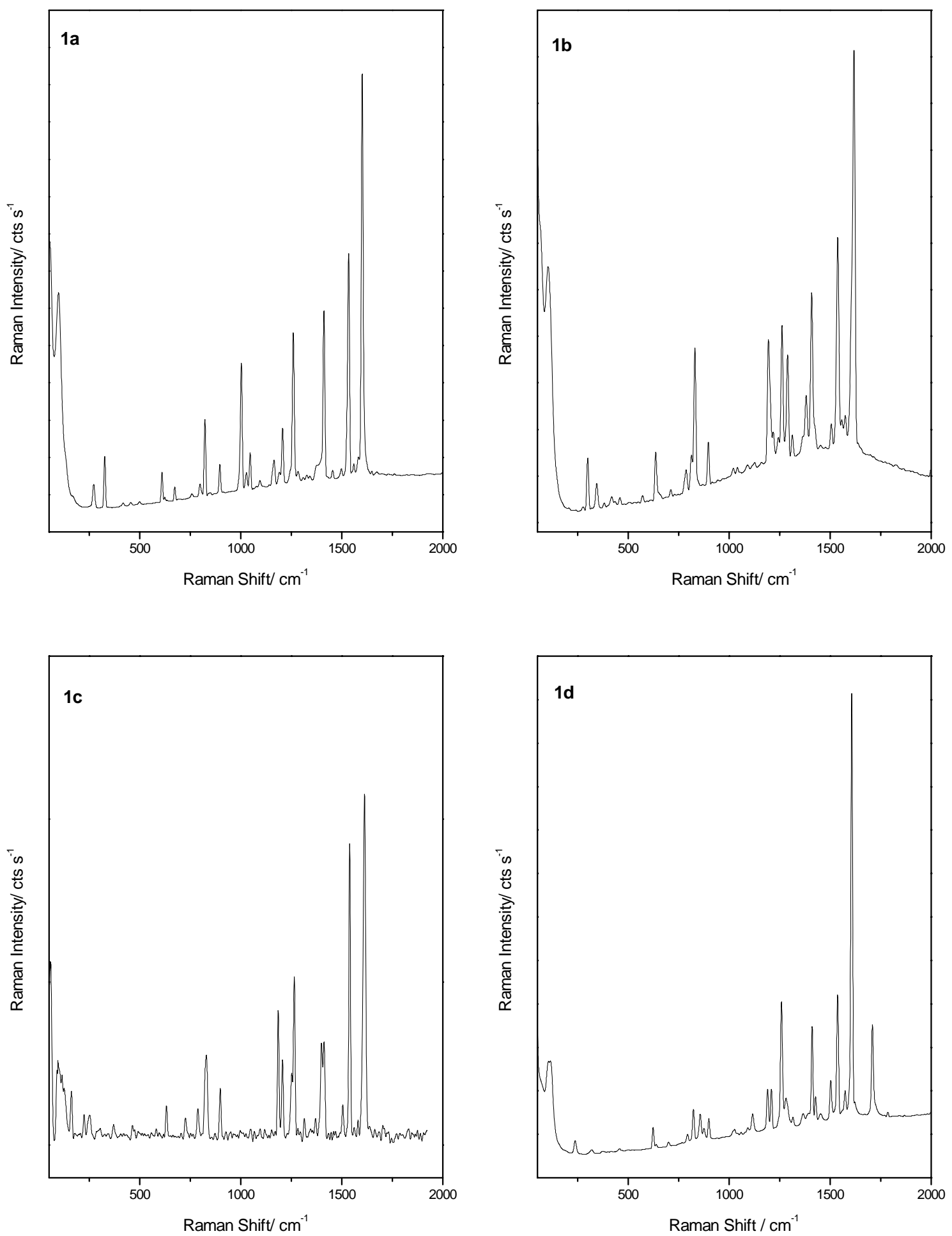

Figure 20. Raman spectra of $p$-(3-thienyl) benzene derivatives (1a-d) with $\lambda_{\mathrm{o}}=514.5 \mathrm{~nm}$ 
Table 3: Band assignments of Raman spectra of poly p-(3-thienyl) benzene derivatives (2a-d).

\begin{tabular}{|c|c|c|c|c|c|}
\hline \multirow[t]{2}{*}{ Mode } & \multirow{2}{*}{$\begin{array}{l}\text { Wilson } \\
\text { Mode \# }\end{array}$} & \multicolumn{4}{|c|}{ Raman bands frequencies of poly-3-Phenylthiophene derivatives $(2 a-d) /\left(\mathrm{cm}^{-1}\right)$} \\
\hline & & PTB (2a) & PPT (2b) & PTAN (2c) & PETB (2d) \\
\hline Skeletal deformation & - & 345 & 342 & 340 & 320 \\
\hline Ring deformation & - & 540 & 540 & 550 & - \\
\hline Ring deformation & - & - & 580 & 590 & 590 \\
\hline$\delta$ (ring) & $6 \mathrm{~b}$ & 644 & - & 630 & - \\
\hline $\mathrm{C}_{\alpha}-\mathrm{S}-\mathrm{C}_{\alpha^{\prime}}$ sym deformation & - & - & 682 & 680 & 685 \\
\hline $\mathrm{C}_{\alpha}-\mathrm{S}-\mathrm{C}_{\alpha^{\prime}}$ asym deformation & - & 730 & 730 & 722 & 725 \\
\hline$v(\mathrm{C}-\mathrm{S})$ & - & - & - & - & 742 \\
\hline$\gamma(\mathrm{CH})$ & - & 761 & 780 & 780 & 778 \\
\hline$\gamma(\mathrm{CH})$ & $10 \mathrm{a}$ & - & - & - & 845 \\
\hline$\gamma(\mathrm{CH})$ & $17 \mathrm{a}$ & 978 & - & - & - \\
\hline $\mathrm{C}_{\beta}-\mathrm{H}$ bending & - & 1050 & 1050 & 1050 & 1045 \\
\hline$\delta(\mathrm{CH})$ & $18 \mathrm{~b}$ & 1109 & 1109 & 1109 & 1109 \\
\hline $\mathrm{C}_{\alpha}-\mathrm{C}_{\alpha^{\prime}}$ stretching (asym) $+\mathrm{C}_{\beta}-\mathrm{H}$ bending & - & 1154 & 1151 & 1148 & 1152 \\
\hline $\mathrm{C}_{\alpha}-\mathrm{C}_{\alpha^{\prime}}$ stretching & - & 1204 & 1202 & 1202 & 1200 \\
\hline$\delta(\mathrm{CH})$ & - & 1236 & 1235 & 1235 & 1237 \\
\hline$\delta(\mathrm{CH})$ & 3 & 1265 & 1280 & 1287 & 1278 \\
\hline$v$ (ring) & 14 & 1306 & 1306 & 1306 & 1307 \\
\hline $\mathrm{C}_{\beta}-\mathrm{C}_{\beta^{\prime}}$ ring stretching & - & 1353 & 1348 & 1348 & 1348 \\
\hline $\mathrm{C}_{\alpha}=\mathrm{C}_{\beta}$ ring stretching (sym) & - & 1448 & 1448 & 1448 & 1457 \\
\hline $\mathrm{C}_{\alpha}=\mathrm{C}_{\beta}$ ring stretching (asym) & - & 1494 & 1496 & 1496 & 1496 \\
\hline$v($ ring $)$ & $19 \mathrm{a}$ & 1528 & 1535 & 1534 & 1531 \\
\hline$v($ ring) & $8 \mathrm{~b}$ & 1580 & 1580 & 1580 & 1580 \\
\hline$v($ ring $)$ & $8 \mathrm{a}$ & 1605 & 1605 & 1609 & 1609 \\
\hline
\end{tabular}

$\delta=$ in-plane deformation, $\gamma=$ out-of-plane deformation, $v=$ stretching 
Table 4: Band assignments of the Raman spectra of $p$-(3-thienyl) benzene derivatives (1a-d).

\begin{tabular}{|c|c|c|c|c|c|}
\hline \multirow{2}{*}{ Mode } & \multirow{2}{*}{$\begin{array}{l}\text { Wilson } \\
\text { Mode \# }\end{array}$} & \multicolumn{4}{|c|}{ Raman bands frequencies of 3-Phenylthiophene derivatives $(1 \mathrm{a}-\mathrm{d}) /\left(\mathrm{cm}^{-1}\right)$} \\
\hline & & (1a) & (1b) & (1c) & (1d) \\
\hline$\overline{n . a}$ & - & 97 & 103 & 93 & 109 \\
\hline n.a & - & 271 & 276 & 115 & - \\
\hline n.a & - & 325 & 299 & 160 & - \\
\hline n.a & - & - & 344 & 222 & 236 \\
\hline n.a & - & - & 381 & 302 & - \\
\hline$\gamma($ ring) & $16 a$ & 416 & 417 & - & - \\
\hline$\gamma($ ring) & - & 455 & 458 & 462 & 458 \\
\hline $\mathrm{C}_{\alpha}-\mathrm{S}-\mathrm{C}_{\alpha^{\prime}}$ ring deformation & - & 609 & - & - & - \\
\hline$\gamma($ ring $)$ & - & - & 571 & - & - \\
\hline$\delta$ (ring) & $6 \mathrm{~b}$ & 623 & 636 & 631 & 624 \\
\hline$\gamma($ ring) & 4 & 673 & 710 & - & 700 \\
\hline$\gamma(\mathrm{CH})$ & - & 798 & 787 & 787 & 794 \\
\hline$\gamma(\mathrm{CH})$ & - & - & 813 & - & 822 \\
\hline$\gamma$ (ring) & $10 \mathrm{a}$ & 822 & 830 & 830 & - \\
\hline asymmetric $\mathrm{C}-\mathrm{S}$ stretch $+\delta$ (ring) $+\gamma(\mathrm{CH})$ & - & 896 & 897 & 899 & 899 \\
\hline$\delta(\mathrm{CH})$ & $18 \mathrm{a}$ & 1003 & - & 1000 & - \\
\hline$\delta(\mathrm{CH})$ & - & 1027 & 1019 & - & 1025 \\
\hline $\mathrm{C}_{\beta}-\mathrm{H}$ bending & - & 1045 & 1040 & 1047 & 1058 \\
\hline$\delta(\mathrm{CH})$ & $18 \mathrm{~b}$ & 1095 & 1090 & 1095 & 1115 \\
\hline$\delta(\mathrm{CH})$ & $9 b$ & 1164 & 1159 & - & - \\
\hline$\delta(\mathrm{CH})$ & $9 \mathrm{a}$ & 1190 & 1194 & 1184 & 1191 \\
\hline Ring vibration for para-disubstuted benzenes & - & 1207 & 1218 & 1206 & 1210 \\
\hline Asymmetric $\mathrm{C}-\mathrm{O}-\mathrm{C}$ stretch & - & - & - & 1251 & 1258 \\
\hline$\delta(\mathrm{CH})$ & - & 1260 & 1260 & 1264 & - \\
\hline$\delta(\mathrm{CH})$ & 3 & 1283 & 1289 & 1282 & 1281 \\
\hline$v$ (ring) & 14 & 1309 & 1312 & 1314 & 1315 \\
\hline$v$ (ring) $\left(\mathrm{C}_{\beta}-\mathrm{C}_{\beta^{\prime}}\right.$ stretching $)$ & - & 1376 & 1380 & 1369 & 1366 \\
\hline $\mathrm{C}_{\alpha}=\mathrm{C}_{\beta}$ symmetric stretching & - & 1411 & 1407 & 1411 & 140 \\
\hline$v$ (ring) & $19 b$ & 1455 & 1451 & 1455 & 1453 \\
\hline $\mathrm{C}_{\alpha}=\mathrm{C}_{\beta}$ asymmetric stretching & - & 1498 & 1505 & 1505 & 1503 \\
\hline$v$ (ring) & $19 \mathrm{a}$ & 1534 & 1537 & 1539 & 1536 \\
\hline$v($ ring $)$ & $8 b$ & 1583 & 1575 & 1580 & 1574 \\
\hline$v($ ring $)$ & $8 \mathrm{a}$ & 1601 & 1618 & 1612 & 1607 \\
\hline$v(\mathrm{C}=\mathrm{O})$ & - & - & - & - & 1709 \\
\hline
\end{tabular}

$\delta=$ in-plane deformation, $\gamma=$ out-of-plane deformation, $v=$ stretching 


\subsubsection{Resonance Raman Spectroscopy of Poly p-(3-thienyl) acetophenone (2e)}

Figure 21 shows the Raman spectra of poly-p-(3-thienyl)-acetophenone (2e), which depicts many characteristic bands. The band at $1733 \mathrm{~cm}^{-1}$ is assigned as stretching of carbonyl group in ketone $(\mathrm{C}=\mathrm{O})$, while the two bands at 1084 and $1008 \mathrm{~cm}^{-1}$ are assigned to in plane deformation of the $\mathrm{C}-\mathrm{H}$ bands of phenyl ring. The bands at 940,827 and $787 \mathrm{~cm}^{-1}$ are due to out of plane deformation in the $\mathrm{C}-\mathrm{H}$ bands of the phenyl ring. The two bands at 712 and 401 $\mathrm{cm}^{-1}$ are ascribed to out of plane deformation of the phenyl ring, while the band at $589 \mathrm{~cm}^{-1}$ is due to the ring deformation of thiophene ring. On the other hand, the disappearance of bands in the region $1150-1600 \mathrm{~cm}^{-1}$ in the Raman spectrum of poly- $p$-(3-thienyl)-acetophenone may be ascribed to the potency of the acyl group as electron withdrawing group. Thus, the electron density within the polymer backbone decreases.

The band corresponding to $\mathrm{C}=\mathrm{O}$ stretching of the polymer (2e) appeared at $1733 \mathrm{~cm}^{-1}$ (Figure 21), while in the monomer (1e) it appeared at $1674 \mathrm{~cm}^{-1}$ with more intensity and sharpness (Figure 22). The bands at 1603, 1570 and $1536 \mathrm{~cm}^{-1}$ are assigned to phenyl origins as characteristic of Raman spectra of para-disubstituted benzenes. The bands at 1407 and 1500 $\mathrm{cm}^{-1}$ are ascribed to a symmetric and asymmetric $\mathrm{C}_{\alpha}=\mathrm{C}_{\beta}$ stretching mode, respectively. The two bands at $1289 \mathrm{~cm}^{-1}$ and $1197 \mathrm{~cm}^{-1}$ are assigned to in plane deformation of the $\mathrm{C}-\mathrm{H}$ bands of the phenyl ring, while the $1255 \mathrm{~cm}^{-1}$ is due to in plane deformation of the $\mathrm{C}-\mathrm{H}$ bond of thiophene ring.

Table 5: Band assignments of the Raman spectrum of poly-p-(3-thienyl)-acetophenone (2e)

\begin{tabular}{lcc}
\hline \multicolumn{1}{c}{ Mode } & $\begin{array}{c}\text { Wilson } \\
\text { Mode \# }\end{array}$ & $\begin{array}{c}\text { Raman bands frequencies } \\
\left(\mathbf{c m}^{\mathbf{- 1}}\right)\end{array}$ \\
\hline$\gamma($ ring $)$ & $16 \mathrm{a}$ & 401 \\
\hline $\mathrm{C}_{\alpha}-\mathrm{S}-\mathrm{C}_{\alpha^{\prime}}$ ring deformation & - & 589 \\
\hline$\delta($ ring $)$ & $6 \mathrm{~b}$ & 674 \\
\hline$\gamma($ ring $)$ & 4 & 712 \\
\hline$\gamma(\mathrm{CH})$ & - & 787 \\
\hline$\gamma(\mathrm{CH})$ & $10 \mathrm{a}$ & 827 \\
\hline$\gamma(\mathrm{CH})$ & $17 \mathrm{a}$ & 940 \\
\hline$\delta(\mathrm{CH})$ & $18 \mathrm{a}$ & 1008 \\
\hline$\delta(\mathrm{CH})$ & $18 \mathrm{~b}$ & 1084 \\
\hline$\gamma(\mathrm{C}=\mathrm{O})$ & - & 1733 \\
\hline
\end{tabular}

$\delta=$ in-plane deformation, $\gamma=$ out-of-plane deformation, $v=$ stretching 


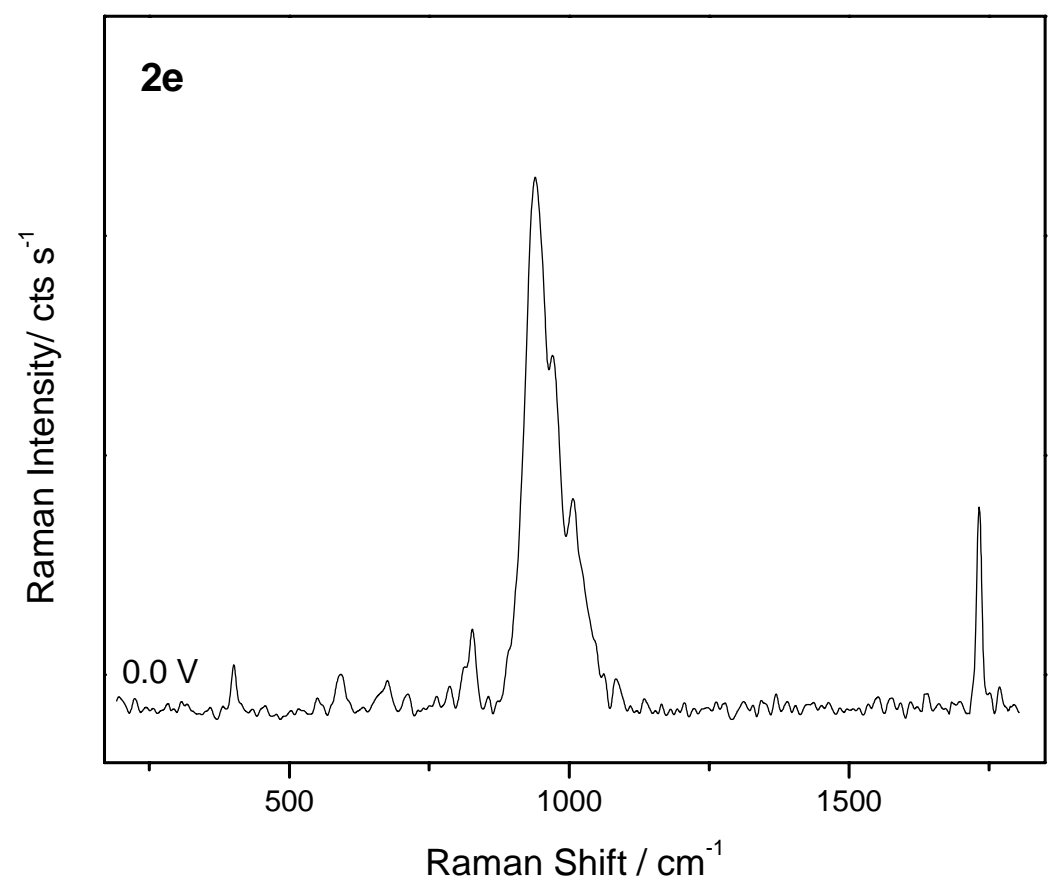

Figure 21. Raman Spectrum of poly- $p$-(3-thienyl)-acetophenone (2e) with $\lambda_{\mathrm{o}}=528.7 \mathrm{~nm}$ in $0.2 \mathrm{M} \mathrm{Et}_{4} \mathrm{NBF}_{4} /$ acetonitrile solution.

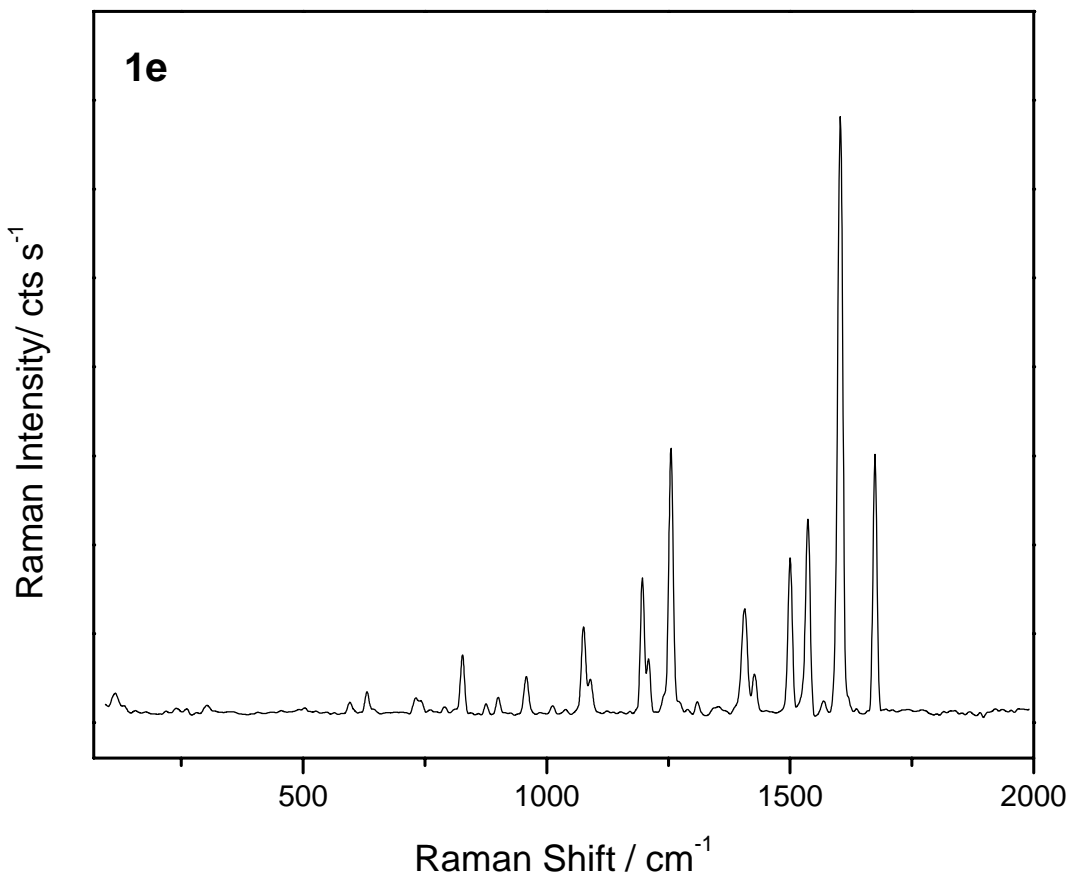

Figure 22. Raman spectrum of $p$-(3-thienyl)-acetophenone (1e) with $\lambda_{\mathrm{o}}=514.5$ 
Table 6: Band assignments of the Raman spectrum of $p$-(3-thienyl)-acetophenone (1e).

\begin{tabular}{|c|c|c|}
\hline Mode & $\begin{array}{l}\text { Wilson } \\
\text { mode \# }\end{array}$ & $\begin{array}{l}\text { Raman band frequencies } \\
\left(\mathrm{cm}^{-1}\right)\end{array}$ \\
\hline n.a & - & 114 \\
\hline n.a & - & 302 \\
\hline $\mathrm{C}_{\alpha}-\mathrm{S}-\mathrm{C}_{\alpha^{\prime}}$ ring deformation & - & 596 \\
\hline$\delta$ (ring) & $6 \mathrm{~b}$ & 631 \\
\hline $\mathrm{C}_{\alpha}-\mathrm{S}-\mathrm{C}_{\alpha^{\prime}}$ ring deformation & - & 731 \\
\hline$\gamma(\mathrm{CH})$ & - & 790 \\
\hline$\gamma($ ring $)$ & $10 \mathrm{a}$ & 827 \\
\hline asymmetric $\mathrm{C}-\mathrm{S}$ stretch & - & 876 \\
\hline$\delta($ ring $)+\gamma(\mathrm{CH})$ & - & 900 \\
\hline$\gamma(\mathrm{CH})$ & $17 \mathrm{a}$ & 958 \\
\hline$\delta(\mathrm{CH})$ & $18 \mathrm{a}$ & 1012 \\
\hline$\delta(\mathrm{CH})$ & - & 1037 \\
\hline $\mathrm{C}_{\beta}-\mathrm{H}$ bending & - & 1076 \\
\hline$\delta(\mathrm{CH})$ & $18 \mathrm{~b}$ & 1091 \\
\hline$\delta(\mathrm{CH})$ & $19 \mathrm{a}$ & 1197 \\
\hline Ring vibration for para-disubstuted benzenes & - & 1209 \\
\hline$\delta(\mathrm{CH})$ & - & 1255 \\
\hline$\delta(\mathrm{CH})$ & 3 & 1289 \\
\hline$v($ ring $)$ & 14 & 1310 \\
\hline $\mathrm{C}_{\alpha}=\mathrm{C}_{\beta}$ symmetric stretching & - & 1407 \\
\hline $\mathrm{C}_{\alpha}=\mathrm{C}_{\beta}$ asymmetric stretching & - & 1500 \\
\hline$v($ ring $)$ & $19 \mathrm{a}$ & 1536 \\
\hline$v($ ring $)$ & $8 b$ & 1570 \\
\hline$v($ ring $)$ & $8 \mathrm{a}$ & 1603 \\
\hline$v \mathrm{C}=\mathrm{O}$ & - & 1674 \\
\hline
\end{tabular}

$\delta=$ in-plane deformation, $\gamma=$ out-of-plane deformation, $v=$ stretching 


\subsubsection{Resonance Raman Spectroscopy of Poly-p-(3-thienyl)-nitrobenzene (2f)}

Figure 23 shows the Raman spectra of poly-p-(3-thienyl)-nitrobenzene (2f), which depicts many characteristic bands, the two bands at 1104 and $1007 \mathrm{~cm}^{-1}$ are assigned to in plane deformation of the $\mathrm{C}-\mathrm{H}$ bands of phenyl ring. In contrary, the $973 \mathrm{~cm}^{-1}$ band is due to out of plane deformation of the $\mathrm{C}-\mathrm{H}$ bands of the phenyl ring. While the band at $1045 \mathrm{~cm}^{-1}$ is due to $\mathrm{C}_{\beta}-\mathrm{H}$ bending in thiophene ring. Finally, the band at $736 \mathrm{~cm}^{-1}$ is ascribed to $\mathrm{C}_{\alpha}-\mathrm{S}-\mathrm{C}_{\alpha^{\prime}}$ asymmetric deformation of thiophene ring. On the other hand, the disappearance of the bands in the region 1150-1600 $\mathrm{cm}^{-1}$ in the Raman spectrum of poly-p-(3-thienyl)-nitrobenzene may be ascribed to the potency of the acyl group as electron withdrawing group. Thus, the electron density within the polymer backbone decreases.

Figure 24 shows the Raman spectra of $p$-(3-thienyl)-nitrobenzene (2f), which depicts many characteristic. The two bands at 1596 and $1536 \mathrm{~cm}^{-1}$ are assigned to phenyl origins as characteristic of Raman spectra of para-disubstituted benzenes. Moreover, the 1407 and 1491 $\mathrm{cm}^{-1}$ bands are ascribed to a symmetric and asymmetric $\mathrm{C}_{\alpha}=\mathrm{C}_{\beta}$ stretching mode, respectively. The two bands at 1293 and $1113 \mathrm{~cm}^{-1}$ are assigned to in plane deformation of the $\mathrm{C}-\mathrm{H}$ bands of the phenyl ring, while the $1264 \mathrm{~cm}^{-1}$ is due to in plane deformation of the $\mathrm{C}-\mathrm{H}$ bond of the thiophene ring. New bands appear in which the bands at $1512 \mathrm{~cm}^{-1}$ and $1340 \mathrm{~cm}^{-1}$ represents asymmetric and symmetric stretching of the nitro group $\left(\mathrm{NO}_{2}\right)$, respectively.

Table 7: Band assignments of the Raman spectrum of poly-p-(3-thienyl)-nitrobenzene (2f).

\begin{tabular}{lcc}
\hline \multicolumn{1}{c}{ Mode } & $\begin{array}{c}\text { Wilson } \\
\text { Mode } \#\end{array}$ & $\begin{array}{c}\text { Raman bands } \\
\text { frequencies } \\
\left(\mathbf{c m}^{-\mathbf{1}} \mathbf{)}\right.\end{array}$ \\
\hline $\mathrm{C}_{\alpha}-\mathrm{S}-\mathrm{C}_{\alpha^{\prime}}$ asym deformation & - & 736 \\
\hline$\gamma(\mathrm{CH})$ & $17 \mathrm{a}$ & 973 \\
\hline$\delta(\mathrm{CH})$ & $18 \mathrm{a}$ & 1007 \\
\hline $\mathrm{C}_{\beta}-\mathrm{H}$ bending & - & 1045 \\
\hline$\delta(\mathrm{CH})$ & $18 \mathrm{~b}$ & 1104 \\
\hline$\delta=$ in-plane deformation,$\gamma=$ out-of-plane deformation, $v=$ stretching &
\end{tabular}

$\delta=$ in-plane deformation, $\gamma=$ out-of-plane deformation, $v=$ stretching 


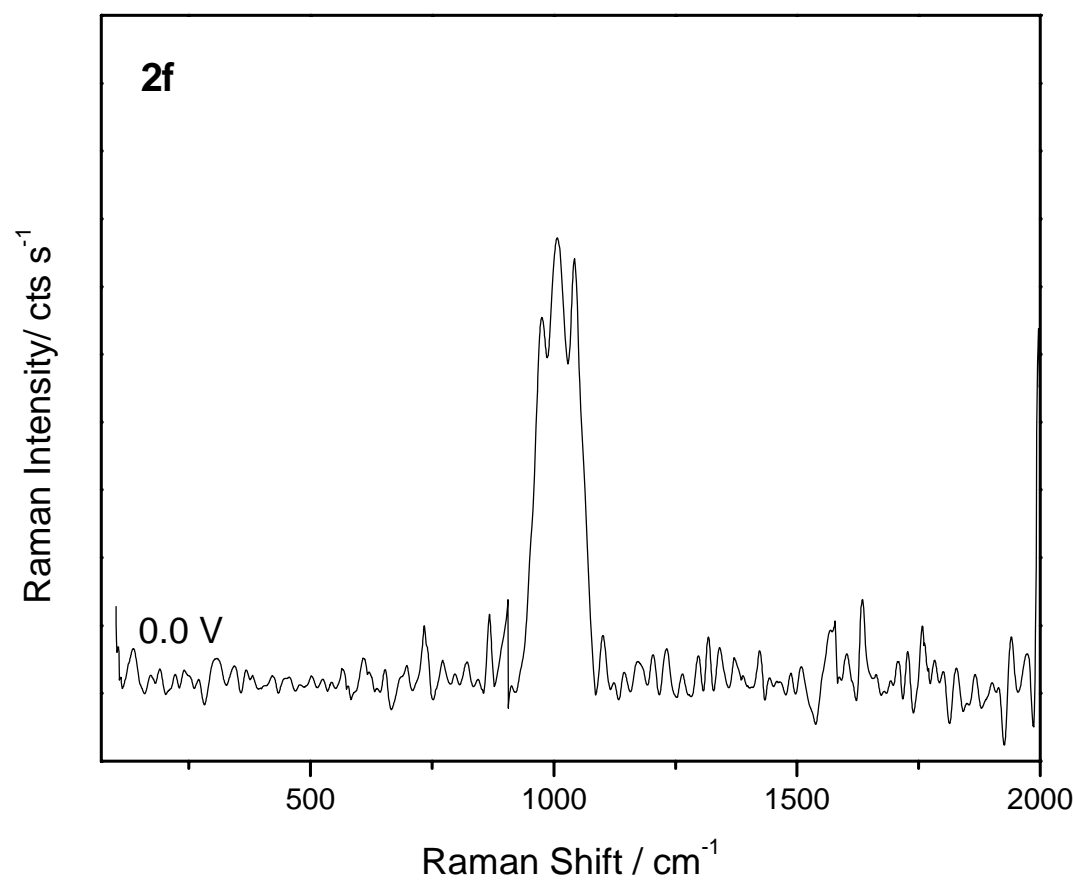

Figure 23. Raman Spectrum of poly $p$-(3-thienyl)-nitrobenzene (2f) with $\lambda_{\mathrm{o}}=488.0 \mathrm{~nm}$ in 0.2 $\mathrm{MEt}_{4} \mathrm{NBF}_{4} /$ acetonitrile solution.

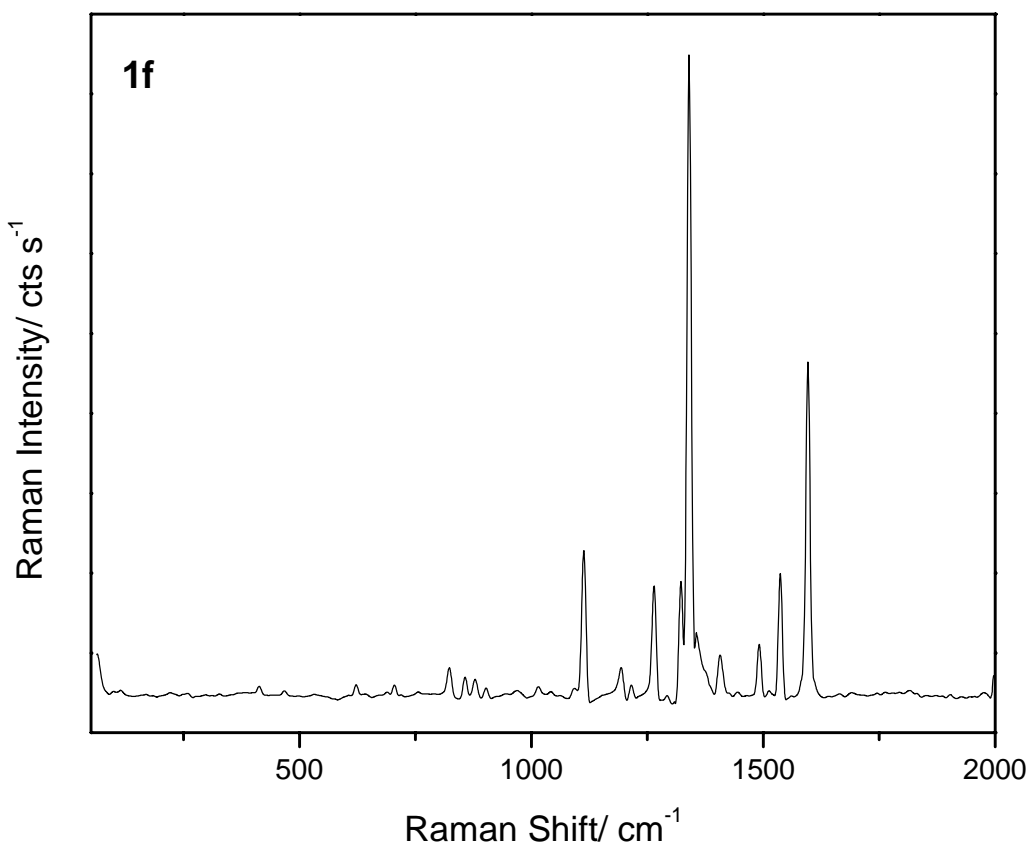

Figure 24. Raman spectrum of $p$-(3-thienyl) nitrobenzene (1f) with $\lambda_{\mathrm{o}}=514.5 \mathrm{~nm}$. 
Table 8: Band assignments of the Raman spectroscopy of $p$-(3-thienyl) nitrobenzene (1f).

\begin{tabular}{|c|c|c|}
\hline Mode & $\begin{array}{l}\text { Wilson } \\
\text { mode \# }\end{array}$ & $\begin{array}{l}\text { Raman band frequencies } \\
\left(\mathrm{cm}^{-1}\right)\end{array}$ \\
\hline n.a & - & 97 \\
\hline n.a & - & 114 \\
\hline$\gamma($ ring $)$ & $16 \mathrm{a}$ & 413 \\
\hline$\gamma($ ring $)$ & - & 467 \\
\hline$\delta$ (ring) & $6 \mathrm{~b}$ & 623 \\
\hline$\gamma($ ring $)$ & 4 & 704 \\
\hline$\gamma($ ring $)$ & $10 \mathrm{a}$ & 823 \\
\hline symmetric C-S stretch & - & 857 \\
\hline asymmetric $\mathrm{C}-\mathrm{S}$ stretch & - & 880 \\
\hline$\delta($ ring $)+\gamma(\mathrm{CH})$ & - & 902 \\
\hline$\gamma(\mathrm{CH})$ & $17 \mathrm{a}$ & 970 \\
\hline$\delta(\mathrm{CH})$ & $18 \mathrm{a}$ & 1016 \\
\hline $\mathrm{C}_{\beta}-\mathrm{H}$ bending & - & 1042 \\
\hline$\delta(\mathrm{CH})$ & $18 b$ & 1113 \\
\hline Ring vibration for para-disubstuted benzenes & - & 1216 \\
\hline$\delta(\mathrm{CH})$ & - & 1264 \\
\hline$\delta(\mathrm{CH})$ & 3 & 1293 \\
\hline$v($ ring $)$ & 14 & 1322 \\
\hline$v(\mathrm{~N}-\mathrm{O})(\mathrm{sym})$ & - & 1340 \\
\hline $\mathrm{C}_{\alpha}=\mathrm{C}_{\beta}$ symmetric stretching & - & 1407 \\
\hline$v($ ring $)$ & $19 b$ & 1445 \\
\hline $\mathrm{C}_{\alpha}=\mathrm{C}_{\beta}$ asymmetric stretching & - & 1491 \\
\hline$v(\mathrm{~N}-\mathrm{O})($ asym $)$ & - & 1512 \\
\hline$v($ ring $)$ & $19 \mathrm{a}$ & 1536 \\
\hline$v($ ring $)$ & $8 \mathrm{a}$ & 1596 \\
\hline
\end{tabular}




\subsubsection{Raman Spectroscopic Studies of Regioregularity of Poly p-(3-thienyl) benzene Derivatives}

Since the regioregularity of polythiophene chain is an important factor for its conductivity, the precise control of regioregularity is an essential technology for obtaining good conducting polymers. Therefore, resonance Raman spectroscopy has been demonstrated as a powerful tool for the elucidation of the molecular structure and the regioregularity of electrochemically formed poly $p$-(3-thienyl) benzene derivatives.

Although in Raman spectroelectrochemical studies poly $p$-(3-thienyl) benzene derivatives behave similarly to unsubstituted polythiophene, one evident difference should be pointed out. Both in unsubstituted polythiophene and poly $p$-(3-thienyl) benzene derivatives the two bands due to $\mathrm{C}-\mathrm{S}-\mathrm{C}$ ring deformations are present at 728 and $688 \mathrm{~cm}^{-1}$ in polythiophene and at 725 and $680 \mathrm{~cm}^{-1}$ in poly-3-phenylthiophene derivatives. The intensity of both bands is very low in poly $p$-(3-thienyl) benzene derivatives with respect to polythiophene $[138,151,153]$.

Upon the doping of unsubstituted polythiophene, two additional bands grow in intensity 675 and $642 \mathrm{~cm}^{-1}$. These additional peaks were attributed by several authors to distorted parts (kinks) in the polythiophene chain [138, 151, 153]. In poly $p$-(3-thienyl) benzene derivatives these bands are practically nonexistent. It seems, therefore, more likely that their presence is associated with structural defects existing in unsubstituted polythiophene such as $\alpha-\beta^{\prime}$ linkage $[31,138]$. Of course, the large substituent at the 3-position virtually excludes the existence of $\alpha-\beta^{\prime}$ linkages in poly $p$-(3-thienyl) benzene derivatives. Thus, it is obvious that regioregularity of poly $p$-(3-thienyl) benzene derivatives is high. 


\subsection{UV-Visible and Electrochemical Bandgaps of 3-Phenylthiophene Derivatives}

According to in situ UV-Vis absorption measurements obtained during anodic polarization the main charge carriers in polythiophenes are polarons and / or bipolarons (Fig. 25), the formation of which results in new quantum states in the energy gap. Thus new transitions become possible and the charging of conjugated polythiophenes is accompanied by dramatic changes in their optical absorption spectra [164].
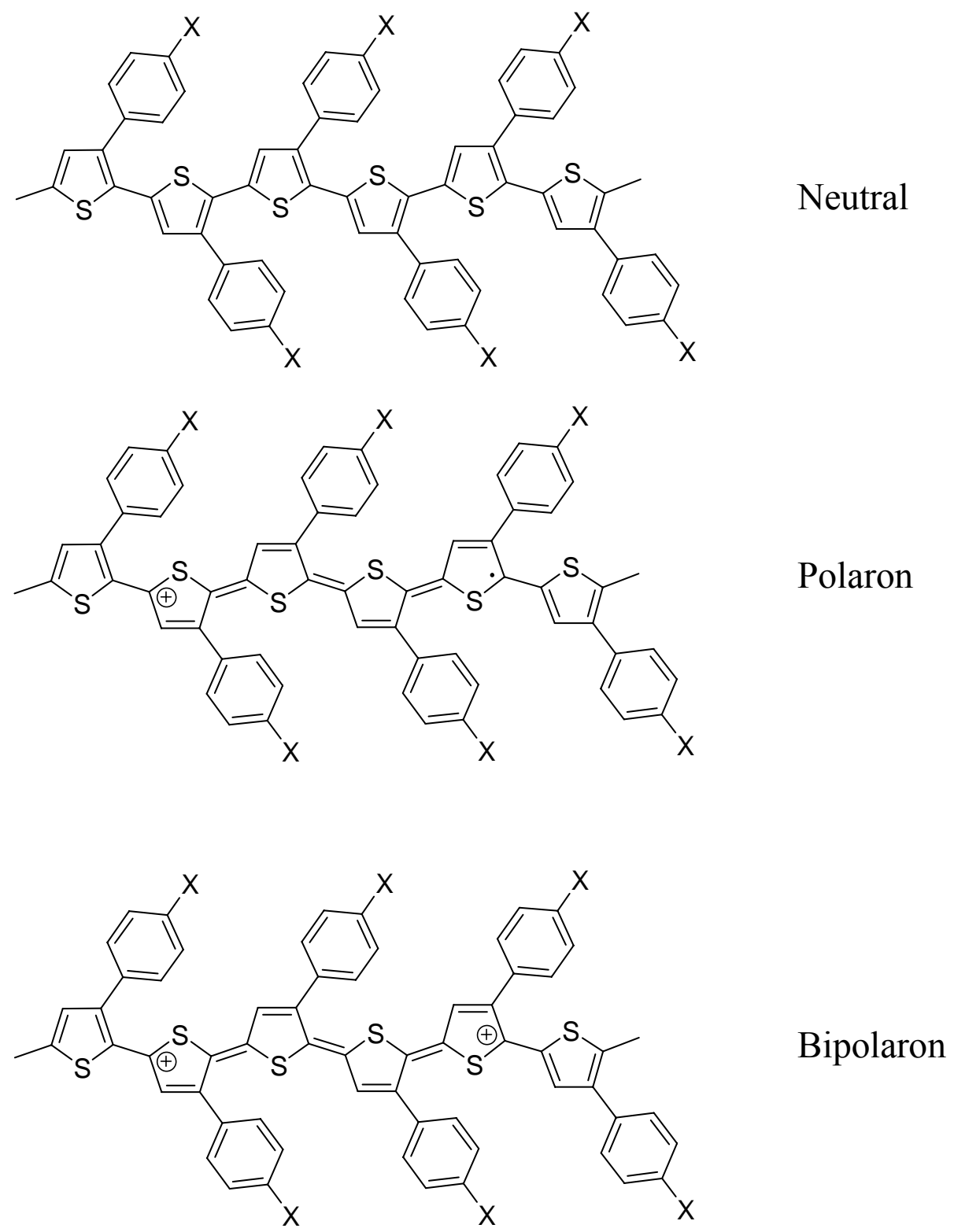

Figure 25: Simplified structural formulas of poly-3-phenylthiophenes in its neutral, radical cation (polaron) and dication (bipolaron) states. 
The evolution of the spectra of poly-3-phenylthiophenes (2a-f) upon doping is characterized by similar features as observed for many polythiophenes with high degree of conjugation. [36, 165-171]. During stepwise oxidation of the poly-3-phenylthiophene films the intensity of the absorption due to the $\pi \rightarrow \pi *$ transition around 450-566 nm decreases and a new broad absorption band related to (bi)polaron states appears at around 730-890 nm ( see Table 9 and Fig 26).

During the oxidation ( $p$-doping) of the poly3-phenylthiophene (2a-f) films a blue/hypsochromic shift is observed for both absorption bands. A similar feature has been observed for poly (3-methyl thiophene) by Visy et al. [167] and for poly(thiophene-3methanol) by Lankinen et al. [169]. It is explained by the fact that a polymer contains a distribution of chain lengths, and the longest polymer chains (the absorption of which occurs at lower energies) start to oxidize at lower potentials. As the potential of the poly-3phenylthiophene is increased to relatively high values, the intensity of the absorbance maximum around 730-890 $\mathrm{nm}$ starts to decrease and the blue shift becomes more pronounced (see Fig. 26). Thus it seems probable that some of the species absorbing at around 730-890 $\mathrm{nm}$ are oxidized further at these higher positive potentials, and that the oxidation products are not absorbing in the wavelength range studied. The decrease of the (bi)polaron absorbance is not necessarily due only to overoxidation but also to formation of another type of charge carrier. This observation combined with the low degree of conjugation found for poly-3phenylthiophenes and the low doping levels obtained supports the previous suggestion that at lower potentials where no overoxidation occurs the charge carriers observed are polarons rather than bipolarons [169, 170].

Table 9:Oxidation, reduction peaks, wavelengths, electrochemical and optical bandgaps for Polymers (2a-f).

\begin{tabular}{|c|c|c|c|c|c|c|c|c|c|}
\hline Polymer & $\begin{array}{c}\text { Ox. } E_{\text {pa }} / \\
\text { V }\end{array}$ & $\underset{\mathbf{V}}{\text { Ox. } E_{\mathbf{p c}} l}$ & $\underset{/ / V}{\operatorname{Red} . E_{p c}}$ & $\underset{/ \text { V }}{\operatorname{Red}_{\mathbf{p a}}}$ & $\begin{array}{c}\boldsymbol{E}_{\text {red }} / \\
\mathbf{V}\end{array}$ & $\begin{array}{c}\boldsymbol{E}_{\mathbf{o x}} / \\
\mathbf{V}\end{array}$ & $\begin{array}{c}E_{\text {g.EC }}{ }^{*} / \\
\text { eV }\end{array}$ & $\begin{array}{c}\mathrm{UV} \\
\lambda_{\max } / \mathbf{n m}\end{array}$ & $\begin{array}{c}\mathbf{E}_{\text {g.opt }} / \\
\text { eV }\end{array}$ \\
\hline $2 a$ & 1.459 & 0.971 & -1.845 & -1.586 & -1.716 & 1.215 & 2.93 & 530 & 2.35 \\
\hline $2 b$ & 1.291 & 0.998 & -2.043 & -1.602 & -1.823 & 1.150 & 2.98 & 566 & 2.20 \\
\hline 2c & 1.281 & 0.987 & -2.080 & -1.634 & -1.857 & 1.134 & 2.99 & 523 & 2.36 \\
\hline 2d & 1.382 & 0.929 & -2.043 & -1.361 & -1.702 & 1.156 & 2.86 & 459 & 2.71 \\
\hline $2 e$ & 1.330 & 1.029 & -1.996 & -1.377 & -1.686 & 1.180 & 2.87 & 450 & 2.76 \\
\hline $2 f$ & 1.505 & 1.091 & -2.147 & -0.890 & -1.519 & 1.298 & 2.82 & 453 & 2.74 \\
\hline
\end{tabular}



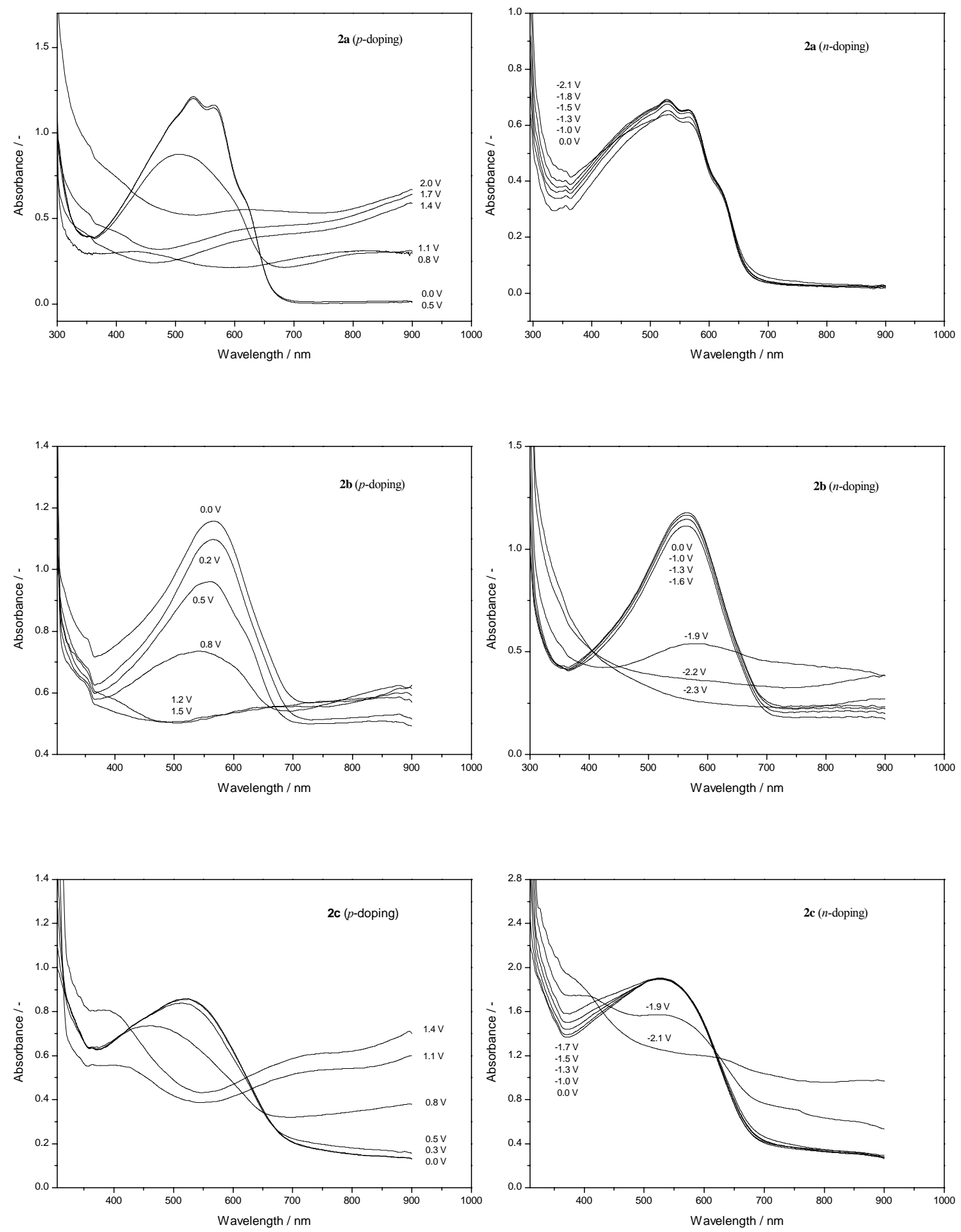

Figure 26: UV-Visible spectra of polymers (2a-f) coated on ITO glass electrodes, obtained at different electrode potential values. Figure continued. 

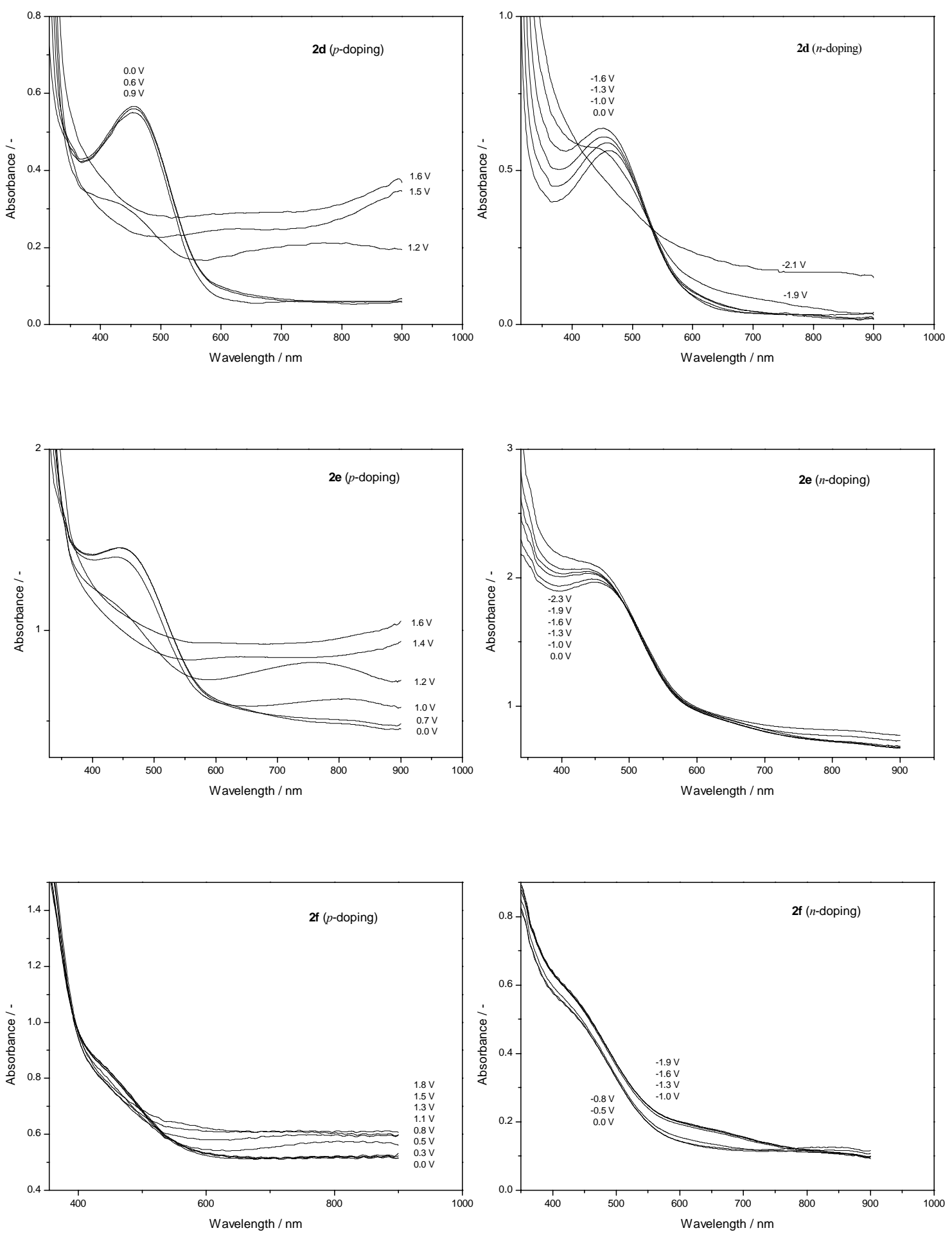

Figure 26: continued from previous page 

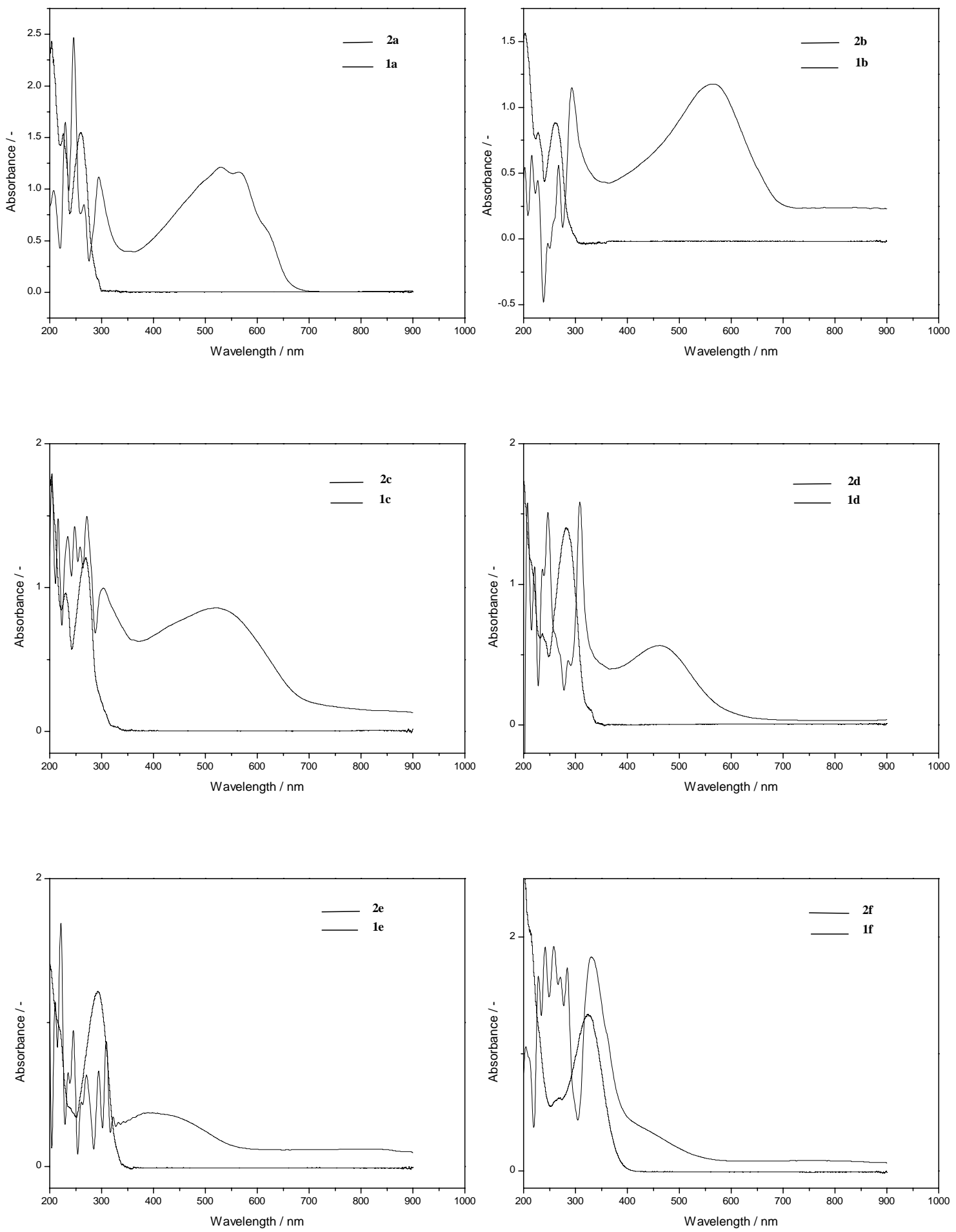

Figure 27: UV-Visible spectra of monomers (1a-f) with acetonitrile as solvent and polymers (2a-f) as films deposited on an ITO glass electrode. 
During the reduction (n-doping) of the poly-3-phenylthiophene films a bathochromic/red shift is observed for the interband $\pi \rightarrow \pi *$ transition peak for polymers 2 b,c. On the contrary, a blue shift is observed for polymer 2d, on the other hand no shift is observed for polymers 2a,e, f. These differences in shift may be ascribed to the nature of substituent or to degradation of the polymers. Three peaks were observed for poly-3-phenylthiophene (2a) and this is due to the presence of polymers with different chain lengths.

The basic theories of cyclic voltammetry of dissolved redox species cannot easily be transferred to a conjugated polymer film formed on the electrode. The frequently used method of evaluating the formal potential of a redox reaction by taking the middle between its anodic and cathodic peaks does not necessarily apply to conjugated polymers. The often asymmetric voltammograms obtained with conjugated polymer films have been discussed for several years. Different explanations have been presented in the literature but a common theme is that the de-doping reaction cannot be regarded as just the reverse reaction of the doping process $[165,167]$. The charges involved in the de-doping process are often ejected from the film over a broad potential interval usually with considerable currents long before the peak is reached. Thus there are reasons to put less emphasis on $E_{p a}^{r e d}$ and $E_{p a}^{o x}$ in evaluation of formal redox potentials, $E^{\text {ox }}$ and $E^{\text {red }}$. Still, for most polymers, peak potentials vary with sweep rate and as a compromise we have used $E^{o x}=\left(E_{p a}^{o x}+E_{p c}^{o x}\right) / 2$ and $E^{r e d}=\left(E_{p c}^{r e d}+E_{p a}^{r e d}\right) / 2$ calculating the $E_{\text {g.EC }}$ in Table 9. On the other hand, Figure 27 shows the difference between the UV-Vis spectra of the monomers (1a-f) and the UV-Vis spectra of the polymers (2a-f)

The difference between the onset of $p$ - and $n$-doping for the evaluation of $E_{\text {g.EC }}$ is sometimes found in the literature. Even if ill defined, onset (the potential for the initial injection of holes and electrons to the HOMO and LUMO, respectively) may be the theoretically proper method. The charging of the polymer during the doping process is associated with conformational reorganisation and modification of the energy levels of the polymer. From this point of view only the onset potential probes injection of charges into neutral polymers in the ground state. Onset is also advantageous when two or more red/ox peaks are not fully resolved (see polymer $2 \mathbf{a}$ for example). The onsets for $E_{p a}^{o x}$ and $E_{p c}^{r e d}$ are given in Table 10 together with the resulting $E_{g, E C \text {.onset }}=E_{\text {onset }}^{o x}+E_{\text {onet }}^{\text {red }}$ The onset has been evaluated by drawing two tangents for each peak and is assumed to be where the two tangents cross as indicated by dashed lines for $E_{p a}^{o x}$ in Fig. 28. 
Table 10: Oxidation, reduction onset peaks and electrochemical onset bandgaps for polymers (2-f)

\begin{tabular}{cccc}
\hline Polymer & $E_{\text {onset }}^{\text {ox }} / \mathrm{V}$ & $E_{\text {onet }}^{\text {red }} / \mathrm{V}$ & $E_{\text {g.EC.onset }} / \mathrm{V}$ \\
\hline 2a & 0.76 & -1.69 & 2.45 \\
\hline 2b & 0.86 & -1.53 & 2.39 \\
\hline 2c & 0.85 & -1.47 & 2.32 \\
\hline 2d & 0.98 & -1.41 & 2.39 \\
\hline 2e & 0.86 & -1.36 & 2.22 \\
\hline 2f & 1.02 & -1.29 & 2.31 \\
\hline${ }^{*} E_{g, E C . o n s e t}=E_{\text {onset }}^{\text {ox }}+E_{\text {onet }}^{\text {red }}$ & & &
\end{tabular}

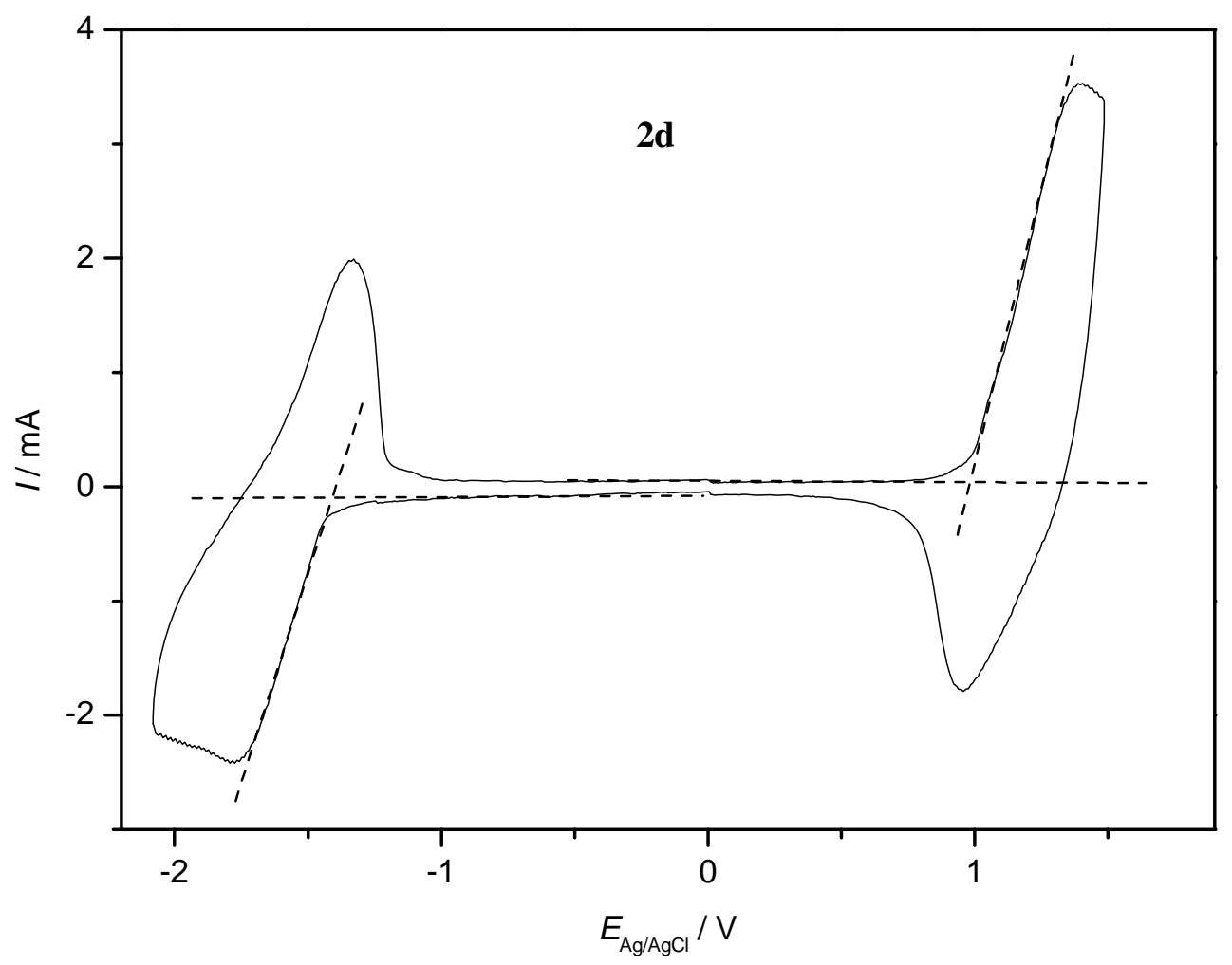

Figure 28: Cyclic voltammogram of polymer 2d. 
In Fig. 29 we compare the two alternative evaluation techniques by plotting the electrochemical bandgaps obtained by peak potential average versus peak onset. As expected, the onset gives a lower bandgap. A poor correlation was observed. The solid line represents a linear fit.

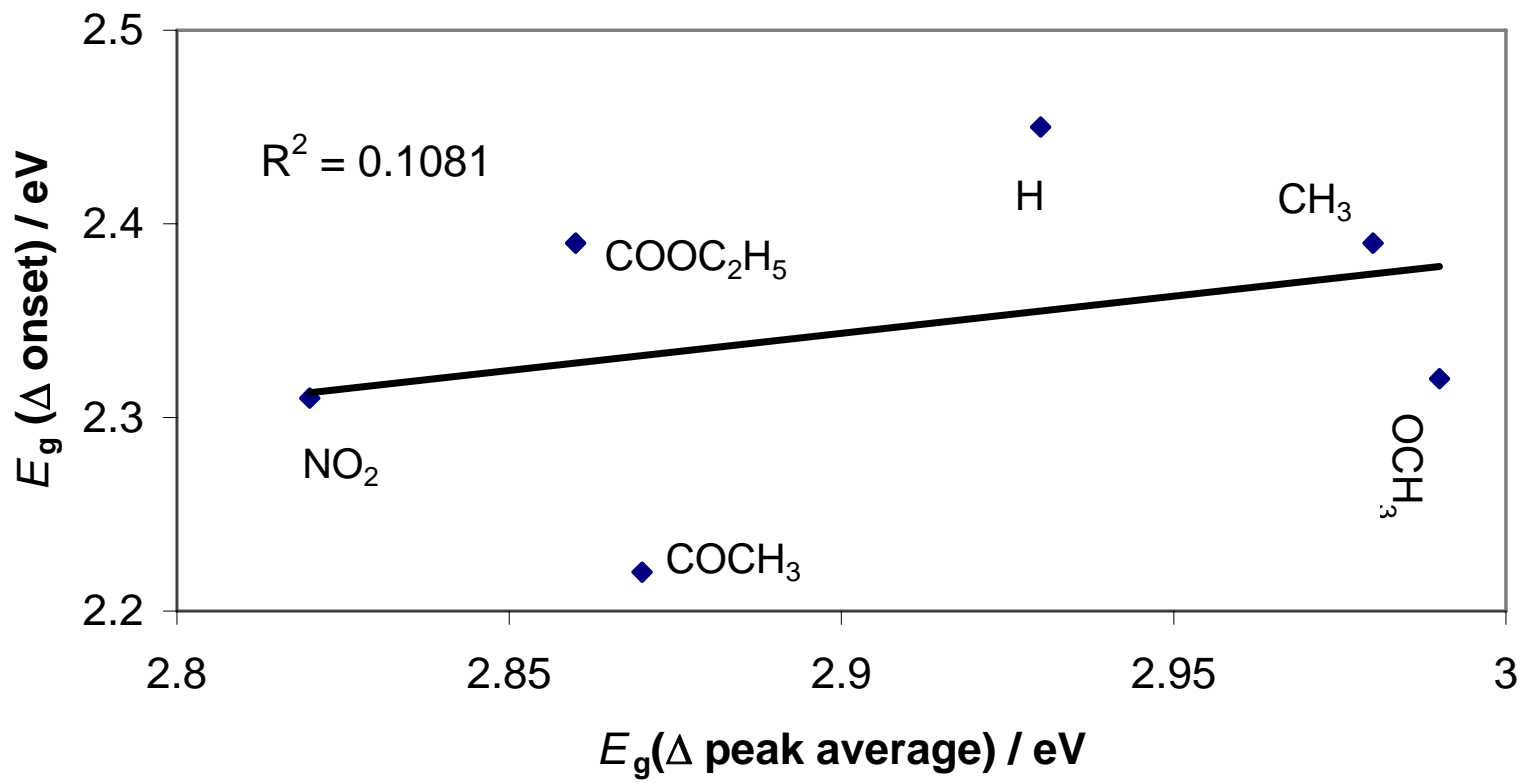

Figure 29: Electrochemical bandgaps, $E_{\mathrm{g}}$, evaluated from onset and peak average, respectively.

In Fig. $30 E_{\text {g.EC }}$ for the polymers are plotted against the optical bandgap, $E_{\text {g.opt, obtained }}$ from the maximum optical absorption of thin films prepared by depositing on ITO electrode. As can be seen, the electrochemical determination gives higher values of the bandgap in all cases. The same observation has been made for other polythiophenes [172], poly(phenylene vinylene)s [173,174] and copolymers thereof [175], poly(quinoxaline vinylene)s and poly(pyridopyrazine vinylene) [176,177] and for fluorene-based copolymers [178]. Alternative evaluation of the optical bandgap is of course possible (absorption onset instead of absorption maximum: evaluation from photoluminescence spectra rather than absorption; optical absorption of polymer in solution rather than in film). All but the last alternative, however, give even worse agreement since they generally deliver lower values of $E_{\text {g.opt }}$ Even if solvatochromic effects can be observed in the solid state we think that the swollen polymer film during electrochemical charge transfer more resembles the solid film than the polymer dissolved in a good solvent [179]. 


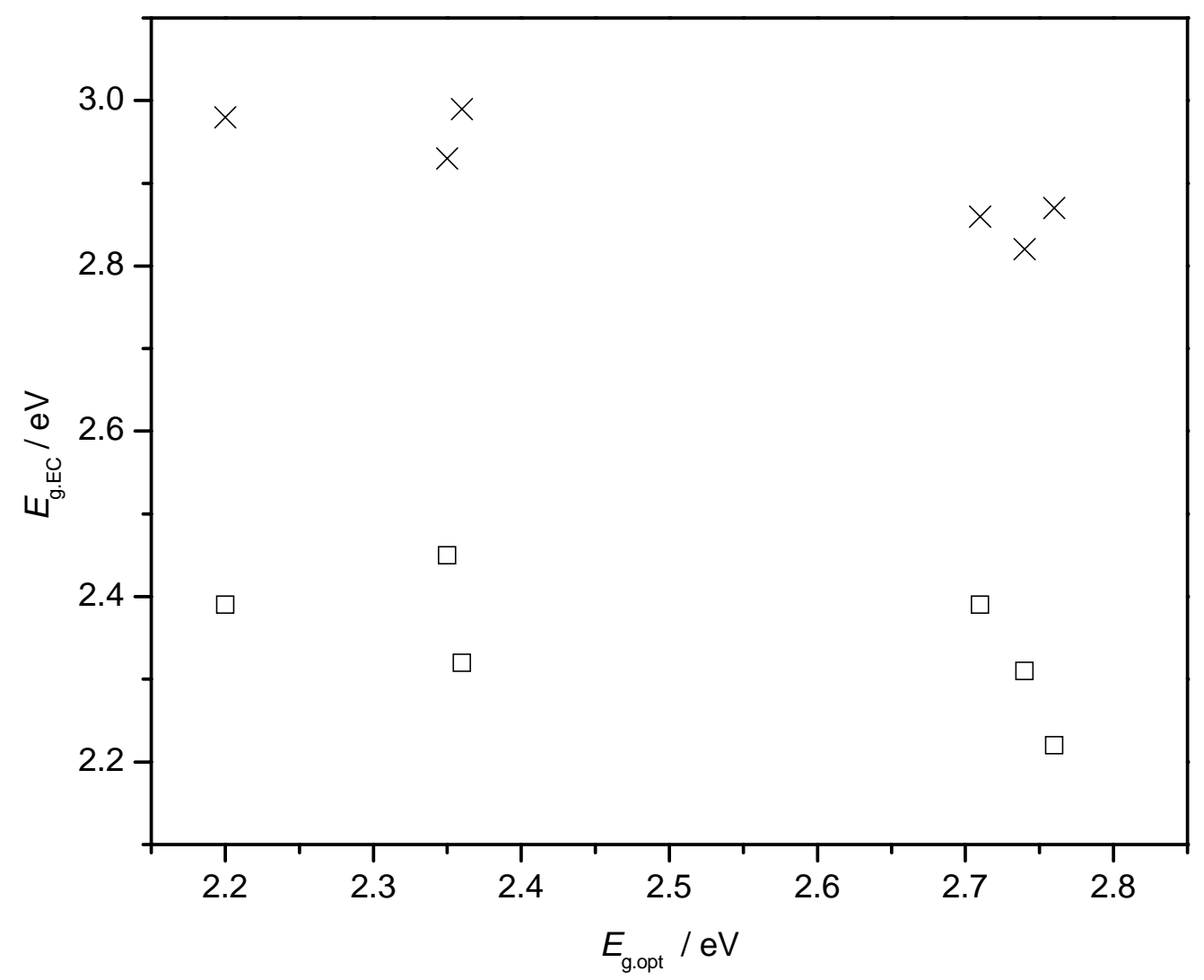

Figure 30: Electrochemical versus optical bandgap of polymers (2a-f), (electrochemical bandgap evaluated by onset (squares) and by peak average (crosses))

Brédas et al. used the valence-effective Hamiltonian method to calculate the ionization potential, $E_{\mathrm{i}}$, and electron affinity, $E_{\mathrm{ea}}$, that define the energies of the HOMO and LUMO levels, respectively, for different oligomer and polymer systems [179, 180]. An inverse chainlength dependence of $E_{\mathrm{i}}$ and $E_{\mathrm{ea}}$ suggested that the theoretical and experimental data for small molecules could be extrapolated to polymers. A good agreement between theoretical results and experimental data (gas phase ionization and electrochemistry) for some of the systems from the literature also made it possible to suggest a correction factor for conversion of theoretical $E_{\mathrm{i}}$ to electrochemically determined $E_{\mathrm{i}}$. The correction factor included two parts; one to account for solid-state polarization energy and another one for relating the potential of the reference electrode to vacuum. However, both parts are subject to uncertainty. There is hardly any general energy associated with the solid-state polarization of conjugated materials although $1.9 \mathrm{eV}$ is mentioned by several authors [180-183]. Brédas et al., however, remark that the polarization energy correction is found in the interval $1.5-2.0 \mathrm{eV}$.

Regarding electrochemical referencing in non-aqueous solvents (which are normally the media for conjugated polymer electrochemistry), a wide range of reference electrodes is used 
in the literature but there seems to be a lack of consensus on how they relate to each other and to the vacuum scale. This makes it sometimes very difficult to compare data in the literature, especially when different solvents have been used. The position of the standard hydrogen electrode, SHE, being approximately $4.5 \mathrm{eV}$ negative to the vacuum level, is well established [184.185]. The SHE is seldom used in practical work and when working with nonaqueous electrolyte solutions there are reasons to avoid other aqueous reference electrodes as well.

IUPAC recommends the use of a reference redox system such as the ferrocene/ferrocenium ion redox couple, $\mathrm{Fe}_{\mathrm{Fe}}{ }^{+}$[186]. For many common solvents and electrolytes, such referencing is reproducible and very practical to use for the experimentalist. In the literature, however, the redox potential for $\mathrm{Fe} / \mathrm{Fe}^{+}$, reported as $E^{1 / 2}$ or $E^{0}$, varies enormously also for one and the same solvent (acetonitrile: 0.19 V vs. SHE, [187], $0.69 \mathrm{~V} v s$. SHE [188], 0.307 V vs. SCE [184]).

Pavlishchuk and Addison [189] have done a more detailed analysis of reference systems in acetonitrile solutions and also collected a lot of values from the literature. They give the values $0.380 \mathrm{~V} v s$. SCE and $0.630 \mathrm{~V}$ vs. SHE for the standard ferrocene/ferrocenium $\left(\mathrm{Fe} / \mathrm{Fe}^{+}\right)$redox couple system based on own measurements and assumptions. It is not our aim to present a solution to these theoretical and experimental problems. But it should be emphasized that when comparing absolute values of electrochemically determined HOMO and LUMO energy levels from different publications, one should be aware of these problems.

Fig. 31 shows a plot of the energies of the HOMO and LUMO levels calculated from both peak average and onset red/ox potentials for the investigated polymers (Table 11). The energy levels were calculated on the basis of the assumption that the normal hydrogen electrode, $\mathrm{SHE}$, is found at $4.5 \mathrm{eV}$ versus vacuum [184]. The difference of $+0.22 \mathrm{~V}$ of $\mathrm{Ag} / \mathrm{AgCI}$ (non aqueous) vs. SHE has been taken into account as well. Thus, the energy of the HOMO is obtained by adding $4.7 \mathrm{~V}$ to the measured $E^{\mathrm{ox}}$ (which gives values between 5 and $6 \mathrm{eV}$ for most of the polymers) and the energy of the LUMO by adding $4.7 \mathrm{~V}$ to the measured $E^{\text {red }}$ (giving values between 3 and $4 \mathrm{eV}$ ). Values of the energy of the LUMO obtained by the difference between the energy of the HOMO (evaluated from peak averages) and the optical bandgap (evaluated as absorption maximum of thin films) have also been included in Fig. 31 (Table 11). The values given in Fig. 31 are of course subject to the uncertainties discussed above. 
Table 11: HOMO and LUMO calculated by peak average, onset and optical methods for polymers $(\mathbf{2 a}-\mathbf{f})$

\begin{tabular}{ccccccc}
\hline \multirow{2}{*}{ Polymer } & \multicolumn{2}{c}{ Peak average / eV } & \multicolumn{2}{c}{ Onset / eV } & \multicolumn{2}{c}{ Optical / eV } \\
\cline { 2 - 7 } & HOMO & LUMO & HOMO & LUMO & HOMO $^{*}$ & LUMO \\
\hline 2a & 5.915 & 2.984 & 5.460 & 3.010 & 5.915 & 3.565 \\
\hline 2b & 5.850 & 2.877 & 5.560 & 3.170 & 5.850 & 3.650 \\
\hline 2c & 5.834 & 2.843 & 5.550 & 3.230 & 5.340 & 3.474 \\
\hline 2d & 5.856 & 2.998 & 5.680 & 3.290 & 5.856 & 3.146 \\
\hline 2e & 5.880 & 3.014 & 5.560 & 3.340 & 5.880 & 3.120 \\
\hline 2f & 5.998 & 3.181 & 5.720 & 3.410 & 5.998 & 3.258 \\
\hline
\end{tabular}

*HOMO values calculated from peak potential average

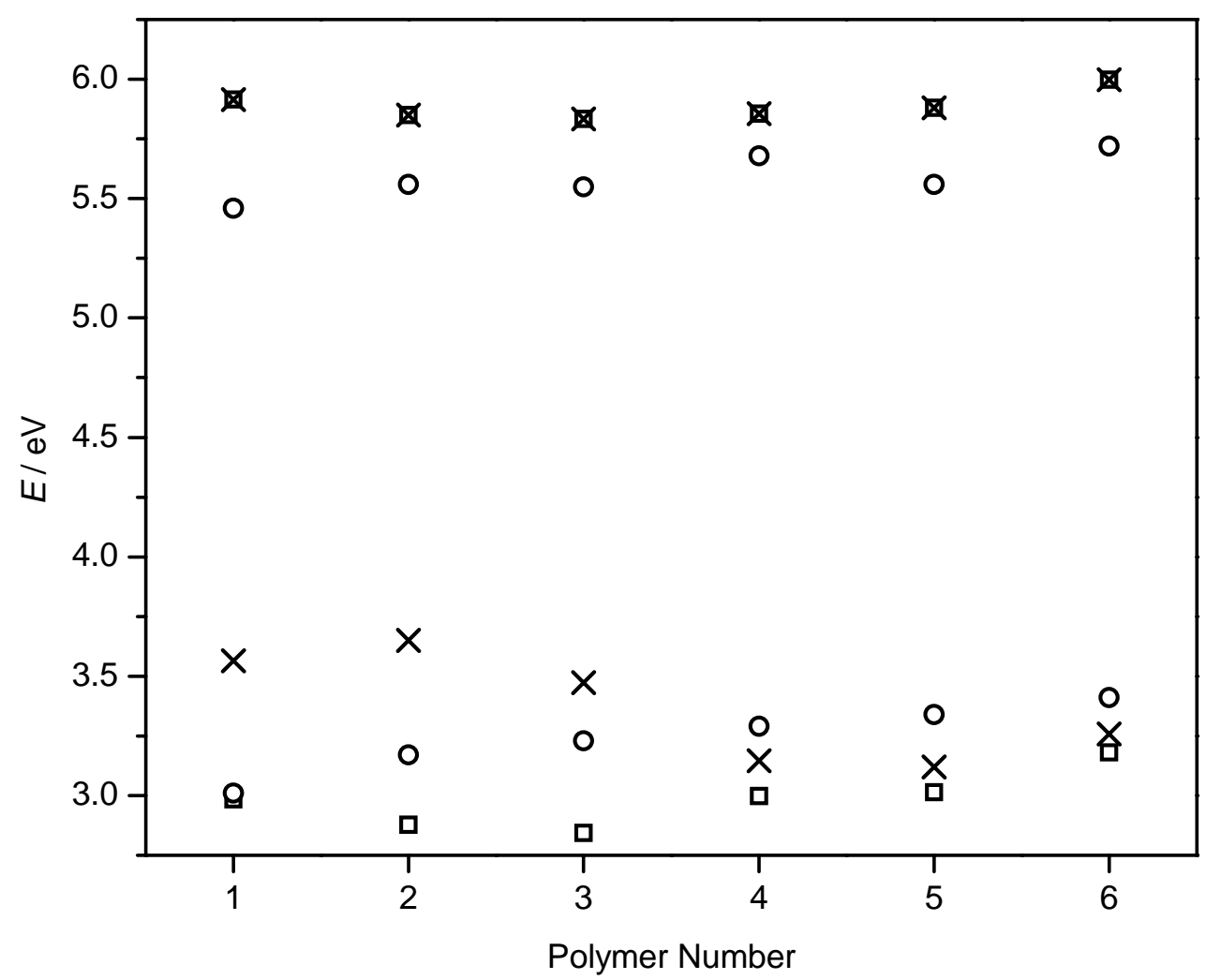

Figure 31: Energies of the HOMO and LUMO for the polymers evaluated by different procedures: Squares: HOMO and LUMO from peak potential averages; Crosses: HOMO and LUMO from onset potentials; Circles: LUMO calculated from HOMO and optical absorption maximum. 


\subsection{Theoretical Treatment of 3-Phenylsubstituted Thiophenes and Their Intrinsically Conducting Polymers.}

DFT calculations were carried out to obtain the absolute energy of the compounds (1a-f) with fixed nuclear coordinates and mobile electrons. The results show that the introduction of substituents into the p-phenyl position of 3-phenylthiophene affects the geometrical parameters (bond lengths and bond angles), orbital energies (HOMO and LUMO) and spin densities. Calculated bond lengths and bond angles of the compounds sketched in Table. 12 (1a-1f), resulting from the geometry optimization, are shown in Table 12. Furthermore, the gap (LUMO-HOMO) decreases especially in the case of electron withdrawing substituents (Table 13).

A generally accepted mechanism for the coupling reaction of thiophene, which consists of a two-step reaction, is shown in Fig. 32 [35, 190]. The initial step is a one-electron oxidation of the monomer to form its radical cation. The probability of this step can be estimated based on the ionization potential of the molecule. The second step is a coupling reaction of two radical cations to form a dihydro-dimer dication, which is followed by the elimination of two protons to form the neutral dimer. The probability of this step should be closely related to the spin density of the unpaired electron and the steric effect between the two cations.
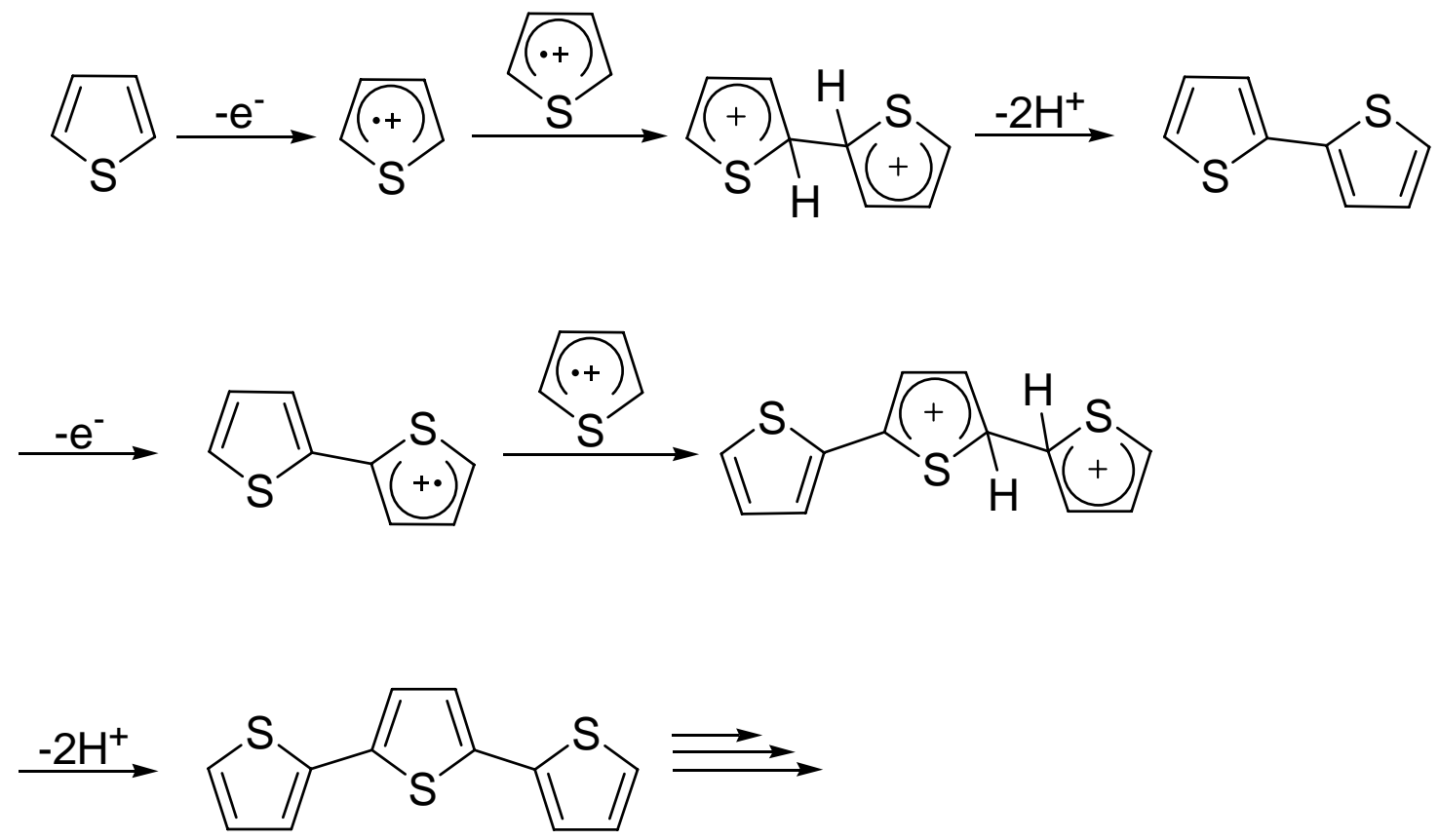

Figure 32. General scheme of the coupling reactions of thiophenes. 
Table 12: Optimized geometrical parameters calculated by B3LYP/ 6-31G(d) of 3phenylthiophene derivatives (1a-1f)

\begin{tabular}{|c|c|c|c|c|}
\hline Compounds & Bond & $\begin{array}{c}\text { Calculated Bond } \\
\text { length / } \mathbf{A}^{\mathbf{0}} \\
\end{array}$ & Bond Angle & $\begin{array}{c}\text { Calculated Angle / } \\
\text { Degree }\end{array}$ \\
\hline \multirow{13}{*}{$1 /$} & $\mathrm{C}_{2}-\mathrm{C}_{3}$ & 1.376 & $<\mathrm{C}_{3} \mathrm{C}_{2} \mathrm{~S}_{1}$ & 112.469 \\
\hline & $\mathrm{C}_{2}-\mathrm{S}_{1}$ & 1.732 & $<\mathrm{C}_{2} \mathrm{C}_{3} \mathrm{C}_{4}$ & 11.206 \\
\hline & $\mathrm{C}_{3}-\mathrm{C}_{4}$ & 1.439 & $<\mathrm{C}_{2} \mathrm{C}_{3} \mathrm{C}_{6}$ & 124.275 \\
\hline & $\mathrm{C}_{3}-\mathrm{C}_{6}$ & 1.478 & $<\mathrm{C}_{3} \mathrm{C}_{4} \mathrm{C}_{5}$ & 133.472 \\
\hline & $\mathrm{C}_{4}-\mathrm{C}_{5}$ & 1.364 & $<\mathrm{C}_{4} \mathrm{C}_{5} \mathrm{~S}_{1}$ & 111.519 \\
\hline & $\mathrm{C}_{5}-\mathrm{S}_{1}$ & 1.736 & $<\mathrm{C}_{6} \mathrm{C}_{11} \mathrm{C}_{10}$ & 120.925 \\
\hline & $\mathrm{C}_{6}-\mathrm{C}_{7}$ & 1.405 & $<\mathrm{C}_{2} \mathrm{~S}_{1} \mathrm{C}_{5}$ & 91.334 \\
\hline & $\mathrm{C}_{6}-\mathrm{C}_{11}$ & 1.405 & $<\mathrm{C}_{3} \mathrm{C}_{6} \mathrm{C}_{7}$ & 121.107 \\
\hline & $\mathrm{C}_{7}-\mathrm{C}_{8}$ & 1.393 & $<\mathrm{C}_{3} \mathrm{C}_{6} \mathrm{C}_{11}$ & 120.755 \\
\hline & $\mathrm{C}_{8}-\mathrm{C}_{9}$ & 1.396 & $<\mathrm{C}_{6} \mathrm{C}_{7} \mathrm{C}_{8}$ & 120.942 \\
\hline & $\mathrm{C}_{9}-\mathrm{C}_{10}$ & 1.396 & $<\mathrm{C}_{7} \mathrm{C}_{8} \mathrm{C}_{9}$ & 120.285 \\
\hline & $\mathrm{C}_{10}-\mathrm{C}_{11}$ & 1.394 & $<\mathrm{C}_{8} \mathrm{C}_{9} \mathrm{C}_{10}$ & 119.421 \\
\hline & & & $<\mathrm{C}_{9} \mathrm{C}_{10} \mathrm{C}_{11}$ & 119.564 \\
\hline & $\mathrm{C}_{2}-\mathrm{C}_{3}$ & 1.376 & $<\mathrm{C}_{3} \mathrm{C}_{2} \mathrm{~S}_{1}$ & 112.490 \\
\hline & $\mathrm{C}_{2}-\mathrm{S}_{1}$ & 1.732 & $<\mathrm{C}_{2} \mathrm{C}_{3} \mathrm{C}_{4}$ & 111.171 \\
\hline & $\mathrm{C}_{3}-\mathrm{C}_{4}$ & 1.439 & $<\mathrm{C}_{2} \mathrm{C}_{3} \mathrm{C}_{6}$ & 124.565 \\
\hline & $\mathrm{C}_{3}-\mathrm{C}_{6}$ & 1.478 & $<\mathrm{C}_{4} \mathrm{C}_{3} \mathrm{C}_{6}$ & 124.261 \\
\hline & $\mathrm{C}_{4}-\mathrm{C}_{5}$ & 1.364 & $<\mathrm{C}_{3} \mathrm{C}_{4} \mathrm{C}_{5}$ & 113.497 \\
\hline & $\mathrm{C}_{5}-\mathrm{S}_{1}$ & 1.736 & $<\mathrm{C}_{4} \mathrm{C}_{5} \mathrm{~S}_{1}$ & 111.518 \\
\hline & $\mathrm{C}_{6}-\mathrm{C}_{7}$ & 1.403 & $<\mathrm{C}_{2} \mathrm{~S}_{1} \mathrm{C}_{5}$ & 91.322 \\
\hline & $\mathrm{C}_{6}-\mathrm{C}_{11}$ & 1.406 & $<\mathrm{C}_{3} \mathrm{C}_{6} \mathrm{C}_{7}$ & 121.416 \\
\hline & $\mathrm{C}_{7}-\mathrm{C}_{8}$ & 1.394 & $<\mathrm{C}_{3} \mathrm{C}_{6} \mathrm{C}_{11}$ & 120.968 \\
\hline & $\mathrm{C}_{8}-\mathrm{C}_{9}$ & 1.400 & $<\mathrm{C}_{7} \mathrm{C}_{6} \mathrm{C}_{11}$ & 117.617 \\
\hline & $\mathrm{C}_{9}-\mathrm{C}_{10}$ & 1.402 & $<\mathrm{C}_{6} \mathrm{C}_{7} \mathrm{C}_{8}$ & 121.061 \\
\hline & $\mathrm{C}_{9}-\mathrm{C}_{12}$ & 1.511 & $<\mathrm{C}_{7} \mathrm{C}_{8} \mathrm{C}_{9}$ & 121.322 \\
\hline$\underline{1} \underline{\underline{b}}$ & $\mathrm{C}_{10}-\mathrm{C}_{11}$ & 1.391 & $<\mathrm{C}_{8} \mathrm{C}_{9} \mathrm{C}_{10}$ & 117.639 \\
\hline & & & $<\mathrm{C}_{8} \mathrm{C}_{9} \mathrm{C}_{12}$ & 121.476 \\
\hline & & & $<\mathrm{C}_{10} \mathrm{C}_{9} \mathrm{C}_{12}$ & 120.885 \\
\hline & & & $<\mathrm{C}_{9} \mathrm{C}_{10} \mathrm{C}_{11}$ & 121.281 \\
\hline & & & $<\mathrm{C}_{6} \mathrm{C}_{11} \mathrm{C}_{10}$ & 121.077 \\
\hline
\end{tabular}


Table 12: Continued

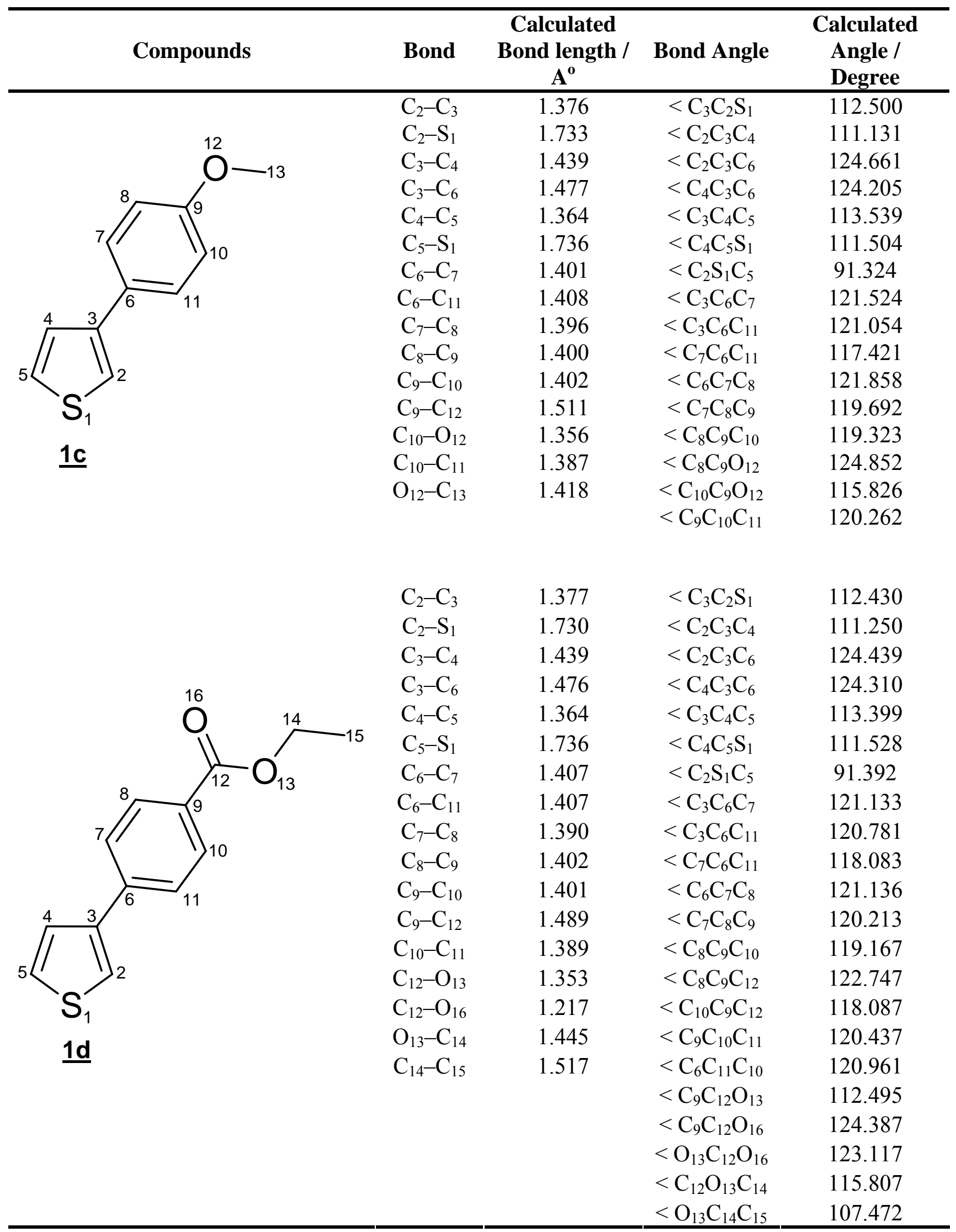


Table 12: Continued

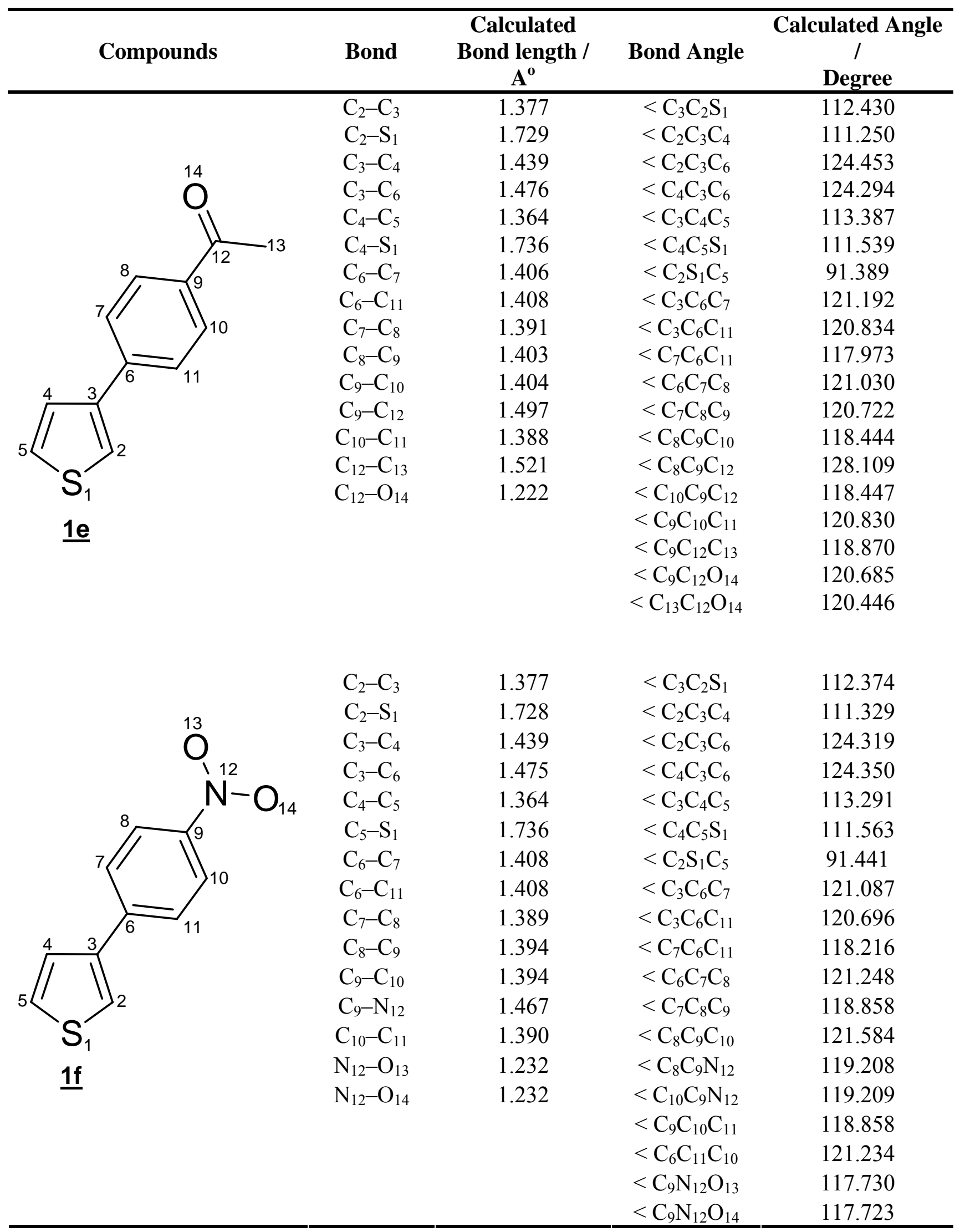


Table. 13. :HOMO, LUMO, bandgap, total energy and ionization potential of 3-phenylthiophenes (1a-1f).

\begin{tabular}{cccccccc}
\hline $\begin{array}{c}\text { Compund } \\
\text { No }\end{array}$ & $\begin{array}{c}\text { HOMO / } \\
\mathbf{e V}\end{array}$ & $\begin{array}{c}\text { LUMO } \\
\text { / eV }\end{array}$ & $\begin{array}{c}\text { Bandgap } \\
/ \mathbf{e V}\end{array}$ & $\begin{array}{c}\text { Total energy } \\
\text { /kcal mol }^{-1}\end{array}$ & $\begin{array}{c}\text { IP for } \\
\text { neutral } \\
/ \mathbf{e V}\end{array}$ & $\begin{array}{c}\text { IP for } \\
\text { radical / } \\
\mathbf{e V}\end{array}$ & $\begin{array}{c}\Delta \mathbf{I P} / \\
\mathbf{e V}\end{array}$ \\
\hline 1a & -5.907 & -0.698 & 5.209 & $-4.920 \times 10^{5}$ & 8.636 & 1.274 & 7.362 \\
\hline $\mathbf{1 b}$ & -5.762 & -0.640 & 5.122 & $-5.167 \times 10^{5}$ & 8.394 & 0.688 & 7.706 \\
\hline 1c & -5.484 & -0.513 & 4.971 & $-5.639 \times 10^{5}$ & 8.200 & 0.804 & 7.396 \\
\hline 1d & -6.118 & -1.426 & 4.692 & $-6.597 \times 10^{5}$ & 8.930 & 1.125 & 7.805 \\
\hline 1e & -6.171 & -1.664 & 4.507 & $-5.878 \times 10^{5}$ & 8.905 & 1.140 & 7.765 \\
\hline 1f & -6.535 & -2.454 & 4.081 & $-6.203 \times 10^{5}$ & 9.340 & 1.350 & 7.990 \\
\hline
\end{tabular}

Since the oxidation of a dimer is easier than that of a monomer, the radical cation of the dimer also formed undergoes further coupling reactions with other radical cations. Fig. 33 lists the calculated total atomic spin densities of radical cations of 3-phenylthiophenes with their calculated ionization potentials $\left(I_{p}\right)$ and the ratios $\left(r_{25}\right)$ of the spin density at carbon $2(\mathrm{C}-2)$ to that of carbon $5(\mathrm{C}-5)$. The highest spin densities are observed at $\mathrm{C}-2$ of the thiophene rings for all molecules. In addition, high spin densities are located on the carbon $9(\mathrm{C}-9)$ of the phenyl rings of the 3-phenylthiophenes. In contrast, very low spin densities are obtained at carbon $4(\mathrm{C}-4)$ of the thiophene rings for all molecules. These facts indicate that the reactivity for the propagation reactions of the radical cations can be deduced from the differences between the spin densities at $\mathrm{C}-2$ and $\mathrm{C}-5$.

A significantly asymmetric distribution of the spin densities between $\mathrm{C}-2$ and $\mathrm{C}-5$ is observed in all 3-phenylthiophenes, especially in the case of the 4-methoxyphenyl compound (1c). We suggest that a value of $r_{25}$ larger than 2.0 indicates a strong directing power of reactivity of radical cations. The calculated spin densities of 3-(4- methylphenyl)thiophene and subsequently deduced substitution patterns agree well with results of the successful synthesis of regioregular head to tail (HT) poly-(3-(4-octylphenyl)thiophene), poly(3-(4-dodecylphenyl)thiophene), and poly(3-(4-butylphenyl)thiophene [191-193].

A methoxy group on the phenyl ring provides the largest directing power in all molecules considered $\left(r_{25}=5.674\right)$. In addition, this molecule exhibits the lowest ionization potential, indicating the highest facility of oxidation to radical cation. However, Andersson et al. reported that 3-(4-alkoxy)phenylthiophenes gave only regioirregular polymers with low molecular weights [194]. It should be noted that the large $r_{25}$ value of 3-(4-methoxy)phenylthiophene originates from the significant decrease in the spin density at $\mathrm{C}-5$, and its 


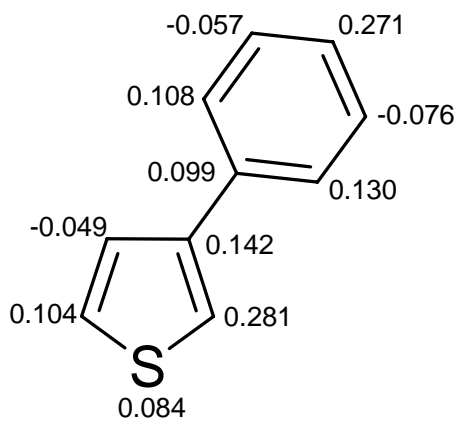

$$
\text { Ip }=7.362 \quad r_{25}=2.702
$$

$1 a$
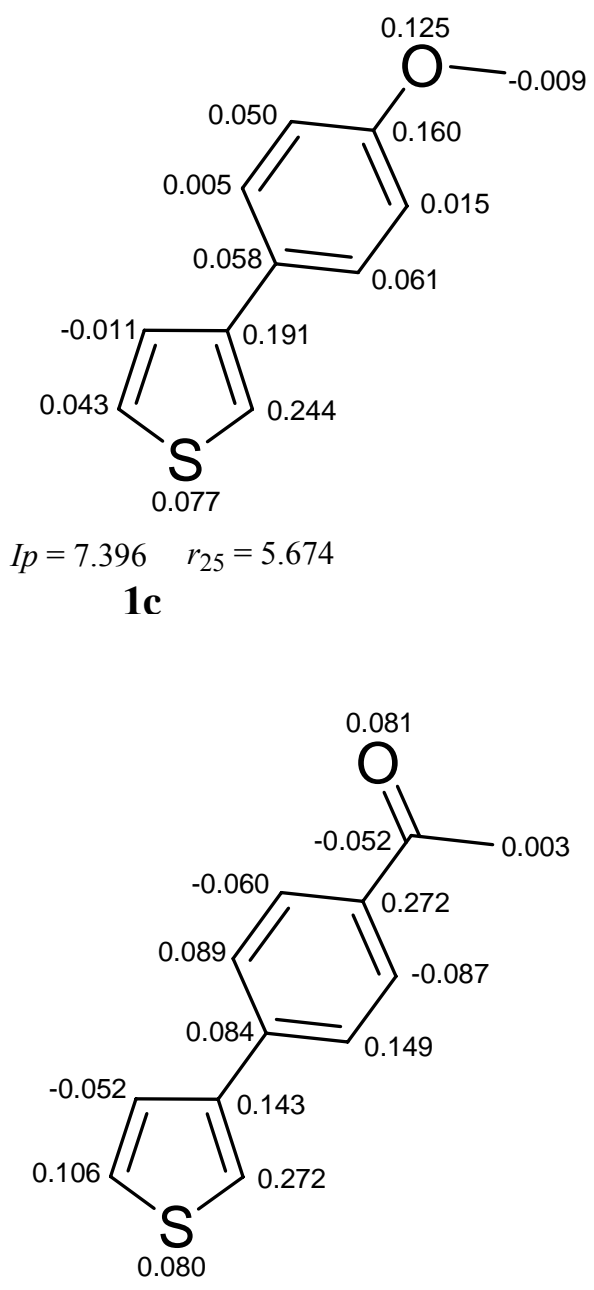

$I p=7.765 \quad r_{25}=2.566$

1e

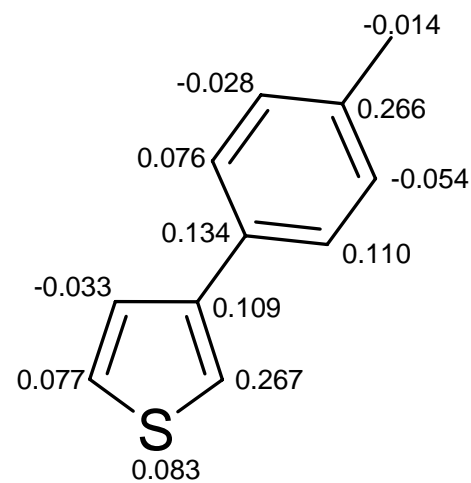

$I p=7.706 \quad r_{25}=3.468$

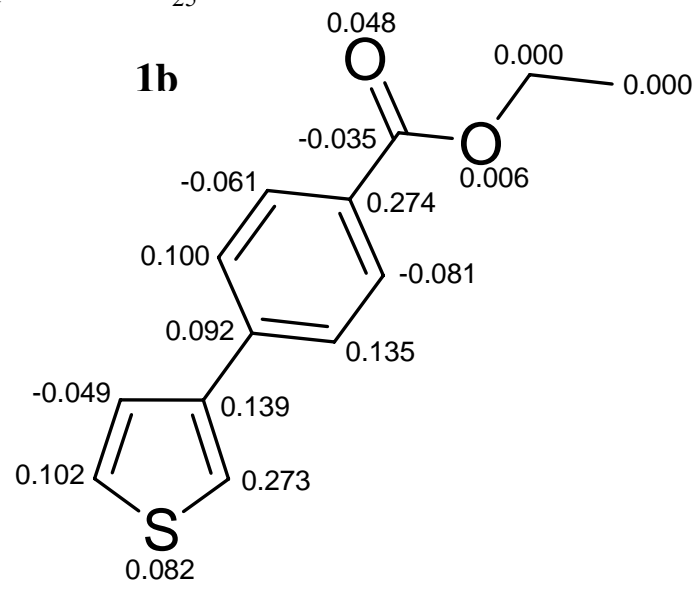

$I p=7.805 \quad r_{25}=2.677$

$1 d$

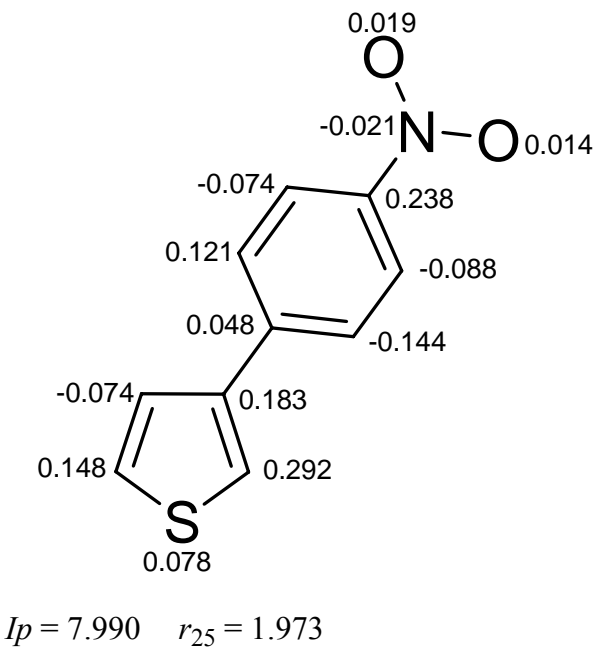

1f

Figure 33. Calculated total atomic spin densities cations for 3-phenylthiophene derivatives with their calculated ionization potentials $\left(I_{p}\right)$ and the ratios of the spin density at 2-position to that of 5-position. 
value $(0.043)$ is the lowest in the thiophenes considered. The very low spin density leads to the low molecular weight of poly-(3-(4-alkoxy) phenylthiophene) because the HT coupling between $\mathrm{C}-2$ and $\mathrm{C}-5$ of two radical cations should be the predominant initiating reaction for 3-phenylthiophene as described later.

It has been reported that when a large substituent is attached to 3-position of thiophene, polymerization reaction does not necessarily proceed efficiently and large quantities of short chain oligomers are formed [36]. Note that the 3-phenylthiophene derivatives have twisted conformations in the optimized geometries of these derivatives in the neutral state, but in the radical cations it takes coplanar conformations. For instance, the optimized torsion angle between the benzene and thiophene rings of 3-phenylthiophene is $32^{\circ}$ (see Table 14) in the neutral state, but its radical cation takes a coplanar structure (the torsion angle is $0^{\circ}$ ). Although steric effects of substituents do not hinder the formation of the radical cation of thiophene, it turns out to be important in the subsequent coupling reaction, when a bulky substituent is attached to $\mathrm{C}-3$ of thiophene.

Steric effect should play an important role in the coupling reactions of 3phenylthiophenes. Since the radical cations have coplanar structures, the distance between the hydrogen at C-2 and the closest hydrogen in phenyl group is only $2.1 \AA[195,196]$. Fig. 34 shows a plausible structure of two radical cations of 3-phenyl thiophene approaching each other. The generation of Head-to-head $(\mathrm{HH})$ linkage would be hindered due to the significant steric effect between thiophene rings and phenyl rings. Accordingly, the first coupling would predominantly generate a HT linkage resulting in formation of a high content of the Head-totail (HT) dimer. This view agrees well with the experimental results with poly(3-(4dodecylphenyl)thiophene) and poly(3-(4-butylphenyl)thiophene) [192, 193].

Table. 14. Torsion angles of 3-phenylthiophenes (1a-1f) calculated by B3LYP/ 6-31G(d).

\begin{tabular}{ccc}
\hline Compound No & Torsion Angles & $\begin{array}{c}\text { Torsion Angles / } \\
\text { Degree }\end{array}$ \\
\hline \multirow{1}{1}{$\mathbf{a}$} & $<\mathrm{C}_{2} \mathrm{C}_{3} \mathrm{C}_{6} \mathrm{C}_{7}$ & -31.960 \\
& $<\mathrm{C}_{4} \mathrm{C}_{3} \mathrm{C}_{6} \mathrm{C}_{11}$ & -32.035 \\
\hline \multirow{1}{*}{$\mathbf{b}$} & $<\mathrm{C}_{2} \mathrm{C}_{3} \mathrm{C}_{6} \mathrm{C}_{7}$ & -31.515 \\
& $<\mathrm{C}_{4} \mathrm{C}_{3} \mathrm{C}_{6} \mathrm{C}_{11}$ & -31.664 \\
\hline \multirow{2}{*}{$\mathbf{1 c}$} & $<\mathrm{C}_{2} \mathrm{C}_{3} \mathrm{C}_{6} \mathrm{C}_{7}$ & -31.849 \\
& $<\mathrm{C}_{4} \mathrm{C}_{3} \mathrm{C}_{6} \mathrm{C}_{11}$ & -32.005 \\
\hline \multirow{2}{*}{$\mathbf{1 d}$} & $<\mathrm{C}_{2} \mathrm{C}_{3} \mathrm{C}_{6} \mathrm{C}_{7}$ & -30.188 \\
& $<\mathrm{C}_{4} \mathrm{C}_{3} \mathrm{C}_{6} \mathrm{C}_{11}$ & -29.989 \\
\hline \multirow{2}{*}{$\mathbf{1 e}$} & $<\mathrm{C}_{2} \mathrm{C}_{3} \mathrm{C}_{6} \mathrm{C}_{7}$ & -29.933 \\
& $<\mathrm{C}_{4} \mathrm{C}_{3} \mathrm{C}_{6} \mathrm{C}_{11}$ & -29.756 \\
\hline \multirow{2}{*}{$\mathbf{1 f}$} & $<\mathrm{C}_{2} \mathrm{C}_{3} \mathrm{C}_{6} \mathrm{C}_{7}$ & -29.517 \\
& $<\mathrm{C}_{4} \mathrm{C}_{3} \mathrm{C}_{6} \mathrm{C}_{11}$ & -29.207 \\
\hline
\end{tabular}




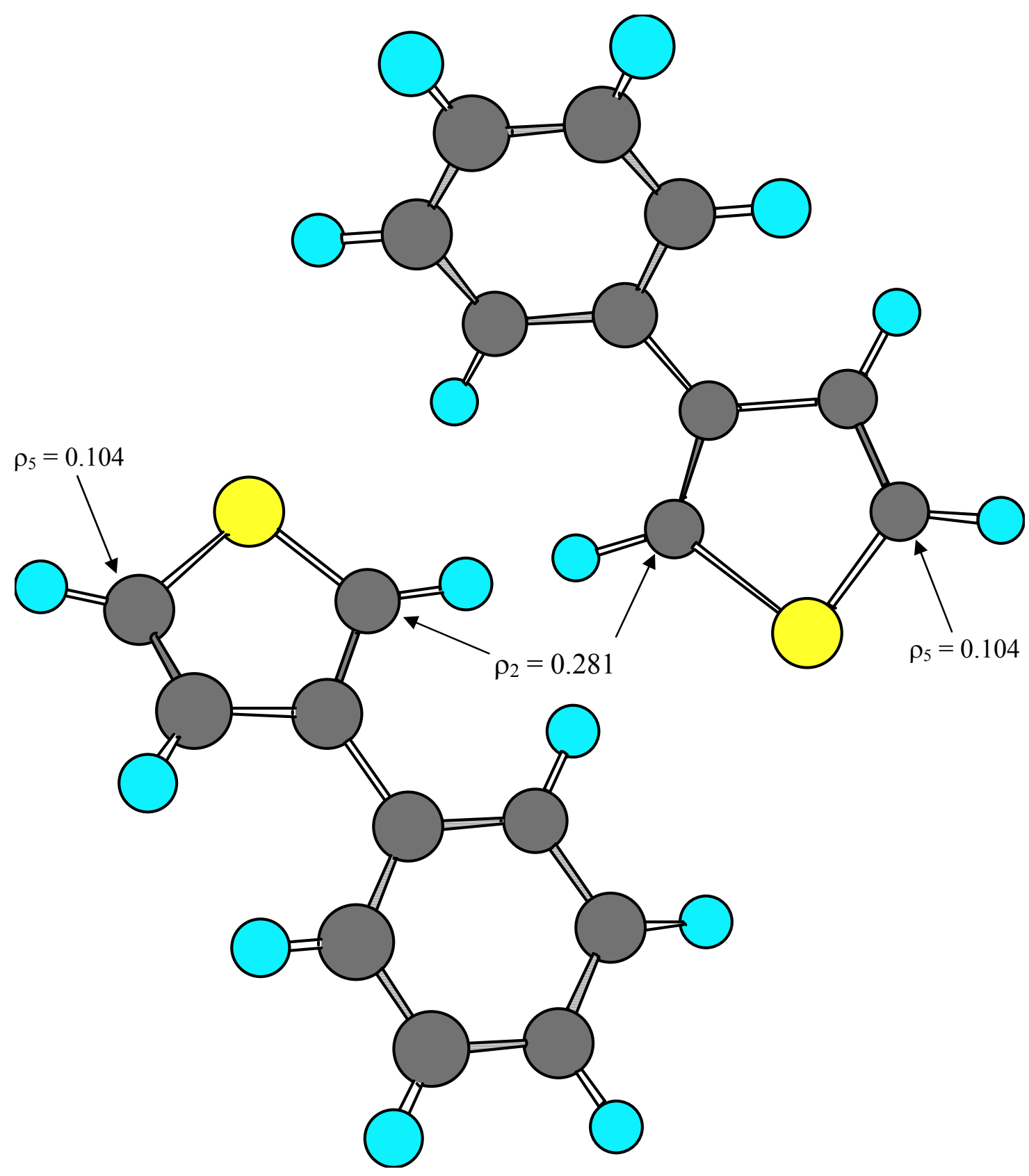

Figure 34. Two radical cations of 3-phenylthiophene are approaching each other with facing their 2-position. The calculated spin densities $(\rho)$ are indicated. 
Hayakawa et al. reported the calculated local spin densities of the monomer and dimers of 3-(4-butylphenyl)thiophene [193]. The spin density at C-5 of the HT dimer (0.315) is significantly higher than that of C-2 of the monomer (0.260). This indicates that the HT dimer is the most reactive species in the case of 3-(4-alkylphenyl)thiophene. Thus, the HT dimer of 3-(4-alkylphenyl)thiophenes should play an important role in the succeeding coupling reactions because of the low probability of $\mathrm{HH}$ coupling. Another important feature of the structure of the HT dimer radical cation of 3-(4-butylphenyl)thiophenes is the absence of the coplanar conformation (the actual torsion angle is $154^{\circ}$ ) of the two thiophene rings. In addition, the thiophene ring and the phenyl ring are not located in the same plane (the torsion angle is $40^{\circ}$ ). This non-coplanar conformation provides good solubility of the radical cations of the dimer, oligomer and polymers. The fact that a small amount of $\mathrm{HH}$ dimer remains unreacted at the later stage $(24 \mathrm{~h})$ of polymerization of 3-(4-butylphenyl)thiophene indicates that the $\mathrm{HH}$ dimer is not the initial species of the polymerization because the $\mathrm{HH}$ dimer exhibits the lowest spin density of the three dimers (2a-c) (see Fig.35), although the yields slightly decreased with increasing polymerization time because of decreasing concentrations of highly reactive species, that is, monomer, HT dimer, and HT oligomers. As a consequence, polymers with over $90 \%$ of HT contents have been obtained for 3-(4-butylphenyl)thiophene through the highly regioselective HT coupling reactions among HT dimers, HT oligomers, and/or monomers [193]. However, this is not the case for 3-(4-alkoxyphenyl)thiophenes because of the low probability of HT coupling between two monomer radical cations [197, 198].

The spin density at C-2 of the radical cation of 3-phenylthiophene (1) is larger than that at $\mathrm{C}-5$ as shown in Fig. 35. This implies that the former is more reactive than the latter. When two molecules of $\mathbf{1}$ are chemically coupled, three regioisomeric coupling products, Head to Head (HH) (2a), Head to Tail (HT) (2b) and Tail to Tail (TT) (2c), can be generated. Although each dimer has two preferential conformers, i.e. syn and anti, we consider only anti forms because the calculated total energies of the $s y n$ forms of $\mathbf{2 a}, \mathbf{2} \mathbf{b}$, and $\mathbf{2 c}$ are higher than those of the anti forms by $1.241,0.097$ and $0.551 \mathrm{kcal} / \mathrm{mol}$, respectively. In addition, syn conformers are rarely found in the crystallographic structures of thiophene oligomers. The proportions of the three types of coupling reactions that generate $\mathbf{2 a}-\mathbf{c}$ can be inferred from the magnitude of calculated total atomic spin densities and the steric effect of the substituents. For 
examining the initiating and propagating reactions, it is reasonable to assume that coupling reactions preferentially occur between the carbons having higher spin densities [199].

Fig. 35 summarizes the reaction paths of the succeeding coupling reactions of $\mathbf{1}$ based on the calculated spin densities. As already discussed, polymerization may proceed through the formation of HT linkages such as HT (2b) dimers and HT oligomers due to the high spin density at the 2-position $(\mathrm{C}-2)$ and the steric hindrance between phenyl groups of the monomer, but smaller amounts of the other formations, that is HH (2a) or TT (2c) linkage, simultaneously occurred.

The calculated spin densities at the termini of the oligomers thus generated are shown in brackets in Fig. 35. In case that the HT coupling of radical cation $\mathbf{1}$ occurs preferentially in the initiating reaction and the generation of $\mathbf{2 a}$ is negligibly small, the most reactive species is a radical cation 1 throughout the reactions. Considering the calculated spin density and steric hindrance of each oligomer, the most probable path of propagation is $\mathbf{1} \rightarrow \mathbf{2} \mathbf{b} \rightarrow \mathbf{3 a} \rightarrow \mathbf{4 a}$ $\rightarrow 5 \mathbf{a} \rightarrow \mathbf{6 a}$ as shown in Fig. 35. This agrees well with the experimental results mentioned above. For instance, when a tetramer is formed from 3a and 1, two regio-isomers can be generated. The spin density of $\mathbf{3 a}$ at the right terminus $(0.177)$ is significantly higher than that of the left terminus (0.092), it is expected that the coupling is formed between the right terminus (0.177) and the carbon, which possess higher spin density $(\mathrm{C}-2)$ of radical cation 1. However, due to the steric hindrance between phenyl and thiophene ring, the coupling is through the right terminus $(0.177)$ of $\mathbf{3 a}$ and the carbon $(\mathrm{C}-5)$, which possess lower spin density $(0.104)$ of the radical cation $\mathbf{1}$. Thus, tetramer 4a should be preferentially formed. The same situation occurs for the reaction of 5a and 1. Repeating this process, the resultant polymer has HT linkage. In Fig. 35, thick lines indicate the favorite path of oligomerization, and pathways unfavorable are indicated by dotted lines. Although the local spin densities at the reactive termini of oligomers gradually decrease as the number of thiophene rings increase, the second oxidation can reactivate the termini. In addition, it is known that the ionization potential gradually decreases as the number of thiophene rings increases [35]. Therefore, this fact indicates that the generated oligomers are immediately oxidized, and thereby, the oligomers exit as reactive cations in the solution. As long as the molar concentrations of oligomers are significantly lower than that of $\mathbf{1}$, the oligomers should sequentially react with a radical cation of $\mathbf{1}$. 


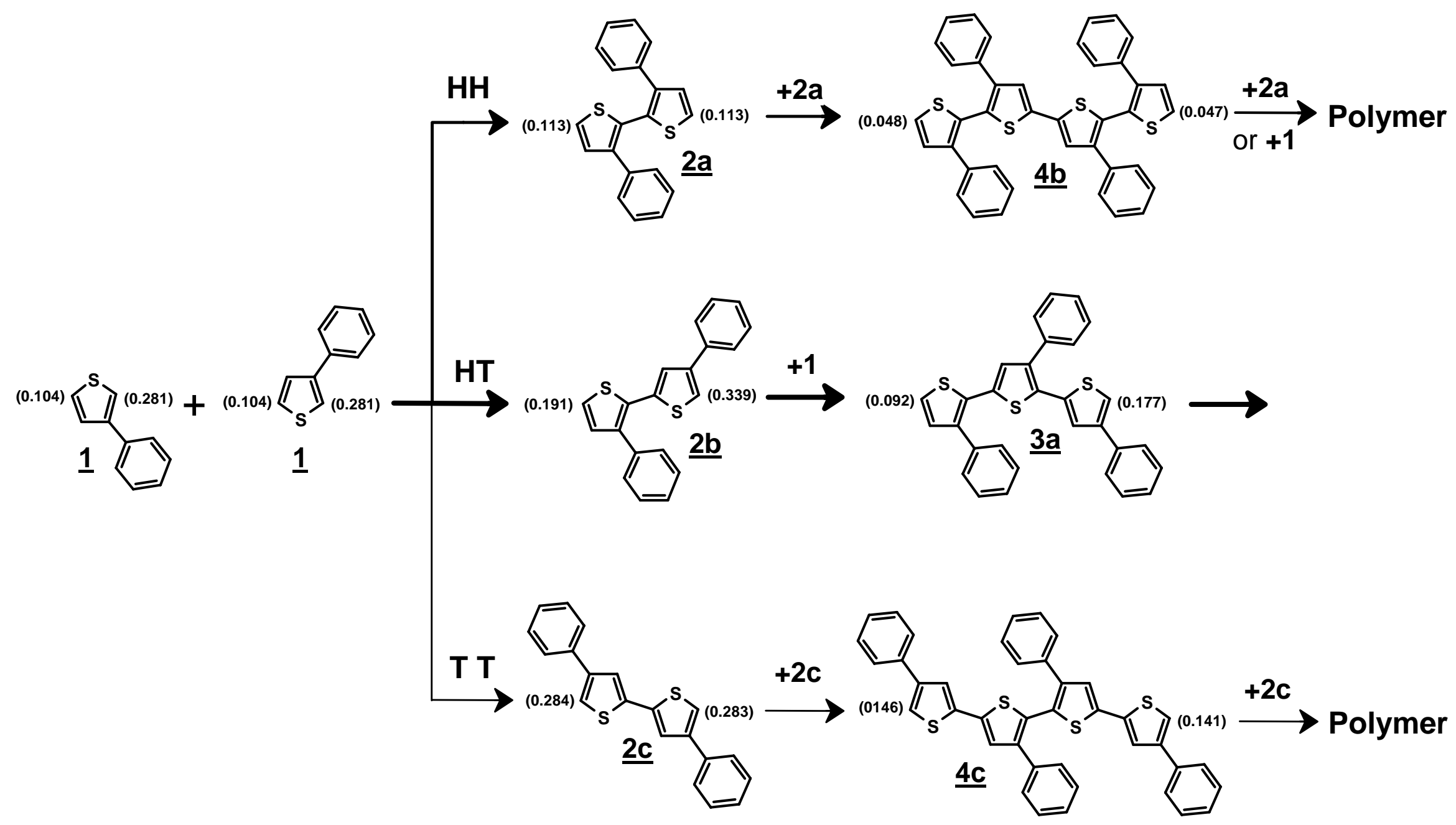

Figure 35: Reaction paths og the oligomerization of 3-phenyl thiophene. The calculated spin densities at termini are shown in brackets. The favorable path of oligomerization (see text) is indicated by thick lines, and paths unfavorable are indicated by dotted lines. Figure continued. 


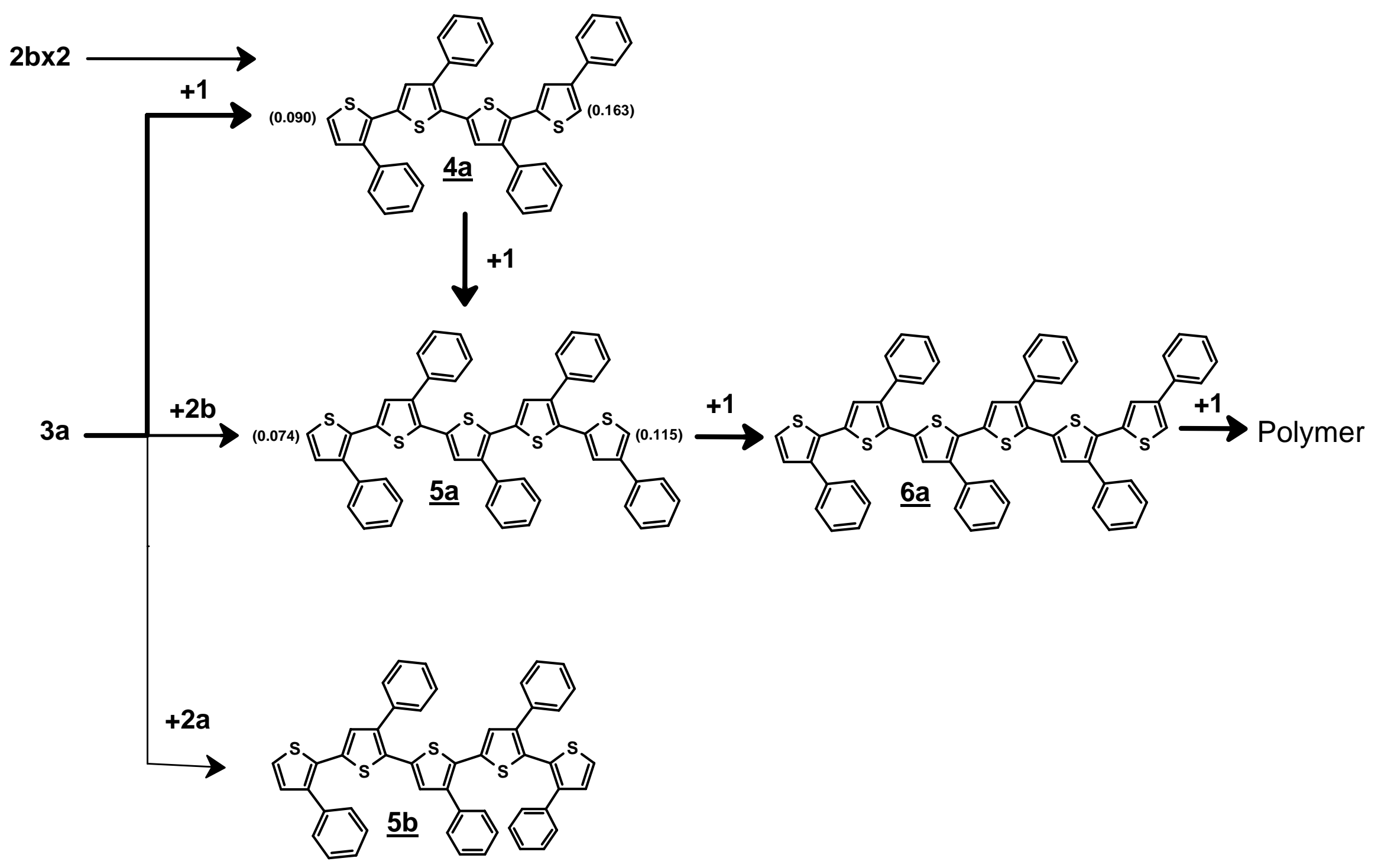

Figure 35: Continued from previous page . 


\section{Summary}

The work presented in this thesis include the synthesis of six monomers / polymers (PTB, PPT, PTAN, PETB, PTAP and PTNB). Their redox properties have been characterized by cyclic voltammetry. Using the Hammett model, the $\sigma$ values for monomers as well as $n$ - and $p$-doped polymers were found to be related to the electropolymerization potential. The semiemperical calculation gives a good correlation between the heat of formation and oxidation potentials of the monomers; on the other hand, the ionization potentials of the monomers calculated via density function theory show also better correlation with the oxidation potentials of the monomers.

The unpaired-electron spin densities of radical cations at C-2 and C-5 for 3phenylthiophene derivatives (1a-f) were calculated together with their ionization potentials. The substituted phenyl groups cause significantly asymmetric distributions in the spin densities, especially with the electron donating groups, which provides a strong directing power of reactivity for these radical cations.

The major regioselective products of propagation reactions of 3-phenylthiophene were well understood in terms of the magnitude of calculated spin densities of the oligomers. The Head to Tail (HT) dimer played an important role in the polymerization reactions of 3phenylthiophene derivatives (1a-f). This originates from the highest spin density at the $5^{\prime}-$ position of the dimer and the low probability of the Head to Head $(\mathrm{HH})$ coupling between monomers, which is due to the steric hindrance between thiophene ring and phenyl group.

The evolution of the in situ UV-Visible spectra of poly-3-phenylthiophene derivatives upon doping has been characterized by similar features as observed for many polythiophenes of high degree of conjugation. During stepwise oxidation of the poly-3-phenylthiophene films the intensity of the absorption due to the $\pi \rightarrow \pi *$ transition around 450-566 nm decreases and a new broad absorption band related to (bi)polaron states appears around 730-890 $\mathrm{nm}$. On the other hand, during the oxidation ( $p$-doping) of the poly-3-phenylthiophene films a blue/hypsochromic shift was observed for both absorption bands. It is explained by the fact that a polymer contains a distribution of chain lengths, and the longest polymer chains (the absorption of which occurs at lower energies) start to oxidize at lower potentials.

Bandgaps calculated from the electrochemical potentials for redox conversion have often been found to be higher than optical bandgaps. The poor agreement and the lack of standards 
in reporting and translating redox potentials suggest that the well known-established method of evaluating HOMO and LUMO positions by cyclic voltammetry may be a misleading method.

In situ resonance Raman spectroscopy has been demonstrated as a powerful tool for the elucidation of the molecular structure of electrochemically formed poly-3-phenylthiophene derivatives.

The green excitation line $\left(\lambda_{\text {exc }}=514.5 \mathrm{~nm}\right)$ was used to study resonance Raman spectra of polymers $(2 \mathbf{a}-\mathbf{d})$, while the yellow-green $(528.7 \mathrm{~nm})$ and blue $(488.0 \mathrm{~nm})$ lines were used to study resonance Raman spectra of polymers $2 \mathbf{e}$ and $\mathbf{2 f}$, respectively. However, assignments of the Raman bands were based on previous studies. In this way, comparisons with previously assigned bands of parent polymers permit to unambiguously assign some of the bands observed in our case to help choosing between possible assignments for the others.

From the Raman spectra of the polymers (2a-d), it was observed that with increasing electrode polarization potential, the overall intensity of the spectrum decreases, while the essential features of the spectrum remain unchanged. This means that the observed Raman bands originate from undoped segments of the polymer, which become less and less abundant with increasing doping level. The difference in the intensity might be attributed to a larger resonance effect of the reduced film, which is associated with a stronger UV-Vis absorption at the laser excitation wavelength $(514.5 \mathrm{~nm})$. However, the peaks in the spectrum of the polymers $2 \mathbf{e}$ and $\mathbf{2 f}$ vanished when the potential increased into the negative or positive direction. On the other hand, the disappearance of the bands in the region $1150-1600 \mathrm{~cm}^{-1}$ in the Raman spectrum of polymers $2 \mathbf{e}$ and $2 \mathbf{f}$ might be ascribed to the potency of the acyl and nitro groups as electron withdrawing group. Thus, the electron density within the polymer backbone decreases.

Finally, this dissertation deals with the synthesis and electropolymerization of a series of 3-phenylthiophene derivatives, new electroactive polymers. Polymers thus synthesized exhibit $n$-type doping, which is less commonly observed in the class of CPs 


\section{References:}

[1] A.F. Diaz, K.K. Kanazawa and G.P. Gardini, J. Chem. Soc., Chem. Commun., 1979, 635.

[2] A.R. Hepburn, J.M. Maud and J.M. Marshall, Met. Mater. (Inst. Mater.)., 7, 1991, 747.

[3] T.J. Yamamoto, J. Chem. Soc., Chem. Commun., 1981, 187.

[4] K.S.V. Santhanam and N. Gupta. TRIP 1.,1993, 284.

[5] M. Mastragostino, A.M. Marinangeli, A. Corradini and S. Giacobbe, Synth. Met., 28, 1989, C501.

[6] S. Panero, S. Passerini and B. Scrosati. Mol. Cryst. Liq. Cryst., 229, 1993, 97.

[7] J. C. Dubois, Synth. Met., 28, 1989, C871.

[8] J. Roncali, R. Garreau, D. Delabouglise, F. Garnier and M. Lemaire, J. Chem. Soc., Chem. Commun., 1989, 679.

[9] W.R. Salaneck, Science and applications of conducting polymers, Proc of the 6th Europhysics industrial workshop, Adam Hilger, 1991.

[10] D.D. C. Bradley, Chem. Ber., 8, 1991, 719.

[11] K. Davidson, Educ. Chem., 28, 1991, 155.

[12] A.F. Diaz, J. Electrochem. Soc., 123, 1989, 115.

[13] R.J. Waltman, Can. J. Chem., 64, 1986, 76.

[14] G. Tourillon and F. Garnier, J. Electroanal. Chem., 135, 1982, 173.

[15] R.J. Waltman, J. Bargon and A.F. Diaz, J. Phys. Chem., 87, 1983, 1459.

[16] T. Yamamoto, K. Sanechika and A. Yamamoto, J. Polym. Sci., Polym. Lett. Ed., 18, $1980,9$.

[17] G. Tourillon and F. Garnier, J. Electrochem. Soc., 130, 1983, 2042.

[18] S. Glenis, D.S. Ginley and A.J. Frank, J. Appl. Phys., 62, 1987, 190.

[19] A.G. Mc Diarmid, Polym. Prep. Am. Chem. Soc. Div. Polym. Chem., 25, 1984, 248.

[20] E. Genies and C. Tsintavis, J. Electroanal. Chem., 195, 1985, 109.

[21] T. Kobayashi, Yoneyama and H. Tamura, J. Electroanal. Chem., 177, 1984, 281.

[22] I. Rubenstein, E. Sabatini and J. Rishpan, J. Electroanal. Chem., 134, $1987,3078$.

[23] A.F. Diaz, J. Castillo, K.K. Kanazawa, J.A. Logan, M. Salmon and O. Fajardo, J. Electroanal. Chem., 133, 1982, 233.

[24] J. Bargon, S. Mohmand and R. Waltman, Mol. Cryst. Liq. Cryst., 93, 1983, 279.

[25] D.M. Ivory, J. Chem. Phys., 71, 1979, 1506. 
[26] M. Satoh, K. Kaneto and K. Yoshino, J. Chem. Soc., Chem. Commun., 1985, 1629.

[27] J.L. Bredas, R.R. Chance and R. Sileby, Phys. Rev., Part B., B26, 1982, 5843.

[28] J.L. Bredas, B. Themans, J. M. Andre, R.R. Chance, D.S. Boudreaux and R. Silbey, J. de Physique Colloque C3, 44, 1983, 373.

[29] J.L. Bredas and G.B. Street, Acc. Chem. Res., 18, 1985, 309.

[30] R. Qian and J. Qiu, Polym. J., 1, 1987, 157.

[31] J. Roncali, F. Garnier, M. Lemaire and R. Garreau, Synth. Met., 15, 1986, 323.

[32] Y. Ito, H. Shirakawa and S. Ikeda, J. Polym. Sci., 13, 1975, 1943.

[33] P. Kovacic and A. Kyriakis, J. Am. Chem. Soc., 85, 1963, 454.

[34] R.B. Kaner, Electrochemical Science and Technology of Polymers, R. G. Linford (Ed), 97, Elsevier Applied Science, Essex, England, 1990.

[35] E. M. Genies, G. Bidan and A.F. Diaz, J. Eletroanal. Chem., 149, 1983, 101.

[36] J. Roncali, Chem. Rev., 92, 1992, 711.

[37] G.P. Evans, Advances in Electrochemical Science and Engineering, Vol. 1, Cambridge Life Science, Cambridge, 1990.

[38] R. J. Waltman and J. Bargon, Tetrahedron., 40, 1984, 3963.

[39] D. J. Walton, Mater. Des., 11, 1990, 142.

[40] S. Hotta, T. Hosaka and W. Shimotsuma, Synth. Met., 6, 1983, 319.

[41] A.F. Diaz and J. Bargon, Handbook of Counducting Polymers, T. J. Skotheim (Ed.), Marcel Dekker, New York, 1986, p. 81.

[42] R. Jansson, M. Armin, R. Bjorklund and I. Lundstrom, Thin Solid Films., 125, 1985, 205.

[43] A.R. Hillman and E.F. Mallen, J. Electroanal. Chem., 220, 1987, 351.

[44] G. Dian, G. Barbey and B. Decroix, Synth. Met., 13, 1986, 281.

[45] D.T. Glazhofer, J. Ulanski and G. Wegner, Polymer, 28, 1987, 449.

[46] M.-A. Sato, S. Tanaka and K. Kaeriyama, J. Chem. Soc., Chem. Commun., 1985, 713.

[47] A. Czerwinski, H. Zimmer, C.V. Pham and H.B. Mark Jr., J. Electrochem. Soc., 132, 1985, 2669.

[48] T.C. Chung, J.H. Kaufman, A.J. Heeger and F. Wudl, Phys. Rev., 330, 1984, 702.

[49] O. Inganäs, B. Liedberg, W. Chang-Ru and H. Wynberg, Synth. Met., 11, 1985, 239.

[50] A.F. Diaz, J. Crowely, J. Bargon, G.P. Gardini and J.B. Torrance, J. Electroanal. Chem., 121, 1981, 355. 
[51] G.P. Evans, Advances in Electrochemical Science and Engineering, Vol.1, Cambridge Life Science, Cambridge, 1990.

[52] K.Y. Jen, G.G. Miller and R. L. Elsenbaumer, J. Chem. Soc., Chem. Commun., 1986, 1346.

[53] M.-A. Sato, S. Tanaka and K. Kaeriyama, J. Chem. Soc., Chem. Commun., 1986, 873.

[54] M.R. Bryce, A. Chissel, P. Kathirgamanathan, D. Parker and N.R.M. Smith, J. Chem. Soc., Chem. Commun., 1986, 466.

[55] R.A. Zoppi and M.-A. De Paoli, Quim. Nova, 16, 1993, 560.

[56] J.L Bredas, R. Silby, D.S. Boudreaux and R.R. Chance, J. Am. Chem. Soc., 105, 1983, 6555.

[57] J.L Bredas, R.L. Elsenbaumer, R.R. Chance and R. Silby, J. Chem. Phys., 78, 1983, 5656.

[58] J.L Bredas, G.B. Street, B. Themans and J.M. Andre, J. Chem. Phys., 83, 1985, 1323.

[59] G. Distefano, M. Dal Colle, D. Jones, M. Zambianchi, L. Favaretto and A. Modelli., J. Phys. Chem., 97, 1993, 3504.

[60] T. Jurimae, M. Strandberg, M. Karelson and J-L. Calais, Int. J. Quant. Chem., 54, 1995, 369.

[61] H.F. Dos Santos, W.R. Rocha and W.B. De Ameida, Annals of the 3rd Brazilian Congress of Polymer Rio de Janeiro, 1995, 1199-1202.

[62] B.E. Conway, Proc. Electrochem. Soc., 92-93, 1993, 15.

[63] A.Rudge, J. Davey, I. Raistrick, S. Gottesfeld and J.P. Ferraris, J. Power Sources., 47, 1994, 89.

[64] A. Nishino, J. Power Sources, 60, 1996, 137.

[65] A. Rudge, J. Davey, I. Raistrick, S. Gottesfeld and J.P. Ferraris, Electrochimica Acta, 39, 1994, 273.

[66] S. Gau, J. Milliken, A. Pron, A. MacDiarmid and A. Heeger, J. Chem. Soc, Chem. Commun.,1979, 662.

[67] J.P. Ferraris, M.M. Eissa, I.D. Brotherston, D.C. Loveday and A.A. Moxey, J. Electroanal.Chem, 459, 1998, 57.

[68] J.P. Ferraris, M.M. Eissa, I.D. Brotherston and D.C. Loveday, Chem. Mater, 10, 1998, 3528.

[69] J.P. Ferraris, I.D. Brotherston, D.C. Loveday, D.S.K. Mudigonda and L. Li, Electrochem, Soc. Proc, 98-15, 1998, 671. 
[70] M. Sato, S. Tanaka and K. Kaeriyama. J. Chem. Soc., Chem. Commun. 1987, 1725.

[71] M. Sato, S. Tanaka and K. Kaeriyama. Makromol. Chem. 190, 1989, 1233.

[72] M. Onoda, H. Nakayama, S. Morita and K. Yashino. Synth. Met. 55-57, 1993, 275.

[73] D.J. Guerrero, X. Ren and J. P. Ferraris. Chem. Mater. 6, 1994, 1437.

[74] H. Shirakawa, E.J. Louis, A.G. MacDiarmid, C.K. Chiang and J.A. Heeger, J. Chem. Soc., Chem. Commun., 1977, 578.

[75] T. A. Scotheim, Handbook of Conducting Polymers, Marcel Dekker, New York, 1966.

[76] H.S. Nalwa, Handbook of Organic Conductive Molecules and Polymers, John Wiley\& Sons, Chichester, 1997.

[77] S.R. Forrest, Chem. Rev., 97, 1997, 1736.

[78] J.L. Bredas, R. Silbey, D.S. Boudreaux and R.R. Chance, J. Am. Chem. Soc., 105, 1983,6555 .

[79] J.L. Bredas, R.L. Elsenbaumer, R.R. Chance and R. Silbey, J. Chem. Phys., 78, 1983, 5656.

[80] J.L. Bredas, G.B. Street, B. Themams and J.M. Andre, J. Chem. Phys., 83, 1985, 1323.

[81] G. Distefano, M. Dal Colle, D. Jones, M. Zambianchi, L. Favaretto and A. Modelli, J. Phys.Chem., 97, 1993, 3504.

[82] H. Wynberg, H. Van Driel, R.M. Kellogg and J. Buter. J.Am.Chem.Soc. 89, 1967, 3487.

[83] R. D Rieke, S-Hoi. Kim and X. Wu. J.Org.Chem, 62, 1997, 6921.

[84] G. Gritzner and J. Kuta. Pure Appl.Chem. 56, 1984, 461.

[85] P. Hohenberg and W. Kohn, Phys. Rev. 136, 1964, B864.

[86] W. Kohn and L.J. Sham, Phys. Rev. 140, 1965, A1133.

[87] The Challenge of $d$ and f Electrons, Ed. D. R. Salahub and M. C. Zerner, ACS, Washington, D.C., 1989.

[88] R.G. Parr and W. Yang, Density-functional theory of atoms and molecules, Oxford Univ. Press, Oxford, 1989.

[89] R. Ditchfield, W.J. Hehre, and J.A. Pople, J. Chem. Phys. 54, 1971, 724.

[90] W.J. Hehre, R. Ditchfield, and J. A. Pople, J. Chem. Phys. 56, 1972, 2257.

[91] P.C. Hariharan and J.A. Pople, Mol. Phys. 27, 1974, 209.

[92] M.S. Gordon, Chem. Phys. Lett. 76, 1980, 163.

[93] P.C. Hariharan and J.A. Pople, Theo. Chim. Acta 28, 1973, 213. 
[94] J.-P. Blaudeau, M.P. McGrath, L.A. Curtiss and L. Radom, J. Chem. Phys. 107, 1997, 5016.

[95] M.M. Francl, W.J. Pietro, W.J. Hehre, J.S. Binkley, D.J. DeFrees, J.A. Pople and M.S. Gordon, J. Chem. Phys. 77, 1982, 3654.

[96] R.C. Binning Jr. and L.A. Curtiss, J. Comp. Chem. 11, 1990, 1206.

[97] V.A. Rassolov, J.A. Pople, M.A. Ratner and T.L. Windus, J. Chem. Phys. 109, 1998, 1223.

[98] V.A. Rassolov, M.A. Ratner, J.A. Pople, P.C. Redfern and L.A. Curtiss, J. Comp. Chem. 22, 2001, 976.

[99] G.A. Petersson and M.A. Al-Laham, J. Chem. Phys. 94, 1991, 6081.

[100] G.A. Petersson, A. Bennett, T.G. Tensfeldt, M.A. Al-Laham, W.A. Shirley and J. Mantzaris, J. Chem. Phys. 89, 1988, 2193.

[101] J.S. Binkley, J.A. Pople and W.J. Hehre. J. Amer. Chem. Soc. 102, 1980, 939.

[102] M.S. Gordon, J.S. Binkley, J.A. Pople, W.J. Pietro and W.J. Hehre, J. Amer. Chem. Soc. 104, 1982, 2797.

[103] W.J. Pietro, M.M. Francl, W.J. Hehre, D.J. Defrees, J.A. Pople and J.S. Binkley, J. Amer. Chem. Soc.104, 1982, 5039.

[104] K.D. Dobbs and W.J. Hehre, J. Comp. Chem., 7, 1986, 359.

[105] K.D. Dobbs and W.J. Hehre, J. Comp. Chem., 8, 1987, 861.

[106] K.D. Dobbs and W.J. Hehre, J. Comp. Chem., 8, 1987, 880.

[107] T. Clark, J. Chandrasekhar, G.W. Spitznagel and P.V.R. Schleyer, J. Comp. Chem. 4, 1983, 294.

[108] M. Pelletier and F. Brisse, Acta Crystallogr., Section C. Cryst. Struct. Commun. 50, 1994, 1942.

[109] E.F. Paulus, R. Dammel, G. Kampf, P. Wegener, K. Siam, K. Wolinski and L. Schafer, Acta Crystallogr., Section B, Struct. Sci. 44, 1988, 509.

[110] G. Barbarella, M. Zambianchi, A. Bongini and L. Antolini, Adv. Mater. 4, 1992, 282.

[111] M. Dewar and W. Thiel, J. Am. Chem. Soc. 99, 1977, 4499.

[112] Gaussian 98, Revision A.3, M.J. Frisch, G.W. Trucks, H.B. Schlegel, G.E. Scuseria, M. Robb, J. R.Cheeseman, V.G. Zakrzewski, J.A. Montgomery, Jr., R.E. Stratmann, J. C. Burant, S. Dapprich, J.M. Millam, A.D. Daniels, K.N. Kudin, M.C. Strain, O. Farkas, J. Tomasi, V. Barone, M. Cossi, R. Cammi, B. Mennucci, C. Pomelli, C.Adamo, 
S. Clifford, J. Ochterski, G.A. Petersson, P.Y. Ayala, Q. Cui, K. Morokuma, D.K. Malick, A.D. Rabuck, K. Raghavachari, J.B. Foresman, J. Cioslowski, J.V. Ortiz, B.B. Stefanov, G. Liu, A. Liashenko, P. Piskorz, I. Komaromi, R. Gomperts, R.L. Martin, D. J. Fox, T. Keith, M.A. Al-Laham, C.Y. Peng, A. Nanayakkara, C. Gonzalez, M. Challacombe, P.M. W. Gill, B. Johnson, W. Chen, M.W. Wong, J.L. Andres, C. Gonzalez, M. Head-Gordon, E.S. Replogle, and J.A. Pople, Gaussian, Inc., Pittsburgh, 1998.

[113] J. Roncali, F. Garnier, New J. Chem., 4-5, 1986, 237.

[114] J. Roncali and F. Garnier, J. Phys. Chem., 92, 1988, 833.

[115] U. Schlick, F. Teichert and M. Hanack, Synth. Met., 92, 1998, 75.

[116] P. Marque, J. Roncali and F. Garnier, J. Electroanal. Chem. 218, 1987, 107.

[117] M. Ue, K. Ida and S. Mori, J. Electrochem. Soc. 141,1994, 2989.

[118] J. Barthel, H. J. Gores, G. Schmeer and R. Wechter, Top. Curr. Chem. 111, 1983, 33.

[119] R. Borjas and D. A. Buttry. Chem. Mater. 3, 1991, 872.

[120] M. Mastragostino and L. Soddn, Electrochim. Acta. 35, 1990, 463

[121] V.D. Pokhodenko and V.A Krylov. Synth. Met. 41-43, 1991, 533.

[122] J.F. Ambrose and R.F. Nelson. J. Electrochem. Soc. 92, 1968, 1161.

[123] R.N. Adams,. Acc. Chem. Res. 2,1969,175.

[124] J. March. Advanced Organic Chemistry, $4^{\text {th }}$ ed.; John Wiley \& Sons: New York, 1992; PP 280ff.

[125] Y. Gofer, J.G. Killian, H. Sarker, T.O. Pochler and P.C. Searson. J. Electroanal. Chem. 413, 1998, 103.

[126] R.J. Wahman, J. Bargon and A.F. Diaz. J. Phys. Chem. 87, 1983, 1459.

[127] R.J. Wahman, A.F. Diaz and J. Bargon. J. Phys. Chem. 88, 1984, 4343.

[128] H. Sarker, Y. Gofer, J.G. Killian, T.O. Pohler and P.C. Searson, Synth. Met. 88, 1997, 179.

[129] E. Kinbara, Y. Kunugi, Y. Harima and K. Yamashita. Synth. Met. 114, 2000, 295.

[130] J. Roncali, Chem. Rev. 97, 1997, 173.

[131] C.-C. Chung, J.H. Kanfman, A.J. Heeger and F. Wudl, Mol. Cryst. Liq. Cryst. 118, $1985,205$.

[132] F.A. Carey and R.J. Sundberg, Advanced Organic Chemistry, $3^{\text {rd }}$ ed, Plenum Publishing Corporation: New York, 1993, 196-210. 
[133] Zuman, P. Substituent Effects in Organic Polarography, Plenum: New York, 1967.

[134] H.D. Abruna, P. Denisevich, M. Umana, T.J. Meyer and R.W. Murray. J. Am. Chem. Soc. $103,1981.1$

[135] Z. Zhang and G. Shi. J. Electroanal. Chem. 569, 2004, 197.

[136] M. Zagrska, I. Kulszewicz-Bajer, A. Pron and J. Sukiennik. Macromolecules. 31, 1998, 9146.

[137] M. Trznadel, M. Zagrska, M. Lapkowski, G. Louarn, S. Lefrant and A. Pron. J. Chem. Soc.,Faraday Trans. 92, 1996, 1387.

[138] G. Louarn, M. Trznadel, J.P. Buisson, J. Laska, A. Porn, M. Lapkowski and S. Lefrant. J. Phys. Chem. 100, 1996, 12532

[139] E.A. Bazzaoui, G, Levi, S. Aeiyach, J. Aubard, J.P. Marsault, P.C and Lacaze. J. Phys. Chem. 99, 1995, 6628.

[140] G. Louarn, J.P. Buisson, S. Lefrant and D. Fichon. J. Phys. Chem. 99, 1995, 11399.

[141] M. Baibarac, M. Lapkowski, A. Porn, S. Lefrant and I. Baltog. J. Raman. Spectrosc. 29, 1998,825 .

[142] S. Lefrant, I. Baltog, M. L. delachapelle, M. Baibarac, G. Louarn, C. Journet and P. Bernier. Synth. Met. 100, 1999, 13.

[143] S. Garreau, J.L. Duvail and G. Louarn. Synth. Met. 125, 2002, 325.

[144] Rudolf Holze, Synth. Met. 40, 1991, 379.

[145] D.W. Scott, J. Mol. Spectrosc, 31, 1969, 451.

[146] S. Garreau, G. Louarn, J.P. Buisson, G. Froyer and S. Lefrant. Macromolecules. 32, 1999, 6807.

[147] G. Shi, J. Xu and M. Fu. J. Phys. Chem. B. 106, 2002, 288.]

[148] E.A. Bazzaoui, J.P. Marsault, S. Aeiyach and P.C. Lacaze. Synth. Met. 66, 1994, 217.

[149] M. Akimoto, Y. Furukawa, H. Takeuchi and I. Harada. Synth. Met. 15, 1986, 353.

[150] C. Yong and Q. Renyuan. Solid State Communications. 54, 1985, 211.

[151] Y. Furukawa. J. Phys. Chem. 100, 1996, 15644.

[152] S.Garreau, M. Leclerc., N.Errien and G. Louarn. Macromolecules. 36, 2003, 692.

[153] Y. Furukawa, M. Akimoto and I. Harada, Synth. Met. 18, 1987, 151.

[154] E.A. Bazzaoui, S. Aeiyach, J. Aubard, N. Felidj, P.C. Lacaze, N. Sakmeche and G. Levi. J. Raman. Spectrosc. 29, 1998, 177. 
[155] J. L. Sauvajol, G. Poussigue, C. Benoit, J.P. Lere-Porte and C. Chorro. Synth. Met. 4143, 991, 1237.

[156] E.A. Bazzaoui, S. Aeiyach, J. Aubard, N. Felidj, G. Levi, N. Sakmeche and P.C. Lacaze. J. Chim. Phys. 95, 1998, 1526.

[157] E. Agosti, M. Rivola, V. Hernandez, M. Delzoppo and G. Zerbi. Synth. Met. 100, 1999, 101.

[158] Y. Furukawa. Synth. Met. 69, 1995, 629.

[159] V. Hernandez, J. Cadsado, S. Hotta and J.T. Lopez Naverrete. Synth. Met. 101, 1999, 549.

[160] F.R Dollish, W.G. Fateley and F.F. Bently. Characteristic Raman Frequencies of Organc Compounds, Wiley, New York, 1974.

[161] N.B. Colthup, L.H. Daly and S.E. Wibereley. Introduction to Infrared and Raman Spectroscopy, Academic Press, California, 1990

[162] D. Lin-Vien, N.B. Colthup, W.G. Fateley and G. Grasselli. The Handbook of Infrared and Raman Characteristic Frequencies of Organic Molecules. Acadmic Press. San Diego, 1991.

[163] G. Varsanyi. Assignments for Vibrational Spectra of Seven Hundred Benzene Derivatives. Wiley, New York, 1974.

[164] G. Horowitz, A. Yassar, and H.J. von Bardeleben. Synth. Met. 62, 1994, 245.

[165] C. Visy, J. Lukkari, and J. Kankare. Macromolecules 26, 1993, 3295.

[166] F.-J. Pern and A.J. Frank, J. Electrochem. Soc. 136, 1990, 2769.

[167] C. Visy, J. Lukkari and J. Kankare, J. Electroanal. Chem. 319, 1991, 85.

[168] C. Visy, J. Lukkari and J. Kankare, Synth. Met. 69, 1995, 319.

[169] E. Lankinen, M. Pohjakallio, G. Sundholm, O.R. Konestabo and E.J. Samuelsen, Acta Chemica Scandinavica. 50, 1996, 749.

[170] M. Pohjakallio, G. Sundholm and P. Talonen, J. Electroanal. Chem. 406, 1996, 165.

[171] E. Lankinen, M. Pohjakallio, G. Sundholm, P. Talonen, T. Laitinen and T. Saario, J. Electroanal. Chem. 437, 1997, 167.

[172] D.R. Greve, J.J. Apperloo and R.A.J. Janssen. Eur. J. Org.Chem. 18, 2001, 3437.

[173] J. Morgado, F. Cacialli, R.H. Friend. B.S. Chuah, H. Rost and A.B. Holmes, Macromolecules 34, 2001. 3094. 
[174] R. Cervini, X.-C. Li, W.C. Spencer, A.B. Holmes, S.C. Moratti and R. H. Friend, Synth. Met. 84, 1997, 359.

[175] M Zheng. A.M. Sarker, E.E. Gürel, P.M. Lahti and F.E. Karasz, Macromolecules 33, 2000, 7426.

[176] M. Jonforsen, T. Johansson, L. Spjuth, O. Inganäs and M.R. Andersson, Synth. Met, 131, 2002, 53.

[177] M. Jonforsen, T. Johansson, O. Inganäs and M.R. Andersson. Macromolecules 35, 2002, 1638.

[178] S Beaupré and M. Leclerc, Adv. Funct. Mater. 12, 2002, 192.

[179] T. Johansson, W. Mammo, M. Svensson, M.R. Andersson and O. Inganäs, J. Mater. Chem. 13, 2003, 1316.

[180] J.L. Brédas, R. Silbey. D.S. Bourdreaux and R.R. Chance, J. Am. Chem. Soc. 105,1983, 6555.

[181] A.K. Agrawal and S.A. Jenekhe, Chem. Mater. 8, 1996, 579.

[182] C.-J. Yang and S.A. Jenekhe, Macromolecules. 28, 1995, 1180.

[183] H. Eckhardt, L.W. Shacklette, K.Y. Jen and R.L. Elsenbaumer, J. Chem. Phys. 91, 1989, 1303.

[184] A.J. Bard and L.R. Faulkner. Electrochemical Methods, Fundamentals and Applications. John Wiley \& Sons, $2^{\text {nd }}$ Ed, 2001.

[185] J. Goodisman, Electrochemistry: Theoretical Foundations, John Wiley \& Sons, 1987.

[186] G. Gritzner and J. Kuta. Pure Appl. Chem. 56, 1984, 461

[187] H.-M. Koepp, H. Wendt and H. Strehlow, Z. Electrochem. 64, 1960, 483.

[188] W.C. Barrette, H.W. Johnson and D.T. Sawyer, Anal. Chem. 56, 1984, 1890.

[189] V.V. Pavlishchuk and A.W. Addison. Inorg. Chem. Acta. 298, 2000, 97

[190] J.R. Smith, P.A. Cox, S.A. Campbell and N. M. Ratcliffe, J. Chem. Soc., Faraday Rrans.91, 1995, 2331.

[191] M. R Andersson, D. Salse, M. Berggren, H. Järvinen, T. Hjertberg, O. Inganäs, O.

Wennerstöm and J.-E. Österholm. Macromolecules, 27, 1994, 6503.

[192] O. Haba, T. Hayakawa, M. Ueda, H. Kawaguchi and T. Kawazoe, React. Func. Polym. 37, 1998, 163.

[193] T. Hayakawa, K. Fukukawa, M. Morishima, K. Takeuchi, M. Asai, S. Ando and M. Ueda, J. Polym. Sci. Part A, Polym. Chem. 39, 2001, 2287. 
[194] M.R. Andersson, W. Mammo, T. Olinga, M. Svensson, M. Theander and O. Inganäs, Synth. Met. 101, 1999, 11

[195] S. Ando and M. Ueda, Synth. Met. 129, 2002, 207.

[196] M.A. D Oliveira, H.F. Dos Santos and W.B De Almeida, Phys. Chem. Chem. Phys., 2, 2000, 3373

[197] G.A. Petersson, A. Bennett, T.G. Tensfeldt, M.A. Al-Laham, W.A. Shirley and J. Mantzaris, J. Chem. Phys. 89, 1988, 2193.

[198] J.S. Binkley, J.A. Pople and W.J. Hehre. J. Amer. Chem. Soc. 102, 1980, 939.

[199] M. Frechette, M. Belletete, J.-Y. Bergeron, G. Durocher and M. Leclerc, Synth. Met, 84, 1997, 223. 


\section{Selbständigkeitserklärung}

Hiermit erkläre ich, daß ich die vorliegende Arbeit selbständig und nur unter Verwendung der angegebenen Literatur und Hilfsmittel angefertigt habe.

Chemnitz, den 18.08.2006

M.Sc. Wasim Alhalasah 


\section{Curriculum Vitae}

Name

Date of birth

Place of birth

Nationality

Status

School Education

1981-1991

1992-1993

University Education

1993-1997

1998-2002

Experience and Skills

1998-2003

Since November 2003
Wasim Fajir Hanna Alhalasah

31.07.1975

Alkarak-Jordan

Jordanian

Single, No Children

Manshiat abu Hamor School for boys

Al-rabah School for boys

B.Sc, Mu'tah University. Alkarak

M.Sc, Mu'tah University. Alkarak
Teacher, Ministry of Education-Jordan, Alkarak

Working as research fellow under the supervision of Prof.

Dr. Holze, TU-Chemnitz, Germany.

\section{Publications and Poster Exhibitions}

*."A Comparison of Experimental Observation and Theoretical Data on 3-Phenylsubstituted Thiophenes and Their Intrinsically Conducting Polymers".

Wasim Alhalasah and Rudolf Holze (to be Submitted).

* "Electrochemical Bandgaps of a Series of Poly-3-phenylthiophenes". Wasim Alhalasah and Rudolf Holze (Journal of Solid State Electrochemistry in press).

*."Theoretical Treatment of 3-Phenylsubstituted Thiophenes and Their Intrinsically Conducting polymers". Wasim Alhalasah and Rudolf Holze (Electrochemical Society Transactions, 2 (23), 2007, 45.

*."Electrochemical Materials Science: Calculation vs. Experiment as Predictive Tools in Tailoring Intrinsically Conducting Polythiophenes". Wasim Alhalasah and Rudolf Holze (Microchimica Acta, 156 (1-2), 2006, 133.

*."Electrochemical Materials Science: Tailoring Intrinsically Conducting Polymers. The Example: Substituted Thiophenes". Wasim Alhalasah and Rudolf Holze (Journal of Solid State Electrochemistry, 9, 2005, 836). 
*."MINDO-Forces Study on the Keto-Enol Tautomerism of $\alpha$-Substituted Acetaldehydes $\mathrm{XCH}_{2} \mathrm{CH}=\mathrm{O}(\mathrm{X}=\mathrm{H}, \mathrm{F}, \mathrm{OH}, \mathrm{CN}, \mathrm{NH} 2, \mathrm{NO} 2, \mathrm{CH} 3, \mathrm{OCH} 3)$ : Comparison with Acetyl Derivatives". Wasim Alhalasah and Salim Khalil (Zeitschrift für Naturforschung., 59a, 2004, 980).

*."MINDO-Forces Study on the Substituent Effect in the Keto-Enol Tautomerism of Acetyl Derivatives". Wasim Alhalasah, Ali Mahasnah, Salim Khalil (Zeitschrift für Naturforschung., 59a, 2004, 299).

*. $4^{\text {th }}$ Chianti Meeting on Inorganic Electrochemistry, $15^{\text {th }}-20^{\text {th }}$ of July 2006 , Certosa di Pontignano, Siena, Italy. Seminar title is "Electrochemical, spectroelectrochemical and theoretical data of Poly-3-p-X-Phenylthiophenes-A critical evaluation". Wasim Alhalasah and Rudolf Holze.

*. International Workshop on Electrochemistry of Electroactive Materials (WEEM2006), $24^{\text {th }}-29^{\text {th }}$ of June 2006, Saint. Petersburg, Russia. Seminar title is "A Comparison Of Experimental Observations and Theoretical Data on 3Pheynylsubstituted Thiophenes and Their Intrinsically Conducting Polymers" Wasim Alhalasah and Rudolf Holze.

*. $209^{\text {th }}$ Meeting of the Electrochemical Society Denver, Colorado, May $7^{\text {th }}-12^{\text {th }}$, 2006. Mechanistic Organic Electrochemistry Symposium in Honor of the $80^{\text {th }}$ Birthday of Professor Petr Zuman. Seminar title is "Theoretical Treatment of 3Phenylsubstituted Thiophenes and Their Intrinsically Conducting polymers". Wasim Alhalasah and Rudolf Holze.

*. Contribution to the $4^{\text {th }}$ Baltic Conference on Electrochemistry $13^{\text {th }}-16^{\text {th }}$ of March 2005, Greifswald, Germany. Seminar title is "Electrochemical Materials Science: Tailoring Intrinsically Conducting Polymers. The Example: Substituted Thiophenes". Wasim Alhalasah and Rudolf Holze.

*. Contribution to GDCh conference (13. Tagung Festkörperanalytik $26^{\text {th }}$ $-29^{\text {th }}$ of June 2005, Chemnitz, Germany). Poster title is "Electrochemical Materials Science: Calculation vs. Experiment as Predictive Tools in Tailoring Intrinsically Conducting Polythiophenes". Wasim Alhalasah and Rudolf Holze. 